\title{
The utilization of adventure based programming to foster posttraumatic growth within a veteran population: A mixed methods study
}

Joseph A. Wassif

Follow this and additional works at: https://researchrepository.wvu.edu/etd

\section{Recommended Citation}

Wassif, Joseph A., "The utilization of adventure based programming to foster posttraumatic growth within a veteran population: A mixed methods study" (2014). Graduate Theses, Dissertations, and Problem Reports. 6920.

https://researchrepository.wvu.edu/etd/6920

This Dissertation is protected by copyright and/or related rights. It has been brought to you by the The Research Repository @ WVU with permission from the rights-holder(s). You are free to use this Dissertation in any way that is permitted by the copyright and related rights legislation that applies to your use. For other uses you must obtain permission from the rights-holder(s) directly, unless additional rights are indicated by a Creative Commons license in the record and/ or on the work itself. This Dissertation has been accepted for inclusion in WVU Graduate Theses, Dissertations, and Problem Reports collection by an authorized administrator of The Research Repository @ WVU.

For more information, please contact researchrepository@mail.wvu.edu. 
THE UTILIZATION OF ADVENTURE BASED PROGRAMMING TO FOSTER POSTTRAUMATIC GROWTH WITHIN A VETERAN POPULATION: A MIXED METHODS STUDY

\author{
Joseph A. Wassif
}

Dissertation submitted to the College of Education and Human Services at West Virginia University in partial fulfillment of the requirements for the degree of Doctor of Philosophy in Counseling Psychology

\author{
Jeff Daniels, Ph.D., Chair \\ James Bartee, Ph.D. \\ Deborah Hendricks, Ph.D. \\ Chris Schimmel, Ph.D. \\ Ian Kellems, Ph.D.
}

Counseling Psychology

\title{
Morgantown, West Virginia 2014
}

Keywords: Veterans, Posttraumatic Growth, PTSD, Posttraumatic Stress Disorder, Outward Bound, Adventure Therapy 


\title{
ABSTRACT \\ The Utilization of Adventure Based Programming to Foster Posttraumatic Growth Within a Veteran Population: A Mixed Methods Study
}

\begin{abstract}
Joseph A. Wassif
There is a lack of research exploring interventions that promote posttraumatic growth with veterans. The current project represents a first attempt to explore posttraumatic growth among veterans who participate in a strength-based program specifically designed for the healthy reintegration and socialization of returning members of the armed services. Through the use of a mixed methods approach, I hoped to show that veterans would report increases in posttraumatic growth following participation in an Outward Bound Veterans Program. Veterans that completed the program were compared to a waitlist control, which consisted of other military personnel that had signed up for, but had yet to participate in an expedition. A total of 95 participants completed self-report measures at two time points. Members of the treatment group $(n=50)$ were sent a pre-program survey two weeks prior to their trip and a post-program survey two weeks after the trip ended. Individuals in the waitlist control $(n=45)$ completed the same surveys in a similar time frame as the treatment group. As predicted, those who completed an Outward Bound Veterans Program reported significantly higher levels of posttraumatic growth when compared to the waitlist control. However, further analysis led to a surprising finding when evaluating the five subscales that comprise posttraumatic growth: Relating to Others, Spirituality, Personal Strength, Appreciations of Life, and New Possibilities. The results suggested Relating to Others was the only statistically significant factor when comparing group means. Although Personal Strength was nearing significance, these results emphasize the importance of acceptance and belonging for returning veterans.

Sequentially, qualitative data was gathered from eight Outward Bound Veterans Program participants after the quantitative data was analyzed. These individuals completed a phone interview at various times after their trip. This information allowed for the development of an integrated theory highlighting the various factors and processes that promoted growth as a result of participation in the program. The trip Environment, Cadre, and Program represent the contextual factors that seemingly influenced the group processes: Social Learning, Cohesion, and Overcoming Adversity. Collectively, these factors reportedly impacted the experience of posttraumatic growth.
\end{abstract}




\section{TABLE OF CONTENTS}

Chapter I: Introduction and Literature Review

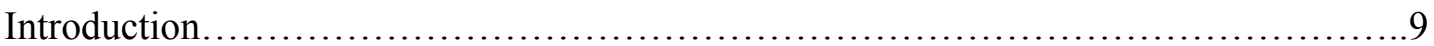

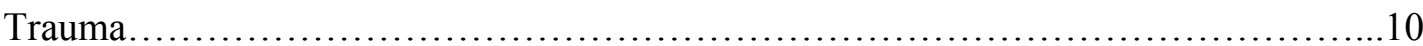

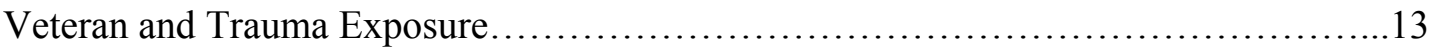

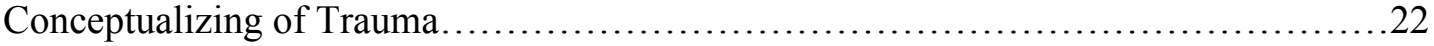

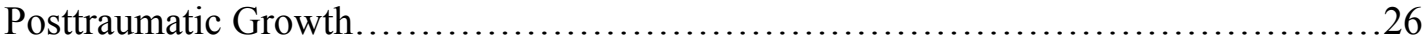

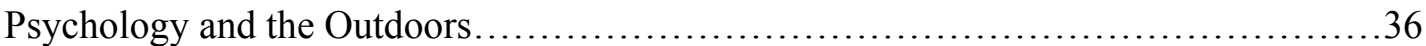

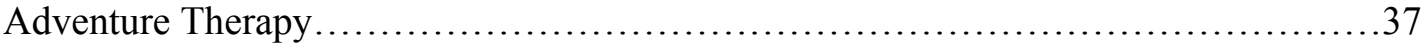

Outward Bound Veterans Program.................................................. 41

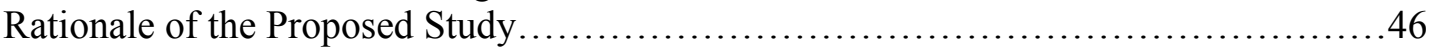

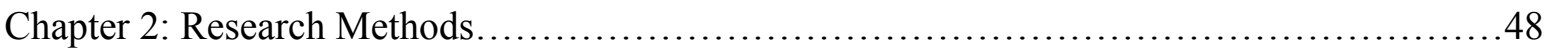

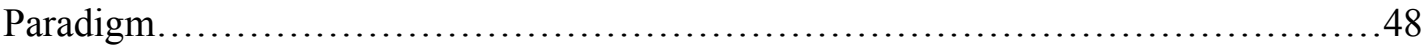

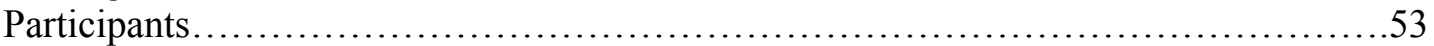

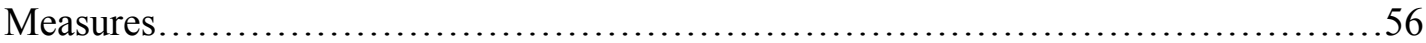

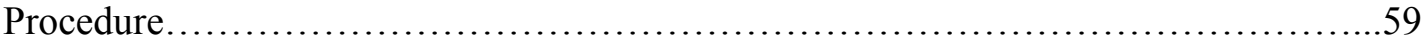

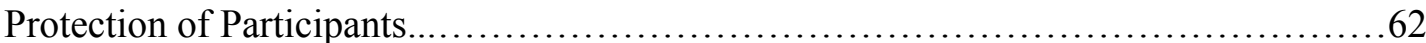

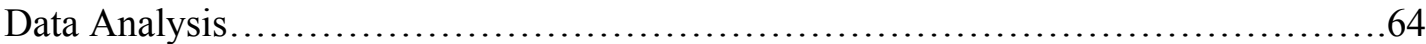

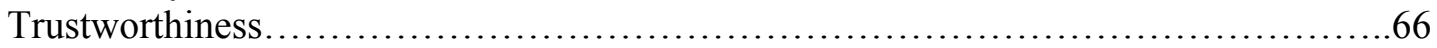

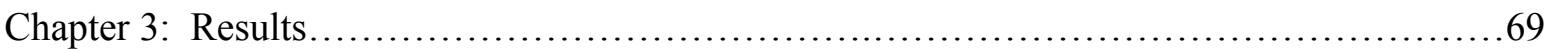

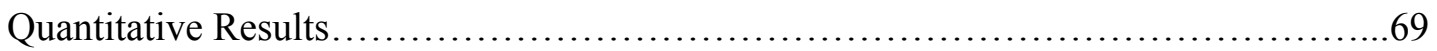

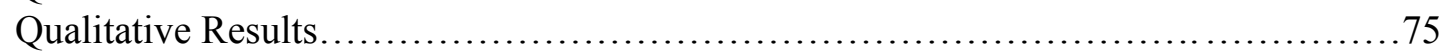

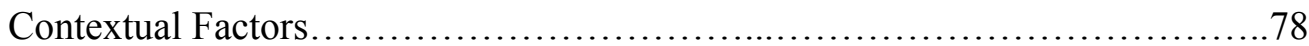

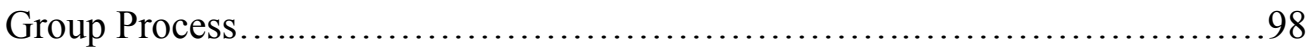

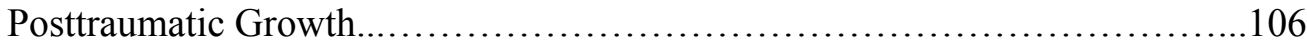

Overview of the Emergent Theory ........................................118

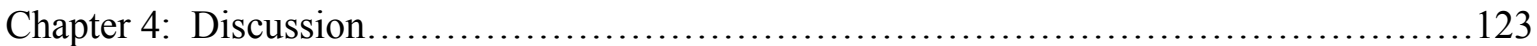

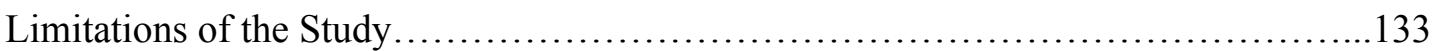

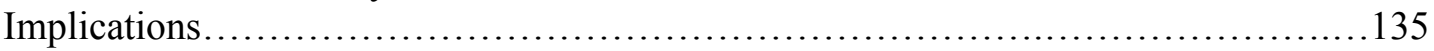




\section{LISTS OF TABLES, FIGURES, ANDAPPENDIXES}

Tables:

Table 1: Distributed Questionnaires by Time and Group.............................53

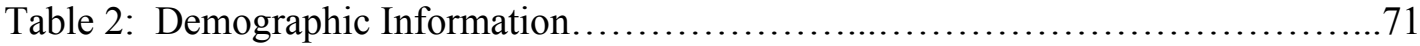

Table 3: Between Groups Comparison of PTG................................... 73

Table 4: Covariate Influence within Multivariate Tests........................... 75

Table 5: Between Subjects Effects for PTG_Post............................... 75

Table 6: Endorsement of Main Categories ....................................... 77

Figures:

Figure 1: Group PTG Pre and PTG Post Means ......................................74

Figure 2: Emergent Theory ................................................ 120

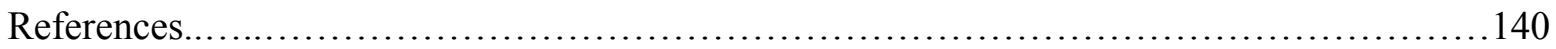

Appendices:

Appendix A: Model of Posttraumatic Growth.................................... 157

Appendix B: Letter of Support from Outward Bound............................. 158

Appendix C: Letter from David Scheinfeld..................................... 159

Appendix D: OBVB Recruitment Letter........................................ 160

Appendix E: Second Recruitment Letter....................................... 161

Appendix F: Initial Email to Treatment Group.................................. 162

Appendix G: Post Course Email................................................ 163

Appendix H: Initial Email to the Waitlist Control Group........................... 164

Appendix I: Waitlist Control - Post........................................... 165

Appendix J: OBVB Interview Recruitment Letter.................................. 166

Appendix K: Consent Form.................................................. 167

Appendix L: Demographic Questionnaire....................................... 171

Appendix M: Permission to Use the PTGI....................................... 174

Appendix N: Posttraumatic Growth Inventory.................................. 175

Appendix O: The Mississippi PTSD Scale ....................................... 177

Appendix P: Interview Protocol............................................. 182 


\section{CHAPTER 1}

\section{Introduction and Literature Review}

The United States has had an active presence in the Middle East since 2001, making Operation Enduring Freedom, Operation Iraqi Freedom, and Operation New Dawn (OEF/OIF/OND) the longest military conflict since the Vietnam War (Seal, Bertenthal, Miner, Sen \& Marmar, 2007). It is better understood that prolonged engagement in combat related experiences is associated with the development of mental health disorders (Hoge et al., 2004). Yet only recently, have researchers begun to uncover and empirically measure the positive gains reported by survivors of traumatic experiences. Trauma, by the very nature of the experience, alters one's perception of the world, humanity, and perceived safety (Tedeschi, Parks, \& Calhoun, 1998). It is theorized by Tedeschi and Calhoun (2006a) that this new view of the world has the capability of fostering both strife and growth.

Larner and Blow (2011) suggested that returning veterans have three general mental health trajectories after combat experiences. The authors stated that men and women may exhibit psychopathology, resiliency, or psychological growth. The authors noted that these paths are not autonomous or stages. Furthermore, individuals may experience multiple levels of functioning based on phases of recovery. Consistent with positive psychology, Larner and Blow (2011) suggested the goal of therapy may not simply be the absence of mental illness, but the enhancement of mental health.

Tedeschi and Calhoun (2004) reported posttraumatic growth (PTG) is a more prevalent response to combat than posttraumatic stress disorder (PTSD). According to the authors, PTG consists of the positive psychological change that emerges following significantly traumatic life events (Tedeschi \& Calhoun, 2004). Reports of PTG have been documented with populations 
such as childhood sexual assault survivors (House, 2006), breast cancer patients (Marlow, Carmill, \& Cieplucha, 2003) and bereaved family members (Gerrish, Dyck, \& Marsh, 2009). Through the synthesis of published studies, Tedeschi and Calhoun (2004) proposed a working model of PTG that accounts for the known variables and pathways to growth. The authors suggested a greater understanding of factors associated with the growth process will allow health professionals to become more intentional about fostering health promoting outcomes and not just symptom reduction strategies. However, the authors reported that within the current literature there are few interventions that have been evaluated for cultivating PTG outcomes.

The Outward Bound Veteran's Program (OBVP) was developed to address concerns of social support and reintegration of those returning from combat (Outward Bound Veterans Program, 2010). Although the program does not promote specific mental health objectives, participation in Outward Bound has been shown to promote positive psychological outcomes (Hyer, Boyd, Scurfield, Smith, \& Burke, 1996). Furthermore, the OBVP addresses many of the actual and perceived barriers to mental health services. Therefore, this dissertation will explore outcomes of PTG among this population after participating in an OBVP.

\section{Trauma}

Since World War I, researchers began identifying patterns of mental health symptomology among individuals who experience a trauma. From 1914-1918, soldiers from around the world engaged in what is remembered as The Great War. Soldiers and sailors returned from battle with psychological symptoms categorized as shell shock. Veterans of the time described indications of what would later be associated PTSD: mutism, nightmares, insomnia, heart palpitations, dizziness, depression, and disorientation (Bourke, 2011). 
Unfortunately, soldiers during that age were treated with little sympathy. Bystanders perceived they were simply not "tough" or were trying to escape wartime responsibilities (Bourke, 2011).

Following World War II, the American Psychiatric Association published the first edition of the Diagnostic and Statistical Manual (APA, 1952). Strongly influenced by the soldiers returning with symptoms associated with combat stress reaction or combat fatigue, the 1952 publication included a disorder known as Transient Situational Disturbance (APA, 1952). This first edition of the DSM reflects a continued perception that pathology resulting from traumatic events was attributed to personal defectiveness. "If the patient has good adaptive capacity, his symptoms usually recede as the stress diminishes" (APA, 1952, p. 48). The perception was Transient Situational Disturbance developed based on the fragility of the individual as only a minority of individuals presented with the disorder.

It was in 1980, with the publication of the DSM-III, that the term posttraumatic stress disorder was first utilized and reflected the current symptoms associated with the diagnosis. The 1980 version seemingly normalized the human stress response. The belief was most individuals would respond similarly in the aftermath of the trauma event (APA, 1980). Therefore, the focus of the disorder moved away from an interpersonal flaw.

The American Psychiatric Association currently describes a trauma as exposure to: death, threatened death, actual or threatened serious injury, or actual or threatened sexual violence (APA, 2013). Breslau (2001) concluded as many as $89 \%$ of the United States population will experience a traumatic event during their lifetimes. Despite the high rate of trauma, the prevalence of PTSD among the general United States population is between $7 \%$ and $12 \%$ (Smith \& Ranch, 2010). These statistics suggest most individuals successfully cope and experience few physiological or psychological 
complications (Tedeschi, 2011). Still, it is evident from modern research examining the prevalence of PTSD that a number of individuals continue to struggle for weeks, months, and years after a traumatic experience (Shapiro \& Laliotis, 2011; Sharpless \& Barber, 2011).

PTSD symptomology has been delineated into three overarching categories: reexperiencing, arousal and avoidance (APA, 2000). Resulting from a life threatening experience, individuals with PTSD have thoughts that intrude upon their consciousness in the form of nightmares, flashbacks, or intrusive memories. They may additionally experience a number of arousal reactions such as irritability, hyper-vigilance, or insomnia as a result of being exposed to some reminder of the traumatic experience. Not wanting to continuously be exposed to heightened stress, individuals with PTSD engage in a variety of avoidance behaviors.

The experience of life-threatening event makes individuals more prone to physiological and psychological complications. According to Meichenbaum (2011), the psychological ramifications vary based on the nature of the trauma (e.g., sexual assault versus a natural disaster), the intrapersonal uniqueness of the individual (e.g., past trauma experiences, coping skills), and their setting (e.g., social support). Traumatic events have the ability to alter one's social, psychological, and biological equilibrium, and for years, memories of the event can taint experiences in the present (Schubert \& Lee, 2009). Beyond psychological dysfunction, clients also report gastric problems, muscle tensions, aches, and general physical discomfort (Tedeschi \& Calhoun, 2004). Given this array of symptoms, clients may present with a variety of clinical disorders: acute stress disorder (Meichenbaum, 2011), adjustment disorder (Currie, Day, \& Kelloway, 2011), depression (DePrince, Chu, \& Pneda, 2011), dissociative identity disorder 
(Martin, Cromer, DePrince, \& Freyd, 2011), generalized anxiety disorder (Hoge et al., 2004), posttraumatic stress disorder (DePrince et al., 2011), and substance abuse (Seal et al., 2007).

\section{Veterans and Trauma Exposure}

For the past 11 years, the US Armed Services have been consistently engaged in military conflict within the Middle East. More than 2 million US military personnel have been deployed to Iraq or Afghanistan since the start of military operations in 2008 (RAND, 2008). According to Adler, Huffman, Bliese and Castro (2005), a majority of these men and women serving in Operation Enduring Freedom (OEF) and Operation Iraqi Freedom (OIF) will have experienced or witnessed life-threatening events. As a result, an increasing number of men and women are returning to the United States with social, occupational, legal, and interpersonal concerns (Kilmer, Eibner, Ringel, \& Rand, 2011).

Military combat has been uniquely described in comparison to other known trauma occurrences such as rape, natural disaster, or the sudden death of a child (Adler et al., 2005). In the modern US military, individuals self-select into the Armed Forces with the foreknowledge that they may be risking their lives (Larner \& Blow, 2011). "Military members are not only allowed, but are specifically expected to kill other human beings, destroy property, take control of territory, and break the enemy's will to fight” (Larner \& Blow, 2011, p. 188). Additionally, combat often represents multiple traumas occurring over an extended period where the individual oscillates between periods of extreme stress and prolonged boredom (Larner \& Blow, 2011). To complicate the matter, military personnel have the unique experience of often being the victim and the perpetrator as combat involves an opposing force (Larner \& Blow, 2011).

Military personnel are exposed to a variety of occurrences meeting criterion A1 of the DSM-5 definition of trauma (APA, 2013). In a workshop sponsored by the Combat Stress 
Intervention Program, Meichenbaum (2011) listed several known armed service experiences associated with mental health complications: being exposed to physical injuries, brutality, mutilated bodies, death of children, injury of an unarmed civilian, loss of a friend, engaging in atrocities, being physically deprived (POW), and high rates of wounds and fatalities in one's combat unit. These experiences are put into perspective as between $48 \%$ and $65 \%$ of service members report being responsible for the death of an enemy combatant (Hoge, Clake, \& Castro, 2007). Furthermore, $90 \%$ of military men and women had received incoming rocket, artillery, or mortar fire (Hoge et al. 2007). Sadly, as of January 2, 2013, military operations in Iraq and Afghanistan had claimed 6,653 lives and more than 30,800 soldiers had been injured (Department of Defense, 2013).

Soldiers are at additional psychological risk due to the repetitive nature of military service. Modern warfare has frequently become associated with enduring time away from home, cultural and environmental dissonance, fatigue, and demanding missions (Cornum, Matthews, \& Seligman, 2011). One-third of deployed soldiers have served at least two tours of duty, over 70,000 individuals have been deployed three times, and 20,000 have been deployed at least five times (Meichenbaum, 2011). The Office of the Surgeon General (2006) reported multiple deployments are associated with a 50\% greater prevalence of mental health problems. Adler and colleagues (2011) proposed that sustained combat stress depletes a soldier's ability to cope. This portrayal of military responsibilities, experiences, and statistics provide clarity for the large number of veterans returning to civilian life with complicated mental health issues.

Although women have been excluded from combat, they are not excluded from supportive positions that may result in physical or emotional harm. As of 2012, more than 283,000 women had been deployed to the wars in Iraq and Afghanistan (Wallechinsky \& Noel, 
2012). This suggests that roughly one out of ten US soldiers in Iraq and Afghanistan are women soldiers and roughly $3 \%$ of the deaths are women (Hoge et al., 2007). Hoge and colleagues reported that women serve by driving armored vehicles outside military bases, work alongside male combat soldiers, come under direct fire, may become causalities, and handle remains of dead or wounded soldiers (Hoge et al., 2007). While being interviewed by Corbet (2007), Matthew Friedman, Executive Director of the National Center for PTSD stated, "One of the most dangerous things you can do in Iraq is drive a truck." As a matter of gender comparison, Hoge et al. (2007) reported $56 \%$ of males and $61 \%$ of females know someone seriously injured or killed, $67 \%$ of males and $72 \%$ of females reported being in serious danger of being injured or killed, and $92 \%$ of males and $87 \%$ of females reported having received incoming rocket, artillery or mortar fire. As a result, female soldiers are equally exposed to traumatic events.

Posttraumatic stress. Due to the unique nature of wartime trauma, a significant number of soldiers are returning home with symptoms of psychopathology (Seal et al., 2007). Researchers have projected that between $25 \%$ and $30 \%$ of the troop population has at least one mental heath diagnosis, and more than half of the individuals treated at veteran medical centers have a co-occurring disorder (RAND, 2008; Seal et al., 2007). Given the disturbing acts seen by many in combat settings, it is not surprising that both studies indicate PTSD is the most frequently endorsed diagnosis for individuals returning from a combat zone. Seal et al. (2007) suggested as many as $20 \%$ of the veteran population have PTSD. The authors speculated the prevalence rate is likely higher as many cases go unreported.

The individuals who appear to be at greatest risk for developing PTSD are young soldiers. Seal et al. (2007) indicated members of the Armed Forces under the age of 25 are more likely to report having a mental health disorder than any other age group. The authors indicated 
this is due to the reality that younger personnel are likely to have responsibilities and ranking that would lead to greater combat exposure. Park (2011) reported 50\% of those involved in firefights are below the age of 25 .

Meichenbaum (2011) postulated that attempting to process atrocities associated with wartime events at such a young age can also lead to a mixture of emotions. Veterans have reported feeling angry towards superiors and guilt for not disobeying acts that caused harm (Meichenbaum, 2011). The guilt associated with feeling responsible for the death or injury of another human can complicate one's ability to cope. Furthermore, during the recovery process, veterans often act aggressively and show feelings of anger towards loved ones. As a result, feelings of guilt are perpetuated.

Recent literature has drawn the nation's attention to the difficulty associated with coping with combat trauma, as there has been a recent increase in completed suicides associated with veterans. The Veterans Administration (VA) suicide hotline receives 1,500 calls a week nationally from family members and veterans in need (Meichenbaum, 2011). Statistical data indicate male veterans are twice as likely to complete a suicide as a civilian counterpart (Meichenbaum, 2011). In July of 2011 alone, 33 veterans killed themselves (Herrall \& Berglass, 2011). All of the reported individuals were within their first year of returning home.

Homecoming. Many military personnel, at least initially, struggle upon their return to civilian life. High levels of homecoming stress are an additional risk factor for the development of psychological complications. Shay (2002) reported that during the reintegration process, the experiences of the combat veteran come into conflict with the surrounding social worldview that is dissociated from any adequate understanding of the combat experience. Milliken, Auchterloine, and Hoge (2007) noted logistical problems associated with the reduction of 
accessible services and diminished peer support. Returning combat veterans struggle to share important meanings with others who cannot comprehend the actual lived experiences they have faced. This likely contributes to a stressful transition into civilian occupational, academic, and family responsibilities.

Recent longitudinal research revealed timelines indicating a delayed development of mental health complications after returning to civilian life. At the time of homecoming, mental health concerns are considerably lower in comparison to the subsequent months (Hoge et al., 2004). When surveyed three to six months after returning from tour, $17 \%$ of soldiers meet the criteria for PTSD (Hoge et al., 2004) and 10\% screen positive for depression (Milliken et al., 2007). Hoge et al. (2004) noted from the time of homecoming in comparison to a 10 month follow up, mental health diagnoses increased from $17 \%$ to $27 \%$ in former active duty soldiers and $17 \%$ to $35 \%$ in former active duty reservists. Meichenbaum (2011) concluded veterans are at greatest risk for the development of disorders such as anxiety, PTSD, depression, and substance abuse four to 10 months after returning from active duty. Therefore early implementation of treatment for posttraumatic stress is crucial to the recovery process and transition to civilian life.

Traditional treatment models for PTSD. A number of treatment approaches have been developed to address veteran posttraumatic stress disorder. "Most combat-related PTSD treatment programs utilize an eclectic treatment approach that includes supportive counseling, exposure to trauma related stimuli, relaxation training, and skill building components intended to assist patients in symptom management" (Donovan, Padin-Rivera, \& Kowaliw, 2001, p. 758). As described in the literature, the evidence-based practices for the treatments of PTSD are Cognitive Processing Therapy, Eye Movement Desensitization and Reprocessing, Stress 
Inoculation Therapy, and Prolonged Exposure Therapy. For more information on these treatment modalities, see Aderka, Foa, Applebaum, Shafran, and Gilboa-Schechtman (2011); Meichenbaum (1996); Resick and Schnicke (2008); and Shapiro and Laliotis (2011). In general, these treatments attempt to reduce trauma-related guilt, reduce unhealthy avoidance behaviors, decrease interpersonal conflicts, confront the re-experiencing of negative trauma memories, reduce hyper-vigilant behaviors, and improve quality of life (Meichenbaum, 2011).

Effectiveness of PTSD treatment models. In 2007, Benish, Imel, and Wampold conducted a meta-analysis of various psychological treatments for adults with a clinical diagnosis of PTSD. They analyzed the effectiveness of prolonged exposure, eye movement desensitization reprocessing, stress inoculation therapy, trauma management therapy, and cognitive therapy. In the 15 studies analyzed, there was "no evidence to suggest outcome differences between bona fide psychotherapies in the treatment of PTSD, for either PTSD symptoms or all outcome measures" (Benish et al., 2007, p. 753). Regardless of the treatment modality, roughly half of the individuals who engage in psychotherapy for PTSD never fully recover (Bradley, Greene, Russ, Dutra, \& Westen, 2005). Additionally, integrating techniques from different modalities did not improve treatment results (Benish et al., 2007). For instance, the inclusion of cognitive restructuring within exposure therapy was shown to be equally effective as exposure therapy alone (Benish et al., 2007). Furthermore, the results were inconclusive as to what common factors were curative. This information suggests no theory adequately accounts for all the complex phenomena and processes involved in PTSD or the mechanisms that underlie effective treatment (Schubert \& Lee, 2009).

Barriers to mental health. The number of military personnel not seeking treatment for mental health issues is concerning. In one study, it was determined that $43 \%$ of servicemen and 
women with PTSD or major depression had not received treatment within the past year (Wang et al., 2005). Meichenbaum (2011) estimated that since 2001, as many as 300,000 returning veterans have PTSD and/or depression and approximately 100,000 have actually sought treatment. With the realization that so many individuals are returning from OEF/OIF/OND with clinical levels of anxiety, depression, and PTSD, researchers are making greater attempts to understand the actual and perceived barriers for seeking mental health treatment.

Hoge et al. (2004) supplied an anonymous survey to four combat infantry units totaling 6,201 active army soldiers and marines. Their sample included men and women that endorsed clinical levels of major depression, generalized anxiety, or PTSD within the past month. Only $23 \%$ to $40 \%$ had received mental health care and only $38 \%$ to $45 \%$ of those personnel who met screening criteria for a mental disorder indicated an interest in receiving help. Respondents replied being concerned that: "I would be seen as weak"; "My unit leadership might treat me differently"; "Members of my unit might have less confidence in me"; "It is difficult getting time off for treatment"; "My leaders would blame me for the problem; and It is difficult to schedule an appointment” (Hoge et al., 2004). In a separate study, Brown et al. (2011) found similar results revealing apprehensions related to embarrassment, lack of trust in mental health professionals, a disbelief that mental health care works, unit stigma towards seeking mental health treatment, and a belief that an officer or noncommissioned officer should not be in a leadership position if he or she was taking medication for mental health problems. This information suggests a change in military culture is required to help traditional mental health services seem more acceptable.

In a separate study, Ouimette et al. (2011) studied non-active military personnel barriers to treatment. Surveying individuals that had received treatment at a VAMC in the past six 
months, it was determined that the barriers to treatment could be categorized into three broad domains: individual background characteristics, institutional factors, and stigma-related beliefs about mental illness and mental health treatment (Ouimette et al., 2011). As the individuals surveyed had visited a VAMC in the past six months, they were already comfortable with the institutional factors such as navigating the VA or interacting with the professional staff. The most salient barriers were stigma-related concerns. The results indicated individuals avoided seeking treatment due to perceived social consequences, not wanting to receive a diagnostic label, fear of being mistreated or forced to revisit past traumas.

Ouimette et al. (2011) indicated the discomfort with mental health services is a symptom of avoidance. The researchers noted individuals with more severe PTSD symptoms were more likely to not engage in treatment to avoid talking about their trauma. Many combat veterans have actively attempted to suppress painful memories known to trigger unwanted raw emotions (Ouimette et al., 2011). Therefore, some veterans may avoid the social sharing of their events, not as an act of defiance, rather as the best available coping mechanism.

Finally, barriers appear to differ across subgroups of veterans suggesting the need to tailor outreach efforts to such cohorts (Ouimette et al., 2011). The authors specifically noted that individuals that were younger felt as though they did not fit in with the VA culture. According to this study, a majority of the individuals using VAMC services are significantly older and do not represent the demographics of modern military personnel (Ouimette et al., 2011). It was suggested that the VA system would benefit from expanding upon the current "one size fits all" approach to treatment. The younger population of returning veterans has already demonstrated difficulties with finding supportive civilian social networks; it is a further disservice for individuals to feel isolated within VA settings. 
Healthcare. An external barrier to the change process is the strain placed on the healthcare system by those currently accessing services. Despite the lack of individuals who access healthcare, the number of military men and women that request medical or mental health services is overwhelming the current resources available. The United States Department of Veterans Affairs (2012) announced a major recruiting effort to hire 1,600 new psychologists to fulfill the drastic need for qualified clinicians to treat mental health issues of returning veterans. Currently, many clients are being placed on waitlists (Orme \& Boswell, 1991). Orme and Boswell (1991) demonstrated an inverse relationship between the length of time on a waitlist and the likelihood of returning for services. As the wait time increases, there is a decreased likelihood that individuals will return for their first appointment. Therefore, veterans who initially make contact with medical centers are less likely to return based on the length of time between intake and being assigned to a primary clinician.

The healthcare system is further being stressed by the burdening of costs. In 2008, $347,750(40 \%)$ of returning $\mathrm{OEF} / \mathrm{OIF}$ service members had received services from a Veterans Affairs hospital (Kilmer et al., 2011). Projected medical costs from OIF alone are estimated between $\$ 300$ and $\$ 400$ billion (Kilmer et al., 2011). It has been approximated that the United States has spent more than $\$ 6.2$ billion in the first two years after discharge treating posttraumatic stress (Burnam, Meredith, Tanielian, \& Jaycox, 2009). However, Kilmer and colleagues suggested determining the total cost for mental health services is complicated by the uncertainty underlying all the components necessary to construct such an estimate, "including the number of people harmed, the number seeking treatment, the types of treatment given, the cost associated with treatment, and the subsequent outcomes that may befall a service member because of impaired health" (Kilmer et al., 2011, p. 201). Therefore, the true emotional, 
physical, and financial costs are likely to be unknown. Although the expressed hope is that more veterans would feel comfortable accessing services, the reality is that there are too few mental health providers and the current services are a financial strain on the system.

The above data suggest current treatment models provide limited effectiveness, are utilized by a fraction of the veteran population, and are currently overwhelming the financial and professional resources available. This information has many theorists questioning our current tactics addressing the mental health needs of returning veterans (Seligman, 2011).

\section{Conceptualizing Trauma}

The "debate still exists today over what constitutes the core element underlying trauma reactions and whether it is the actual event, the un-integrated memories, the associated meaning, or personal vulnerabilities" (Schubert \& Lee, 2009, p. 118). Schubert and Lee (2009) perceived the DSM definition of trauma to be outdated as it reflects a narrow perception of standard symptoms associated with PTSD. Additionally, the authors expressed that it unnecessarily limits those who can have access to treatment and the types of treatments developed.

Several researchers have adopted a broad view of trauma whereby it is explained as a response to an event that overwhelms an individual's ability to cope with the experience. Such perceptions reflect earlier beliefs found in first editions of the DSM regarding the etiology of PTSD. Resick et al. (2008) suggested the disorder is a disruption or stalling out of the normal recovery process rather than the development of a unique psychopathology. Similarly, JanoffBulman (1992) perceived trauma as consisting of an experience or circumstance that poses significant challenges to the adaptive resources of a person, and represent significant challenges to individuals' ways of understanding the world and their place in it. As reflected in these 
conceptualizations, the goal of therapy is helping individuals remove barriers that impede natural coping.

Janoff-Bulman (2006) suggested a cognitive approach to the understanding of trauma. She posited that an event that is defined as traumatic is not the loss of home or a loved one, but rather the "internal disorganization and disintegration that follows our psychological unpreparedness" (Janoff-Bulman, 2006, p. 83). She (2006) described how at the core of our inner world are fundamental assumptions that provide each individual with a necessary sense of safety and security. Individuals "attempt to minimize the likelihood of random outcomes and maximize control over outcomes by relying on culturally constructed theories of person-outcome contingencies" (Janoff-Bulman, 2006, p. 84). Internal fallacies, such as, good things will happen to those that work hard, protect us from the harsh reality that something bad could happen without any explanation. The author suggested, at least in western cultures, core beliefs contribute to human engagement in cautious behaviors. This gives the individual the illusion of control. Janoff-Bulman posed this is why in the wake of a traumatic event it is natural for individuals to seek meaning in the experience. This is also why individuals, not directly involved in a crisis, speculate evidence to support the contingencies between people and their associated outcomes. She gave the example that people will often assume a driver of a vehicle that caused a horrific accident must have been impaired. These fundamental assumptions are what allow us to carry on with our day without the constant sense of fear.

Positive psychology. The relationship between suffering and meaning has been discussed for centuries and is depicted in nearly every major religion. From a secular perspective, several adages exist within the United States that depicts similar views. The term, "No pain, no gain” or "What doesn’t kill you makes you stronger" are commonly heard within 
the vernacular. Therefore, such collective awareness that positive gains can occur through traumatic experience is seemingly within the schematic realm of citizens throughout the country.

Yet for decades, psychotherapy has primarily drawn its attention to human dysfunction. Zoellner and Maercker (2006) described this perspective as a deficit orientation whereby therapists focus solely on symptom reduction. Understandably, clients most often seek professional help in times of distress and to negotiate conflicts they feel independently incapable of resolving. Clients present seeking alleviation from psychological pain; therefore it seems logical to formulate treatment goals around minimizing suffering. Harris, Thoresen, and Lopez (2007) wrote that ignoring the client's presenting concerns would be ineffective, frivolous, and minimizing the severity of perceived problems. Furthermore, negative emotions can create a sense of urgency within a helping professional to alleviate symptomology (Seligman \& Csikszentimihalyi, 2000).

However, it was global turmoil that nurtured into existence the roots to existential and positive psychology. Victor Frankl (1984), a holocaust survivor, demonstrated that mental suffering has the capability of fostering human resiliency and instilling the ability to grow in the face of insurmountable turmoil. He wrote, "There is nothing in the world, I venture to say, that would so effectively help one to survive even the worst conditions as the knowledge that there is a meaning in one's life" (Frankl, 1984, p. 126). He postulated that pathology results when an individual lacks life purpose and meaning, therefore the focus of psychology should be the instillation of such values.

Frankl (1984) suggested the will to achieve a sense of significance is in everyone and is regarded to be the most fundamental value. When addressing a group of inmates, he stated, "you are human beings like me, and as such you were free to commit a crime, to become guilty. Now, 
however, you are responsible for overcoming guilt by rising above it, by growing beyond yourselves, by changing for the better" (Frankl, 1984, p.174). Suffering is perceived to be a choice. One does not choose to experience a trauma, yet he or she "can still choose his attitude" (Frankl, 1984, p. 172). He wrote, "Even the helpless victim of a hopeless situation, facing a fate he cannot change, may rise above himself, may grow beyond himself, and by so doing change himself. He may turn a personal tragedy into a triumph" (Frankl, 1984, p. 170). He used the term "tragic optimism" to describe making the decision to fully engage in life in spite of everything else negative that may have happened.

Frankl's approach moved the field of psychology away from a one-dimensional approach to health. Diagnostic labels are seen as a single conceptual layer of an individual, which is influenced by a rich history, social influence, cultural background, and environment. Holistically viewing a client's strengths and weaknesses allows for a more complete understanding of an individual's health (Gelso \& Fretz, 2001). Focusing solely on a client's pathology ignores possible areas of growth and resilience that may be occurring.

According to Fredrickson (2001), the most effective way to reduce stress and increase calm and tranquility may be to focus on increasing positive states, rather than just the eradication of negative states. Positive human virtues such as courage, future-mindedness, optimism, interpersonal skill, faith, work ethic, hope, honesty, and perseverance have been shown to buffer against negative mental health symptoms (Seligman \& Csikszentimihalyi, 2000). "Much of the task of prevention in this new century will be to create a science of human strength whose mission will be to understand and learn how to foster these virtues in young people" (Seligman \& Csikszentimihalyi, 2000, p. 7).

\section{Posttraumatic Growth}


Calhoun and Tedeschi (2006a) have attempted to expand the perceived outcomes associated with trauma. They have spurred an area of research called posttraumatic growth (PTG), which focuses on the positive psychological change that emerges following significantly difficult or traumatic life events (Tedeschi \& Calhoun, 2004). Although such a concept is far from new, the authors were among the first to empirically study PTG resulting in a flurry of recent research that focuses on the psychological and behavioral growth that emerges from traumatic experience. This area of research has the potential of expanding the goal of trauma therapy from symptom reduction to life enhancement.

Combining and condensing existing perspectives on PTG, Tedeschi (2011) offered a definition that will be used to operationalize the construct for this study. Posttraumatic growth is broadly defined as the "positive personal changes that result from a struggle to deal with trauma and its psychological consequences" (Tedeschi, 2011, p. 137). Tedeschi and Calhoun (2004) have noted posttraumatic growth can occur independently on five domains. It is not expected that individuals will show positive growth equally in each area, however, individuals often express notable gains in at least one of the following: 1) an increased appreciation for life or a radical change in priorities; 2) more meaningful relationships with others; 3) a general sense of increased personal strength; 4) identification of new possibilities for one's life; and 5) growth in spiritual or existential matters (Tedeschi \& Calhoun, 2004).

The factors of PTG have been empirically shown within a variety of different populations. Researchers have demonstrated PTG with patients diagnosed with cancer (Cohen \& Numa, 2011), experiencing the death of a loved one (Gerrish et al., 2009), or being involved in military combat (Pietrzak et al., 2010). Of significant note is the prevalence rate of PTG within each of these samples. Meta-analysis of PTG studies indicate reported personal growth within 
$75 \%$ to $90 \%$ of tested samples (Tedeschi, Park \& Calhoun, 1998; Updegraff \& Taylor, 2000). Therefore, the occurrence of PTG is seemingly more prevalent than PTSD following traumatic exposure.

Despite the high incidence of PTG, growth has frequently been perceived as a secondary gain. Individuals rarely express the desire to grow from a traumatic experience. Additionally, it is not within the realm of capability for therapists to "command or order" such viewpoints as "one cannot force oneself to be optimistic indiscriminately against all odds, against all hope" (Frankl, 1984, p. 162). In the aftermath of a traumatic event, some individuals report that they would not undo the crisis and return to the way things were before the event (Calhoun \& Tedeschi, 2006b). However, a majority of research subjects stated they "would indeed give up all of the positive changes if they could simply recover what had been lost" (Calhoun \& Tedeschi, 2006b, p. 7). This final statement highlights the difficulty of encouraging growth and the grief customarily associated with the process. Yet, as Frankl suggested, it is within human nature to strive for meaning, clarity, and purpose. This provides rationale for the high rates of PTG among trauma survivors despite the agony associated with the process.

Calhoun and Tedeschi (2006b) developed a model that depicts the process of PTG (See appendix A). After a trauma has occurred, the victim must first manage his or her emotional distress. Most individuals will display symptoms consistent with acute stress disorder or PTSD. However, after a few weeks, symptoms subside for most people (Tedeschi, 2011). This occurs as the individual engages in healthy rumination and cognitive processing of the event (Calhoun, Cann, \& Tedeschi, 2010). According to Calhoun et al. (2010), growth is further influenced by contextual factors surrounding the disclosure of the traumatic events. Attempts to process, disclose, and resolve trauma is inhibited or encouraged by the reactions of others and the socio- 
cultural context in which the trauma occurs. Finally, the personal disposition of the survivor influences subsequent growth. The degree to which they are resilient will influence the amount of gains that transpire (Calhoun et al., 2010). A more thorough portrayal of each factor follows below.

Acute symptomology. The development of short-term symptoms is very common among trauma survivors. According to the American Psychiatric Association, as many as 33\% of the US population develops acute stress disorder immediately following a crisis (APA, 2000). Survivors are often plagued by symptoms of arousal and re-experiencing which tend to be automatic and intrusive. Therefore, in early stages of the coping and growth process, persons must find ways of managing their symptoms (Tedeschi \& Calhoun, 2004).

Tedeschi and Calhoun (2004) suggested PTG is contingent upon experiencing a certain amount of personal distress. However, prolonged re-experiencing and sense of arousal is debilitating, and without intervention will develop into psychopathology. Calhoun and Tedeschi (1998) indicated a number of resources that may help an individual buffer against continued psychological pain. An individual's innate personality, coping skills, and past life experience contribute to a sense of resiliency. Furthermore, an individual may have a number of external resources available such as social support or spirituality that may inhibit symptomology. Finally, the authors noted traditional evidenced based strategies for PTSD are designed specifically to reduce symptoms of distress. These treatments help manage stress-related reactions and provide a supportive environment in which to process the trauma (Donovan et al., 2001). Additionally, therapies such as Cognitive Processing Therapy, Eye Movement Desensitization and Reprocessing, Stress Inoculation Therapy, and Prolonged Exposure Therapy address the 
avoidance behaviors associated with PTSD that might hinder cognitive-emotional processing of the crisis, thus giving the opportunity for growth (Zoellner \& Maercker, 2006).

Rumination. Calhoun and Tedeschi (2006b) proposed rumination is a natural cognitive response in the wake of negative life events. The authors defined rumination as "repeated thinking that is not necessarily intrusive and that includes reminiscing problem solving, trying to make sense, and perhaps searching for how the struggle has changed one in positive ways" (Calhoun \& Tedeschi, 2006b, p. 9). However, the process of incorporating a trauma experience does not always result in positive integration. Recalling negative life events can create overwhelming sensations and trigger a flight or fight response. Nolen-Hoeksema and Davis (2004) suggested clinicians should encourage reflective rumination, which evokes a more constructive and deliberate way of understanding the world. Engaging in healthy ruminative thoughts is the process shown to produce posttraumatic growth (Calhoun \& Tedeschi, 2006b).

Calhoun and Tedeschi (2006c) described rumination as potentially healthy as it involves reminiscing, problem solving, and attempts to make sense out of the event. Such a holistic perspective reframes rumination as an adaptive process. Cognitive theorists have long since recognized this process as assimilation, accommodation and over-accommodation (Resick et al., 2008). After a trauma, individuals may attempt to assimilate the trauma experience into their existing cognitive framework. Therefore, the individual alters his or her perceptions of the experience so it is consistent with prior beliefs. Individuals may also over accommodate, altering their beliefs about world and self in order to feel safer and more in control. For instance, an individual may avoid all city streets that remind him or her of a given trauma experience. However, Resick et al. (2008) reported the goal of therapy is to have clients engage in accommodation, cognitive flexibility that allows for the transformation of previous beliefs and 
incorporation of the new information. Understanding the different forms of appraisals gives insight to the cognitive and behavioral variances seen in individuals that experience similar crises (DePrince et al., 2011).

Social sharing. Tedeschi and Calhoun (2004) identified social sharing and social support as highly correlated with reducing unhealthy ruminative patterns and promoting posttraumatic growth factors. However, not all social support creates a medium for positive change. For instance, Berrera (1986) found that the number of individuals in a survivor's social network is not predictive of healthy functioning or growth. However, the survivor's perceptions of the quality of the received social support were a significant indicator of posttraumatic growth. As expected, it is the perceived value of these relationships and not the quantity that matters most.

Social networks offer the opportunity to begin the reconstruction and reorganization of shattered internal beliefs (Tedeschi \& Calhoun, 2004). If processing a trauma related event occurs in a supportive social context, associations between the traumatic stimuli and negative emotional responses may be weakened, and even replaced by positive emotional responses (Lepore, 1997). Furthermore, individuals have the opportunity to passively engage in the process by listening to the perspectives and multiple realities offered by others. Seeing others embark on a positive transformative experience gives hope and possibility that others may as well.

Rime, Finkenauer, Luminet, Zech, and Philippot (1998) argued that sharing an emotional experience might specifically benefit groups such as veterans due to the additional fulfillment of emotional and social needs. The authors argued groups often foster a sense of relatedness, interpersonal relationships, and social integration. Rime (2009) postulated higher perception of 
social support reduced feelings of enhanced positive affect and strengthened pro-social behavior. Need fulfillment not only has the possibility of fostering growth, but also addresses many of the issues of misunderstanding and social isolation commonly reported by returning combat veterans.

Social Reference. Calhoun and Tedeschi (2006c) indicated social support was strengthened when it occurred within a supportive group with similar customs, attitudes, and assumptions. "The individual's proximate cultural influences may provide a more direct avenue for evaluating how the process of PTG may occur" (Calhoun \& Tedeschi, 2006c, p. 13). Currie et al. (2011) noted unique growth opportunities within environments consisting of members with a similar trauma experience. Those who experience similar stressors are better positioned to provide social support due to a genuine understanding of the perceived need (Currie et al., 2011). The recounting of traumatic life narratives to an empathetic audience solicits validation of one's experience and provision of social support, both of which can facilitate healing and growth (Neimeyer, 2006). Therefore the research encourages the creation of groups comprised of individuals with similar trauma experiences and when possible, similar cultural background. De Rivera and Paez (2007) suggested such groups not only foster healthy cognitive processes through open dialogue, but for survivors of a single terrorist attack in Madrid, also encouraged the engagement in healing activity. The authors discovered these groups regularly performed communal coping activities in the form of memorials, demonstrations, and altruistic behaviors. In turn, research demonstrates these behaviors elicit positive collective feelings such as solidarity, hope and trust (Páez, Ubillos, \& Gonzalez-Castro, 2007). Páez et al. (2007) found participation in symbolic ceremonies strengthened well-being, positive affect, increased interpersonal attraction, empathy, pro-social behavior, and positive emotional climate. 
Military environment has frequently been viewed as disparate from civilian life, only recently have authors made attempts to identify how the Armed Services comprise a unique cultural entity. Strom et al. (2012) emphasized the distinctive language, norms, customs, and beliefs that are a part of military life. Therefore, providing healing opportunities comprising of groups open only to military personnel may help encourage growth by providing a collective environment comprised of individuals with similar backgrounds.

Human narrative. According to Neimeyer (2006), unprocessed trauma events can neurologically be stored in the brain, unprocessed, for months, years, or decades. Such examples are consistent with Vietnam era veterans continuing to seek treatment as a result of unresolved PTSD. The author suggested undigested emotion is stored within the amygdala, "a deep brain structure that in trauma can be functionally stratified from neocortical processing of the event, intruding periodically into awareness without being integrated into conscious, declarative memory" (Neimeyer, 2006, p. 72). Trauma events bypass normal schematic coding and therefore can be viewed as pre-narrative. Neimeyer (2006) postulated this is partially the reason for intrusive memories. The veteran perpetually is inflicted with tormenting and unmetabolized images and experiences that are schematically inconsistent with one's personal narrative.

Neimeyer (2006) suggested that treatment for individuals with PTSD initially consists of providing language for the traumatic event and associated intrusive thoughts. Meichenbaum (2006) suggested that humans are natural storytellers and will develop their own vernacular to create meaning out of daily events. The telling of stories to self and others puts words and language to an event, which then can be explained, rationalized and challenged if necessary (Meichenbaum, 2006). 
An individual's self narrative organizes the detailed cognitive, behavioral, and affective components of daily living into a more consolidated storyline, which allows individuals to identify a sense of self and perceptions of the social world (Neimeyer, 2006). Neimeyer (2006) proposed identity is a product of the narratives we tell about ourselves, the stories that influential individuals tell about us, and the stories mutually communicated with these individuals. It is this self-narrative that is profoundly shaken by seismic life events instigating the process of revision, repair, or replacement of basic thematic assumptions.

As the individual narrating our lives, Wortham (2001) perceived that human beings create a biased worldview, as both the storyteller and the story. Certain overarching narratives organize the person's sense of self under a single hegemonic label or description (Neimeyer, 2006).

When the dominant narrative is negative and preemptive as perceiving self as nothing but a PTSD case then the dominant narrative can colonize the person's public identity and private self-concept, producing real effects on the way in which the person relates to self and others. (Foucault, 1970 as cited in Neimeyer, 2006, p. 74)

To the extent that the person can externalize the dominant narrative and see it as a problemsaturated story separate from the self, he or she is better able to resist it and reclaim the sense of new possibilities. Meichenbaum wrote, "beware of the stories you tell yourself and others for you will be lived by them" (Meichenbaum, 2006, p. 355). The premise of such a quote implies that regardless of true reality, what we believe about ourselves becomes our internal truth. Therefore, the opportunity to tell one's story and how the image of self changes over time influences the adjustment process. 
Posttraumatic growth and posttraumatic stress disorder. Larner and Blow (2011) recently published an article exploring the psychological trajectories for military personnel exposed to combat. Their findings corresponded with past research suggesting three possible courses of mental health: resilience, decline, and PTG (Larner \& Blow, 2011). Likewise, Seligman and Fowler (2011) reported, that the human response to high adversity, such as combat, is normally distributed: On the left of the distribution are the minority who collapseexhibiting what is called variously PTSD, depression, or anxiety. In the middle are the great majority who are resilient; they return to their normal level of functioning after a brief period of disruption. On the right hand side of the distribution are those who grow: people who after adversity attain a higher level of functioning than they began with or, in other words, exhibit posttraumatic growth. The aim of any prevention program should be to move the entire distribution toward growth.

Both studies indicate that the initial trajectories are not linear.

Cadell, Regehr and Hemsworth (2003) remind readers that the presence of growth does not necessarily mean the absence of negative symptoms. The authors found that participants in their study who met full criteria for PTSD also reported significantly more PTG than those who did not meet the criteria for the diagnosis. The presence of PTG is an indication that persons are living in ways that, from their point of view, are fuller, richer, and perhaps more meaningful in spite of the continued endorsement of negative symptomology (Calhoun \& Tedeschi, 2006b). For many individuals who have struggled with a traumatic event, the satisfactory resolution to 
major existential questions about how to live in the fullest way possible may be more important than the reduction of psychological discomfort (Tedeschi \& Calhoun, 1996).

Studies exploring the influence of PTSD on reported PTG have yielded mixed results. Davis and Macdonald (2004) found distress to be positively correlated with posttraumatic growth. Yet, other studies have shown the increase of distress to be negatively correlated with growth related factors (Lepore, 1997). More recently, researchers have integrated previous data to now demonstrate a curvilinear relationship between negative pathology and meaning making (Linley \& Joseph, 2004). Linley and Joseph (2004) reported in high doses, the trauma seems to overwhelm the psychological resources of most persons. The individual is overwhelmed and incapable of growth. Too little distress indicates the event was not seismic resulting in reflection of one's worldview and values. Therefore, moderate levels of distress are associated with highest levels of PTG (Linley \& Joseph, 2004).

Posttraumatic growth and veterans. Tedeschi and McNally (2011) published an article entitled, Can We Facilitate Posttraumatic Growth in Combat Veterans. Condensing broad research conducted on PTG with articles focusing on veterans, the authors offered the following suggestions: provide opportunities for "constructive" self-disclosures whereby veterans can receive emotional support and develop a coherent trauma narrative, encourage the use of metaphors to convey complex constructs, find models for healthy trauma responses and growth, learn how to use social support or develop new ones, and develop life principles (e.g., altruistic acts, honoring deceased comrades, and accepting changes of social identity).

Factors that mediate PTG in veterans have primarily focused on social support. Many returning soldiers report enhanced meaning and comradeship with members of their unit as a result of their service experiences (Meichenbaum, 2011). They are separated from a familiar 
environment and living in unparalleled dangerous environments. As a result, there is a perspective that only those that have served can understand their experiences. Meichenbaum (2011) suggested these reasons contribute to why it is difficult for military personnel to reintegrate into mainstream society. Maguen, Vogt, King, King, and Litz (2006) identified social support of fellow soldiers as the most important attribute in predicting growth. Tedeschi (2011) noted a direct relationship between a veteran's social support and his or her disclosure and the development of a coherent trauma narrative. Park (2011) suggested there is an urgent need to develop programs that focus on the development of veteran social support and personal strengths. A comprehensive approach to this issue "may be more effective than a problem focused strategy, and it would certainly reduce the stigma that surrounds the seeking of mental health care" (Park, 2011, p. 71).

\section{Psychology and the Outdoors}

Programs such as Project Healing Waters (Project Healing Waters, n.d.), Wounded Warriors (Wounded Warriors, n.d.), and the Outward Bound Veterans Program (Outward Bound Veteran Program, 2010) are experientially based programs that theoretically address the recommendation made by Park. Several of these programs, such as Project Healing Waters, have chapters supported by major VA Medical Centers from around the country. However, the psychological benefits of such programs remain unknown, as few efforts have been made to study them. Nevertheless, research from outside the field of psychology suggested adventure therapy often establishes prosocial communities that elicit social sharing, processing, and repeated opportunities to practice newly formed cognitions and behaviors (Gass, Russell, \& Gillis, 2012). Although adventure therapy is a relatively new term, healing properties of the wilderness have been utilized for generations in the United States. 
In an edition of the APA Monitor, Stiles (2011) described the history of outdoor experiences as an early treatment for psychological disorders. The $19^{\text {th }}$ century physician, Silas Weir Mitchell, was known for treating "nervous" men. Individuals were sent to western states to engage in prolonged periods of cattle roping, hunting, rough riding and male bonding. The "West Cure" was designed to treat neurasthenia, which included symptoms such as depression, insomnia, anxiety and migraines. Individuals prescribed such a treatment included a youthful President Theodore Roosevelt and Walt Whitman. The effects of the "West Cure" supposedly resulted in feelings of confidence, assertiveness, and reinvigoration (Stiles, 2011).

Adventure therapy. In modern treatment settings, psychology and the outdoors co-exist within the field of adventure therapy. Adventure therapy is "the prescriptive use of adventure experiences provided by mental health professionals, often conducted in natural settings that kinesthetically engage clients on cognitive, affective, and behavioral levels" (Gass et al., 2012, p. 1). Adventure therapy is associated with contrived experiential activities encouraging risk taking, self-discovery, and challenge within a group context (Crisp, 1998).

As already described, natural environments have long been remarked as restorative, yet little research exists within traditional psychology journals regarding adventure therapy as a viable treatment modality (Hartig, Boo, Garvill, Olson, \& Garling, 1996). Lepore and Revenson (2006) reported no studies exist linking natural, healing environments with resilience or particular coping mechanism. Researchers such as Gass et al. (2012) have prompted the field to begin more empirical study verifying the growth related attributes of the outdoor/adventure setting.

Spellman and Gillis (2008) conducted what appears to be the most recent meta-analysis of the benefits associated with outdoor programming. The researchers analyzed studies 
published between 1996 and 2006. They demonstrated that the overall effect size of treatment outcomes was $d=.43$. A range of samples was listed including adolescents, college students, families, and adults. The results revealed outdoor programming positively influenced each of the following factors: self-efficacy, self-esteem, trust, cohesion, interpersonal development, hope, teambuilding, leadership skills, and improved affect (Spellman \& Gillis, 2008). Many of these reported variables correspond with or may promote posttraumatic growth factors.

Spellman and Gillis' meta-analysis allows for the plausibility that individuals who have experienced combat related trauma may benefit from such environments. Yet, as these programs vary greatly based on the type of activity, length of program, setting, and role of the instructor, further clarity of what constitutes adventure therapy is required. Over the past four decades several authors have contributed to the narrowing of necessary components that must exist within an adventure therapy experience (Gass, 1993; Gass et al., 2012; Walsh \& Golins, 1976). Gass et al. (2012) were among the latest authors to consolidate previous attempts suggesting the inclusion of seven mandatory factors: a motivated learner, prescribed physical environment, social environment, adventure-based experience, role of the instructor, a success or mastery experience, and a transfer of learning.

Motivated learner. The first element described by Gass et al. (2012) is the inclusion of an active and motivated learner. The client must be engaged to absorb learning objectives. He or she is a participant, not a spectator in the completion of the activity. These individuals are actively involved, requiring a degree of energy, responsibility, and motivation to complete a task. Although adventure therapy is also utilized with mandatory clientele, these experiences foster engagement despite possible low motivations at the onset of treatment (Gass, 1993). 
Physical environment. Often, the removing of an individual from familiar and comfortable surroundings creates a sense of "adaptive dissonance" (Gass, 1993). The person must learn how to become comfortable in a potentially uncomfortable environment. Further, each activity is accompanied by a notion of perceived risk. Csikszentimihalyi (1991) has suggested growth and learning occurs most readily when there is an optimum level of elicited anxiety. If a participant is not stimulated enough, he or she becomes bored and loses interest. However, if the individual is in a state of panic, fear will override any positive learning opportunities. Therefore, the facilitator must attempt to create a sequential set of activities that continuously provides an increased level of excitement and appropriate stress to keep the participants engaged and learning.

Social environment. As described above, the inclusion of group participation allows for social learning and transmission of knowledge (Gass et al., 2012). As these environments are unfamiliar to all participants involved, it allows for a more flexible construction of social norms established by the participants. The new social setting often challenges perceived societal norms, freeing the individual to try new behaviors. Group experiences provide a constant source of social and behavioral feedback from other participants. Additionally, group members recognize that other members share similar feelings, fears, desires, thoughts, and problems about their lives.

Adventure-based experience. An adventure-based experience includes various forms of activities, climate, equipment, and length of programming. The use of sea kayaking, backpacking, rock climbing, dog sledding, challenge course elements, canoeing, and sailing are described in the literature as activities associated with adventure programming (Gass et al., 2012; Miner \& Boldt, 2002). Within each experience is a purposeful sequence of activities, which 
allows participants to utilize previously learned skills to complete a more challenging task. The sequencing of activities often leads to some culminating peak experience. This could equate to the arrival at some distant beach, summiting a mountain, or the participation in an anticipated destination. At the end of the activity, there is some degree of processing that occurs allowing participants to reflect upon the learning of a given activity.

Role of instructor. The role of an adventure leader differs from a traditional therapist in several ways (Gass et al., 2012). Therapists are seen outside the office where they have the opportunity to role model and be a part of the shared experiences. The leaders also have a greater amount of contact time with the client. As a result, there is opportunity to establish deeper and more meaningful relationships (Walsh \& Golins, 1976). Additionally, participants are engaged in real life situations designed to evoke certain behavioral patterns and emotional responses, allowing the therapist/leader to observe the patterns in real time. This provides the opportunity to discuss strategies based on these observations and address them with the client immediately.

Debriefing. A strong component of the outdoor field is processing or making sense of one's experience (Passarelli, Hall, \& Anderson, 2010). For instance, it is not always known what awareness is taken from paddling a rapid until being prompted to reflect on the experience. Appropriate questioning and thought provocation may help an individual categorize what was learned by participation in the activity. The authors indicated debriefing an activity creates new cognitive pathways allowing for positive future action. Passarelli et al. (2010) used the slogan "words create worlds" to describe the impact of putting language to a shared experience. This perspective is consistent with the data on trauma, which suggests information is not fully stored until language is ascribed (Neimeyer, 2006). 
Transfer. A constant struggle of any therapeutic condition is for the client to transfer perceived gains made in session to actual life. The literature suggested adventure therapy has two advantages over traditional settings: the inclusion of a fun and enjoyable experience (Walsh \& Golins, 1976), and the use of isomorphic connections (Gass \& Priest, 2006). Isomorphisms are contrived situations or objects that parallel everyday life experiences (i.e., the difficulty of hiking a mountain symbolically representing overcoming an emotional struggle). When engaged and distracted by pleasurable activities, clients often forget there is a therapeutic component, thus reducing reluctance to share personal issues (Gass et al., 2012). Therefore, learning often occurs without much awareness.

The transfer of knowledge to everyday life is also aided through the purposeful inclusion of isomorphisms (i.e., situations that parallel real life situations). The adventure activity serves as a kinesthetic metaphor that not only is discussed, but also experienced by the client. It allows clients to practice new behaviors in a training experience that parallel those experienced in everyday life. Gass and Priest (2006) specifically demonstrated isomorphic connections serve as a contributing factor to treatment gains.

Outward Bound Veterans Program. All modern adventure programming can be traced back to the beginnings of Outward Bound (Miner \& Boldt, 2002). Kurt Hahn, commonly known as the father of adventure programming and the founder of Outward Bound, was asked to develop an experiential school devoted to the preparation of young men for seaward battles occurring during WWII. Reports indicated young men were less likely to survive the rigors of war and naval combat due to a lack of experience, training, and confidence. "Unlike sail-trained old-timers, the younger men and youths had not acquired a sense of wind and weather, a reliance on their own resources, and a selfless bond with their fellows" (Kurt Hahn quoted in Miner \& 
Boldt, 2002, p. 35). Hahn, an educator by trade, was tasked with developing an experiential program offering a practical experience for young men preparing for sea. It was Hahn's belief that individuals should learn from their failures and weaknesses to prevail against adversity and learn about internal difficulties. Through experiential activities, the participants learned the connection between self-discovery and supporting the needs of the greater community.

Outward Bound continues to exist today internationally as the "premier provider of experience based outdoor leadership" offering programming to the general population, at-risk youth, and returning veterans (Outward Bound USA, 2012). Although the program was not originally designed with specific therapeutic intentions, Outward Bound clearly provides strength based, life enhancing opportunities. Josh Miner, the founder of Outward Bound USA wrote,

Outward Bound tries hard to save people from the misery of their unimportance, but wants them to account for others as well as for themselves. Outward Bound's chief passion is compassion, its strength to develop the capacity to face squarely and to overcome calmly all manner of adversity. (Miner \& Boldt, 2002, p. 9)

Such a slogan seems to fit the expressed need of many returning veterans.

Outward Bound seems to naturally fulfill such a mission. From its inception, Outward Bound had the specific purpose of aiding military personnel in survival and personal growth. In fact, the Outward Bound motto of: "To Serve, To Strive, and Not to Yield" sounds as if it could represent a branch of the US Armed Forces. Therefore, it is not surprising that soon after Outward Bound USA opened, a relationship was born with the US military. The US Armed Forces and Outward Bound began communicating in 1969 as a result of common philosophical and experiential training approaches (Outward Bound Veteran Program, 2010). In 1971, 
Outward Bound was used as a consultant with the US Army to develop Spartan Pathfinder, a disciplinary program to help reform military personnel with a history of drug use and/or had been convicted of a disciplinary offense. In 1975, the Dartmouth Outward Bound Center coordinated with the Dartmouth Medical School to run an experimental psychiatric program. This relationship is responsible for the initiation of a veteran-specific program that began in 1983. Between 1985 and 1992, Outward Bound Veterans Program (OBVP) opened at Pacific Crest Outward Bound School, North Carolina Outward Bound School, Voyageur Outward Bound School, and Colorado Outward Bound School. After 1991, OBVP continued to gain support from several veteran organizations from around the country: Disabled American Veterans, Agent Orange Class Assistance program, Denver Vet Center, White River Junction VA Hospital, Northampton VA Medical Center, American Lake VA Medical Center, Readjustment Counseling Service VA Central Office, North Chicago VA Medical Center, and Maine VA Hospital. In 2007, Outward Bound received multi-year funding from the Military Family Outdoor Initiative Project, a program affiliated with the Sierra Club, to offer full scholarship OBVP courses to veterans from Operation Enduring Freedom and Operation Iraqi Freedom. The project was specifically designed to help military personnel reintegrate into civilian life, honor their past experiences, and combat the sense of alienation shown to be a contributing variable in the development of PTSD (Outward Bound Veteran Program, 2010).

Presently, Outward Bound offers diverse outdoor experiences for younger veterans (Outward Bound Veterans Program, 2010). Every season, multi-day expeditions are offered that include backpacking, sea kayaking, rock climbing, canoeing, mountaineering, or sailing. The programs are held throughout the country and are offered solely to veterans. In conjunction with the outdoor expedition, the participants are involved in a shared experience with other veterans. 
In general, members are led in nightly discussions regarding their experience of returning home, current struggles, transition, self-management, and past military experiences. OBVP instructors have the flexibility and are encouraged to lead a remembrance ceremony as a way to honor fallen soldiers. It should be noted that the discussions are not standardized and different topic areas are more heavily discussed than others based on the needs of the participants and the decisions of the trip facilitators. Instructors are specifically educated on military structure, expectations, and values to increase sensitivity to the re-immersion and healing processes involved. Although trained therapists do not explicitly lead the programs, research indicates mental health benefits occur (Hyer et al., 1996).

Research on Outward Bound Veterans Program. The little research on the Outward Bound Veterans Program provides an initial understanding of the potential psychological benefits of these expeditions. Ewert, Puymbroeck, Frankel, and Overholt (2011) analyzed the program outcomes of the OBVP. Participation in OBVP was shown to improve self-confidence, self-actualization, compassion, healthy and balanced lifestyle, goal setting, group collaboration, effective communication, conflict resolution, problem-solving, social responsibility, and environmental responsibility immediately following the program.

The study most influential to this dissertation is Hyer et al's. (1996) exploration of an adventure program's effect on PTSD. The authors conducted an influential study using a fiveday modified OBVP as an adjunctive treatment for veterans diagnosed with PTSD. Participants were randomly selected from inpatient treatment programs at two different Veteran Administration Medical Centers. The inpatient stays lasted between 11 and 14 weeks. The results of the study demonstrated that individuals who participated in Outward Bound reported no discernable difference on general or PTSD-specific symptoms in comparison to the control 
group (treatment as usual). These findings are not surprising given the probable severity of PTSD symptomology of individuals being treated at an inpatient facility.

Despite the lack of statistical differentiation in treatment versus control groups, the authors reported unexpected qualitative findings. Although there was no indication of how qualitative data were collected and analyzed, the authors noted five themes consistently reported by the participants. The participants described notable gains in the ability to enjoy life again, rediscovering enjoyment in the outdoors, overcoming negative emotions, being more in control, and an improved relationship with others (Hyer et al., 1996, p. 275). This information suggested indications that the OBVP provides a rich environment, which may promote posttraumatic growth.

Therefore, this study will attempt to re-examine Hyer and colleagues' 1996 inquiry with specific attention to both PTSD and PTG variables. This study will deviate slightly from the

original study, as growth factors are the primary focus. Additionally, the range of participants will expand. This study will recruit a larger number of participants from around the United States with varying levels of pathology, not just those that would qualify for inpatient treatment. Furthermore, the adventure programming to support the veterans' needs have likely changed. In 1996, OBVP did not yet exist and Hyer and colleagues did not list any of the activities associated with the modified program. Therefore, it is impossible to directly compare the current OBVP with the five-day program created in 1996, though a number of parallels exist between the two studies.

\section{Rationale of the Proposed Study}

The story of Outward Bound and its founder, Kurt Hahn, is a testament to the resiliency of one man and his ability to see growth in the education of trauma and hardship. As a 19-year- 
old young man, Hahn was struck by a severe case of sun poisoning (Miner \& Boldt, 2002). The result left Hahn confined to a darkened room for most of a year following the event. Like so many influential people in psychology that began life with a crippling medical condition, Hahn also developed life principles that would guide his worldview and influence the philosophy of Outward Bound. Hahn was quoted several times saying, "Your disability is your opportunity" (Miner \& Boldt, 2002, p. 29). It fitting that a program influenced by Kurt Hahn would also attempt to help veterans grow from experiences of war.

As a result of sustained fighting, significant evidence of psychopathology has been cataloged within returning OIF/OEF/OND veterans. A disproportionate number of veterans have posttraumatic stress in comparison to civilian counterparts, leaving them vulnerable to social, occupational, legal, and intrapersonal difficulties. Despite the hundreds of thousands of veterans diagnosed with PTSD, only a fraction access services due to sociocultural barriers, resulting in dysfunction in familial, social, occupational, and intrapersonal domains. George Washington once said that "the willingness with which our young people are likely to serve in any war, no matter how justified, shall be directly proportional to how they perceive the veterans of earlier wars were treated and appreciated by the nation" (as cited in the Congressional Records - House, 2003). This suggests a need for new strength-based initiatives that aim to not only reduce negative pathology but also enhance healthy behavior and cognitive restructuring.

Shifting the view away from pathology, few studies have explored the positive effects that befall soldiers as a result of war related trauma. Perhaps this is related to the social, cultural, or political ramifications of suggesting the possibility of interpersonal growth attributed to war events. The intention is not to suggest that war is positive, but rather to explore how combat experiences may positively influence one's values, perspective, priorities and resilience. Society 
is familiar with the negative response associated with war. This study builds upon the limited existing literature that provides evidence for growth-related factors that may also exist. This positive focus on health and wellness shifts the focus solely from symptoms and despair to a lens of hope, growth and resilience.

As no current studies currently have explored interventions that promote PTG in veterans, the following project explored the influence of the Outward Bound Veterans Program on growth outcomes. OBVP has several social and cultural components known to promote PTG and is specifically designed to engage veterans in purposeful experiential activity while allowing them frequent opportunities to discuss their collective experiences. The following two questions will be addressed: 1) For current and former members of the United States Armed Forces, does Outward Bound Veterans Program promote posttraumatic growth? 2) How, if at all, does Outward Bound Veterans Program promote posttraumatic growth? 


\section{CHAPTER II}

\section{Research Methods}

There is an emerging curiosity within the field of psychology directed at exploring growth related factors that occur due to wartime events. The goal of this study was to build upon existing research by elucidating variables that allow professionals a greater understanding of how PTG can be intentionally fostered with veterans. Therefore, a mixed method design was used to address the following research questions: Does Outward Bound Veterans Program promote posttraumatic growth for current and former members of the United States Armed Forces? How, if at all, does Outward Bound Veterans Program promote posttraumatic growth?

\section{Rationale of the Design}

Pragmatist Paradigm. A common practice within qualitative or mixed method designs is for the researcher to explain his or her existing paradigm. Paradigms are the worldview or belief systems that guide a researcher (Tashakkori \& Teddlie, 1998). The investigator's paradigm modulates his or her perception of the world, morals, values, and aesthetics permeating all aspects of scientific inquiry (Morgan, 2007). Therefore, it is implied that the research question, participant selection, method, and data analysis are influenced by the researcher's paradigm. Although it has been suggested that paradigms influence all research designs, discussion of paradigms is more heavily utilized in qualitative research due to the influence of the researcher's biases on data collection and analysis (Miles \& Huberman, 1994). The following section is dedicated to explaining the investigator's paradigm for the purposes of describing the rationale for different methodological choices, as well as making known biases observable. 
A pragmatic paradigm was adhered to for purposes of this study. Pragmatism offers a bridge between the traditional constructivists' and positivists' worldviews by capitalizing upon the benefits and compatibility of each epistemology (Tashakkori \& Teddlie, 1998). The positivist paradigm is commonly associated with the search for a single known truth or reality through fact and traditional scientific inquiry. In opposition, constructivists hold a worldview where truth and reality are subjective experiences. The pragmatic paradigm integrates the constructivist and positivist perspectives by suggesting there is one reality, but it is uniquely understood based on individual interpretation and experience. Therefore, it is my belief that knowing each person's subjective experience is valuable in determining how a phenomenon is perceived. I anticipate this view has impacted my design, interview questions, interactions with participants, and likely the emergent theory. Therefore, the following provides the reader with an understanding of my personal connection to the research topic.

Bracketing. Within the social sciences, there may be a strong relationship between the researcher and the chosen topic. Due to the potential emotional investment in the project, unintentional misrepresentation of data may occur, as the researcher is the primary instrument through which data is gathered and analyzed. This subjective endeavor "entails the inevitable transmission of assumptions, values, interests, emotions and theories within and across the research project. These preconceptions influence how data are gathered, interpreted and presented" (Tufford \& Newman, 2010, p. 81). To mitigate these factors, and in an effort to provide greater trustworthiness to the data, the authors encourage qualitative researchers make efforts to remain transparent about their decisions, interpretation, and writing throughout the research process. 
Bracketing is a tool used in qualitative inquiry to help minimize preconceived notions that may accompany the process. There are a variety of definitions given, but as grounded theory guided the analysis process, I utilized Creswell and Miller's description of bracketing:

The importance of researchers acknowledging their beliefs and biases early in the research process to allow readers to understand their positions, and then bracket or suspend those researcher biases as the study proceeds...individuals reflect on the social, cultural, and historical forces that shape their interpretation. (Creswell \& Miller, 2000, p. 127)

Creswell and Miller (2000) suggested bracketing should occur early in the research process, before any form of data collection or analysis has begun. The authors also recommended bracketing be integrated throughout the process.

Researcher's relationship with the topic. It is likely my dissertation topic was influenced by my personal, occupational, and academic pursuits. My direction in higher education has allowed me to complete two Master's degrees in recreational therapy and counseling. Although my professional endeavors are moving me towards more traditional psychotherapy settings, I maintain an experiential approach to therapy when appropriately indicated. I also continue to participate in outreach programming to support the needs of the local community. Often, these activities include adventure-based programming such as leading outdoor orientations, developing inclusive outdoor activities for disabled college students, and facilitating a substance abuse program conducted at the university's challenge course. Regardless of my occupational obligations, I anticipate always participating in some form adventure activity in either my personal or professional roles. 
I am a proponent of wilderness environments as both a treatment setting as well as the basis for general outdoor activity. I have a nine-year occupational history in wilderness therapy and adventure-based counseling, in addition to my own personal outdoor pursuits. I have found tremendous personal and perceived benefit in the outdoors. I recognize that not all individuals find equal joy in backpacking, kayaking, or sailing. However, I consistently see repeated benefits in individuals that self-select into such activities. The different types of populations I have assisted in the outdoors include: traditional adults, adolescents, court/family mandated adolescents, university mandated individuals that have received alcohol citations, and individuals with physical disabilities.

My interest in creating a research study on veterans' experiences in the outdoors was born out of therapeutic intent of using the outdoors and respect for members of the US Armed Services. I felt compelled to assist those that have sacrificed for the greater good. Additionally, I was motivated by the need to explore interventions that promote growth and are encumbered by perceived societal barriers. The non-stigmatizing nature of programs such as Outward Bound attracts numerous returning veterans and potentially enhances psychological growth.

Since beginning this research project, I gained clinical experience working with veterans in more traditional treatment facilities. I completed a summer practicum at a Veteran's Medical Center conducting both individual and group therapy for military personnel diagnosed with PTSD. I used traditional evidence-based treatment models such as Cognitive Processing Therapy and Seeking Safety as part of the veterans' treatment plan. In my free time, I also volunteered to assist with the unit's recreational therapy, which consisted of classic challenge course activity to promote problem solving, pro-social behavior, communication, and social 
support. I found each of these experiences fulfilling, as well as somewhat disheartening having seen many individuals that had struggled with the disorder for decades.

Based on the information listed above, the reader should note my history of treating veterans and working in adventure-based environments. It is likely I carry assumptions about how programs such as OBVP may influence factors such as PTG. I have attempted to minimize my personal influence by not being a part of the treatment process, triangulating the data, implementing a semi-structured interview protocol, and by striving to make my personal assumptions transparent.

\section{Research Design}

To address the research questions listed above, I used a mixed methods, between-subjects design. This study adhered to a sequential triangulation design suggesting the quantitative data were collected first to inform the assembly of the qualitative data (Morse, 1991). This study can also be described as a two group, quasi-experimental design. Although effort was made to increase validity and reliability of results due to the inclusion of a control group and use of repeated measures, randomization of participants into groups was impractical. The adherence to a nonrandomized, pretest-posttest control group design allows "for the examination of some of the inevitable between group, pretreatment differences" and such differences "are unlikely attributed to factors such as history, maturation, or testing” (Heppner, Wampold, \& Kivlighan, 2008, p. 184). Heppner et al. (2008) also suggested such designs are frequently utilized in social science research when randomization of participants cannot be achieved. Furthermore, the results are statistically interpretable as there is an identified control group and treatment group receiving the same pre- and posttest instruments (See Table 1). Participants assigned to the Treatment group completed a single Outward Bound Veterans Program. Simultaneously, data 
were collected from participants who selected into a Waitlist control group. The control group consisted of participants that had signed up for, but had yet to participate in an OBVP.

Table 1

Distributed Questionnaires by Time and Group

\begin{tabular}{lll}
\hline & \multicolumn{1}{c}{$\begin{array}{c}\text { Treatment: Participation in } \\
\text { OBVP }\end{array}$} & Waitlist Control \\
\hline Pre-test & $\begin{array}{l}\text { Demographic } \\
\text { Questionnaire }\end{array}$ & $\begin{array}{l}\text { Demographic } \\
\text { Questionnaire }\end{array}$ \\
& $\begin{array}{l}\text { Posttraumatic Growth } \\
\text { Inventory }\end{array}$ & $\begin{array}{l}\text { Posttraumatic Growth } \\
\text { Inventory }\end{array}$ \\
& Mississippi Combat & Mississippi Combat \\
Related PTSD Scale & Related PTSD Scale \\
& & \\
Post-test & Posttraumatic Growth & Posttraumatic Growth \\
& Inventory & Inventory \\
& Mississippi Combat & Mississippi Combat \\
Related PTSD Scale & Related PTSD Scale \\
\hline
\end{tabular}

\section{Participants}

The purpose of this study was to investigate the experience of PTG within veterans that self-select into an Outward Bound Veterans Program. The researcher first established a relationship and subsequent approval from the Outward Bound Veterans Coordinator, Chad Spangler, to gain access to OBVP participants. A copy of this letter is available in Appendix B and was submitted to the West Virginia University Institutional Review Board.

To be eligible for this study, participants needed to be a current member or veteran from a branch of the United States Armed Forces. Secondly, individuals were therefore at least 18 years of age or older. Third, only data reported by those deployed to a combat setting were 
analyzed. This included veterans that served in supportive roles (e.g., drove vehicles, handled bodily remains, etc.). Fourth, each member of the study participated in at least one Outward Bound Veterans Program. There was no discrimination based on gender, culture, rank, religion, military branch, or number of tours. Outward Bound required all participants to be in adequate health and deemed fit to participate in the described activity.

Sample Size. Sample size for the quantitative measures was determined using $G^{*}$ Power software (Erdfelder, Faul, \& Buchner, 1996). The statistical software requires the following information in order to determine appropriate sample size: type of analysis, $p$-value, power specification, and effect size. I used ANCOVA to assess the differences in PTG between groups as well as from pre- to post treatment. Rationale for this statistical analysis is covered later in the chapter. Additionally, I used a standard $p$-value of .05. A $p$-value represents the probability that a test statistic is actually true. Frequent $p$-values in the literature are listed at .05 indicating a $95 \%$ confidence that the null hypothesis should be accepted. Power, which is influenced by the effect size and number of participants in the study, is the likelihood of detecting an effect, if one actually exists (Cohen, 1992). Cohen (1992) suggested using a power specification of .80 in social science research. Finally, effect sizes were determined by existing related literature. Pietrzak et al. (2010) reported an effect size of $r=.29$ correlating the self-reported measure of PTG among veterans of Operations Enduring Freedom and Iraqi Freedom that also had a diagnosis PTSD. Therefore, using a power of .80, effect of $r=.29$, a $p=.05$, G* Software yielded a suggested sample size of 96 individuals. This served as the ideal number of participants solicited for this study. Individuals were recruited until I reached a total of 102. However, only 95 participants successfully completed the pre- and posttest measures. 
Once IRB was approved for this study, a purposive sample was drawn from military personnel and veterans that participated in any Outward Bound Veterans Program. In 2011, a total of nine expeditions with a maximum of 12 participants per trip were identified. Therefore, this allowed for the solicitation of over 100 individuals within a single year. According to Chad Spangler, these numbers were projected to increase in 2012 to over 200, though no statistics were yet available. Therefore, it was predicted that the number of participants needed for this study would be accumulated within a single year.

Determining the number of participants needed in qualitative research is less dependent on number of individuals and more on data saturation. According to Kvale and Brinkman (2009), enough participants have been interviewed when the data no longer yield new categorical or thematic information. Therefore, this will require some degree of analysis between interviews. However, the authors generally suggested, "the number of interviews tends to be around $15+/-10$ " (Kvale \& Brinkman, 2009, p. 113). The authors further commented that most researchers report they would have profited from fewer interviews but faulted on the side of over saturation. Based on this information, eight participants were interviewed.

\section{Independent Variable}

The independent variable associated with this study was the participation in the Treatment or Waitlist control. The treatment consisted of the completion of an Outward Bound Veterans Program. In 2012, OBVP offered the following expeditions: North Cascades mountaineering, Deschutes River - rafting, North Carolina - backpacking, Gulf Coast - canoeing, Everglades - canoeing, Colorado - backpacking, Utah - rafting, Sierra Nevada - rock climbing and backpacking, Boundary Waters - canoeing. Instructors receive training in wilderness expedition, backcountry medicine, group dynamics, and processing techniques. Furthermore, 
each instructor is educated in military culture and struggles associated with the reintegration process. The stated purpose of this program is to, provide a supportive community for war veterans, facilitate genuine discussion on readjustment and transitions challenged, re-energize and reinvigorate spirit through adventures and challenges, reduce the feeling of isolation, provide the opportunity to bond with comrades outside of the typical military structure, and transfer veterans military values and experiences to civilian life so that veterans are prepared to serve their stateside communities. (Outward Bound Veteran Program, 2010)

The Waitlist control group consisted of OBVP participants that had not yet, but were scheduled to participate in a future expedition. Each of these individuals completed the registration and application packet required by Outward Bound.

\section{Measures}

Demographic Questionnaire. General demographic information was collected on OBVP participants using an existing questionnaire used by Outward Bound. In addition to basic questions related to age, gender and marital status, this questionnaire solicited information about military background. This form included questions correlated with posttraumatic stress such as branch of service, number of tours, and rank. This information provided an understanding of the risk-related factors that accompanied the OBVP participants included in this study. For more detailed information about the demographic questionnaire, see Appendix L.

Dependent Variable. The dependent variable for this study was self- reported posttraumatic growth. To account for PTG, participants in the Treatment and Waitlist control 
groups were asked to complete a survey on psychological growth at pre- and post-assessment periods.

The Posttraumatic Growth Inventory (PTGI, Tedeschi \& Calhoun, 2004). The PTGI is highly regarded in the literature for evaluating positive change that occurs as a result of the struggle with challenging life crises (Tedeschi \& Calhoun, 2004). The PTGI is a 21-item selfreport inventory that uses a 6-point Likert scale to assess growth across five subscales: (a) relating to others, (b) new possibilities, (c) personal strength, (d) spiritual change, and (e) appreciation for life. Many researchers have commonly used a single factor score as a measurement of overall growth; however there is growing research supporting the separation of subscales into five independent factors represented by the original subscales (Lee, Luxton, Reger, \& Gahm, 2010). The PTGI yields a total score ranging from 0 to 105 with higher scores representing greater psychological growth.

The PTGI was originally normed on 604 college students (199 men, 405 women) who had experienced negative events in the past five years (Tedeschi \& Calhoun, 1996). Of this sample, $92 \%$ of the individuals were between the ages of 17 and 25 and the majority was single. The endorsed negative events included: bereavement, parental divorce, pregnancy, break up, and physical injury. Tedeschi et al. (1998) demonstrated high internal reliability using Cronbach's alpha for the full-scale measurement of the PTGI $(\alpha=.90)$ and the individual subscales $(\alpha=.67$ .85). A sample of the original total was re-administered the same assessment after a two month lapse demonstrating an adequate test-retest reliability of the full PTGI $(r=.71)$. Tedeschi et al. (1998) noted two of the subscales showed low test-retest reliability: personal strength $(r=.37)$ and appreciation of life $(r=.47)$. Tedeschi and Calhoun (1996) demonstrated construct validity by comparing 54 individuals that had experienced a trauma in the past year to 63 individuals that 
had experienced no trauma in the past year. Statistical significance was demonstrated at $p=.01$ that individuals who experienced a trauma in the past year were more likely to endorse higher averages on the PTGI. Since its creation, the PTGI has been utilized to measure growth in the aftermath of a cancer diagnosis (Manne et al., 2004), bereavement (Neimeyer, 2001), sexual assault (Tayor, Kemeny, Reed, \& Aspinwall, 1991), and combat (Lee et al., 2010). See Appendix N.

Covariate. As described earlier, researchers have found a relationship between PTSD and PTG (Tedeschi \& Calhoun, 2004). Therefore, gradients of PTSD symptomology were likely to account for levels of variance in the dependent variable. Therefore, results from a selfreported measure of PTSD were treated as a covariate, thus allowing for greater statistical control.

Mississippi Combat-Related PTSD Scale (Keane, Caddell, \& Taylor, 1988). To account for levels of PTSD, participants were asked to complete the Mississippi Combat-Related PTSD Scale (MCS). The MCS is a free measure supplied by the United States Department of Veterans Affairs for the purpose of measuring symptoms of posttraumatic stress disorder among a military population (Keane et al., 1988). The MCS is a 35-item measure that assesses PTSD-related symptoms derived from the Diagnostic and Statistical Manual of Mental Disorders- Fourth Edition. Specifically it assesses for avoidance, emotional numbing, hyper-arousal, and related functional impairment. Items are rated on a 5-point Likert scale, with responses ranging from not at all true to extremely true. The MCS yields a total score of 0 to 165 with higher scores associated with greater symptomology.

This measure was chosen based on a number of factors. Unlike most other PTSD scales, the MCS was normed on a veteran population in order to assess for combat related stress 
reactions. After three different studies, Keane et al. (1988) established psychometric properties of the MCS based on the data collected from 431 Vietnam veterans. The measure demonstrated excellent internal consistency reliability (Chronbach's $\alpha=.94$ ) and after a spacing of seven days, a high test-retest reliability $(r=.97)$ (Keane et al., 1988). Beyond assessing for the traditional PTSD symptoms, the MCS includes symptoms of posttraumatic stress traditionally experienced by returning combat veterans (Keane et al., 1988). The measure includes questions related to suicidality, depression, and substance abuse. In comparison to the Posttraumatic Stress Disorder Checklist - Military Version, the MCS demonstrated sensitivity to subtle changes in symptom presentation allowing a researcher to plot symptoms on a continuum. As a result, Keane et al. (1988) suggested the MCS is useful in outcome research in comparison to other measures that only offer dichotomous diagnostic classification.

\section{Procedure}

A web-based survey method was used to collect quantitative data. According to Ritter and Sue (2007), the advantages of using an internet-based survey include lower costs, rapid dissemination of requested material, rapid response time, ability to simultaneously communicate with individuals in varying geographic environments, and transferability of data into analysis software. The primary concern of using this format is evidence that web surveys have lower response rates (Ritter \& Sue, 2007). Additionally, the authors suggested that online surveys are only practical and sensible if the target population has frequent access to web-based technology.

For the purposes of this study, the benefits of an online survey listed above appear to outweigh the potential deficits. Additionally, the research participants already had computer/ Internet access, as this is the primary form of communication used by Outward Bound. Prior to

my project, David Scheinfeld, a doctoral student from another university, was conducting a study 
using a similar format with the same population. In an email correspondence (Appendix C) sent in July of 2012, Scheinfeld reported that he was getting a 50-60\% response rate. It should be noted that he had received a grant that allowed for the offering a 20-dollar gift card per survey to participants. As a majority of the money used to fund this study came directly from me, I was only able to offer 10 dollars to participants who completed the entire study. Of the $\$ 980$ spent on this study, $\$ 400$ was provided by the College of Education and Human Services at West Virginia University.

Quantitative. Chad Spangler provided a contact list for each participant and his or her associated OBVP. Therefore, I made initial contact with participants by emailing a recruitment letter (Appendix D) that described the purpose of the study, why they were chosen to participate, and the potential benefits of the study. Interested prospective participants then voluntarily emailed me. In an effort to reduce bias, I alternated which groups were assigned to the Waitlist control and Treatment Group. However, the Treatment group filled at an unbalanced rate requiring an additional month of recruitment for the Waitlist control.

The participants were given my phone and email contact information. A veteran's decision to participate in the research study had no impact on his or her relationship with Outward Bound. OBVP administrators and staff were not aware of which individuals agreed to participate in the research study. Furthermore, the OBVP staff was not involved with the dissemination of research materials. The participants were not subject to any type of coercion or manipulation.

Research protocol for Treatment group. At time one (pre-test), participants who were selected to the Treatment group were sent an "Initial Email to Treatment Group" (Appendix F). The consent form, demographic questionnaire, Mississippi Combat-Related PTSD Scale, and 
Posttraumatic Growth Inventory were provided to participants through the Qualtrics secure online program within two weeks of their expedition and completed the questionnaires before participating in their OBVP. At time two (post-test), participants selected to the Treatment group were sent "Post Course Email" (Appendix G). Individuals were sent a Qualtrics link to complete the Mississippi Combat-Related PTSD Scale and Posttraumatic Growth Inventory. This occurred two weeks following the completion of their course. Participants were asked to complete the questionnaire within one week of receiving the email. Participants were informed that only surveys completed in the requested time frame were eligible to receive the Amazon gift card.

Research protocol for Waitlist control group. At time one (pre-test), participants who were selected to the Waitlist control were sent "Initial Email to the Waitlist Control Group" (Appendix H). Members of the Waitlist control were prompted to complete the first set of surveys at least five weeks before their course. The consent form, demographic questionnaire, Mississippi Combat-Related PTSD Scale and Posttraumatic Growth Inventory were provided to participants through the Qualtrics secure online program upon notifying the primary investigator of their interest. At time two (post-test), participants who were selected to the Waitlist control group were sent "Waitlist Control-Post" (Appendix I). Individuals were prompted and sent a Qualtrics link to complete the Mississippi Combat-Related PTSD Scale and the Posttraumatic Growth Inventory. This occurred four weeks after the participant completed time one questionnaires. The time frame between completion of the pre- and posttests was roughly the same time designated for the Treatment group. Participants were again informed that only surveys completed in the requested time frame were eligible to receive the Amazon gift card. 
Qualitative Procedure. As part of the informed consent, participants agreed to be contacted regarding participation in a follow-up phone interview. Individuals with increased scores on the PTGI from pre- to posttest were sent the "OBVP Interview Recruitment Letter" (Appendix J) to participate in a phone interview. If participants responded, I contacted them via email to arrange an appropriate time to conduct a 25 to 35 minute interview. All interviews were recorded using an iPhone application called Handsfreely. This software allowed each of the phone calls to be easily recorded and uploaded to a computer for transcription. The software also automatically deletes all recordings after three months. Before activating the application, I asked each participant to give verbal agreement to be recorded.

Interviews. A semi-structured interview was conducted as this format afforded me greater flexibility to ask follow up questions unique to the individual's experience. Each participant was asked six broad questions designed to triangulate any findings of PTG, and if present, how OBVP may promote growth.

- Can you tell me about your experience with OBVP?

- Please describe three particularly meaningful moments?

- What did you learn about yourself as a result of the OBVP?

- Do you think the experience of OBVP will have an impact on you in the future?

- Do you view life any differently now that you've completed your OBVP?

- Is life different now, in comparison to pre-deployment?

Varying response patterns elicited predetermined prompts. The interview protocol can be found in Appendix P.

\section{Protection of the Participants}


Any study that consists of human subjects includes efforts to protect the safety and wellbeing of the participants. Research participants were only solicited after they independently registered for an OBVP. Therefore, any risk associated with participation in OBVP activities would naturally occur regardless of the current study. Furthermore, this study made no attempts to influence OBVP curriculum. Additionally, OBVP had no knowledge of which participants were involved in the study. The purpose was only to measure the effects of participation in the existing program structure.

Participants were asked questions that may have caused varying degrees of discomfort. Although no individuals indicated experiencing any harmful effects from the study, I provided resources should they become psychologically distressed in the future. The informed consent (Appendix K) form included the following information:

- $\quad$ The telephone number for the Military Crisis Hotline: (800) 273-8255.

- $\quad$ The Department of Defense Safe Helpline Sexual Assault Support: (877) 9955247.

- The website http://www.militaryonesource.mil/ and telephone number for Military One Source (800) 342- 9647. This is a national organization that provides opportunities for telephone or face-to-face counseling. Should a veteran decide he or she is interested in counseling, this individual would take the following steps described on the Military One Source website. The person seeking face-to-face, non-medical counseling contacts a Military OneSource consultant by phone. The consultant would determine whether face-to-face non-medical counseling is the most appropriate referral. If the consultant determines that this level of service is appropriate, he or she would authorize up to twelve sessions and provide the caller with contact information for a 
counselor that best matches his or her needs. Generally, counselors are located within a thirty-mile radius of the caller. The consultant may offer to conduct a conference call with the veteran and the counselor to schedule the first session.

\section{Data Analysis}

Quantitative Data. The analyses included a series of descriptive analyses, which assessed the demographic information listed on the initial questionnaire. This type of information included number of tours served, the length of each tour, and highest rank achieved.

A repeated-measures Analysis of Covariance (ANCOVA) was conducted to compare Total PTG scores among participants. Two independent variables were used: (1) before and after they participate in an OBVP (within-subjects) and (2) Treatment group (OBVP) and control group (no OBVP). [Note: individuals in the control group had pre- and post-treatment scores, although no "treatment" was applied to these individuals.] Level of PTSD served as the covariate. The advantage of using a repeated measures ANCOVA was it provided increased power by using the same individual's scores pre-treatment and post-treatment (Tabachinck \& Fiddell, 2012). I then was able to determine if the dependent variable PTG scores differ (1) Pretreatment versus post-treatment, and (2) OBVP versus control group while controlling for the level of PTSD.

As the PTGI has five subscales representing individual components of psychological growth, a MANCOVA was also conducted. This analysis was chosen as each subscale was treated as five unique dependent variables. Additionally, a MANCOVA was required due to the inclusion of the covariate, PTSD. As with the ANCOVA, two independent variables were used: (1) pre-treatment vs. post-treatment and (2) Treatment versus Waitlist control group. With this analysis, some power loss was to be anticipated given the number of variables in the equation. 
As noted above, participants were asked to complete a post-treatment measure of the MCS. For the purposes of this study, no analysis was conducted using this information as the current research questions pertain to the changes in posttraumatic growth. However, the posttreatment measures of posttraumatic stress will allow for future analysis.

Qualitative Data. The qualitative data analysis was conducted through a grounded theory approach. This method involves a systematic procedure for collecting and analyzing data leading to a theoretical framework that explained the findings. In grounded theory, it is assumed that individuals construct meaning of the world through social interactions (Fassinger, 2005). This strategy provides innovative theory that is "grounded" in the data and does not attempt to explain an existing theory. The theory is developed through an inductive process that requires direct input from the environment through means such as interviews.

Open Coding. The constant comparative method found in grounded theory involves the use of "open coding, axial coding and selective coding in specifying the properties and dimensions of categories and organizing the emerging theory in a conditional matrix that contains the antecedents, context, intervening conditions, and consequences of core categories" (Wang, 2008, p. 263). Open coding involves assigning descriptors to segments of transcribed manuscripts. The researcher reviewed the data line by line, noting significant phrases, sentences, or paragraphs. These codes were then compared to other codes and grouped together into categories. As new data were transcribed and coded, this information is compared to existing data, which may result in the modification of existing categories or the development of an entirely new category.

Axial Coding. Axial coding involves the grouping together of categories into key encompassing themes (Fassinger, 2005). In comparison to open coding, this phase involves the 
reassembling of data to create main categories. Fassinger noted that four different comparisons are commonly generated:

(a) Comparing and relating subcategories to categories, (b) comparing categories to new data, (c) expanding the density and complexity of the categories by describing their properties and dimensions, and (d) exploring variations (e.g. disconfirming instances) in the data and re-conceptualizing the categories and their relationships. (Fassinger, 2005, p. 160)

Fassigner (2005) suggested when no new information consistently falls outside the developed categories, data collection can cease as saturation has occurred.

Selective Coding. The final stage in grounded theory is selective coding. The original data were previously fractured during the open coding, however selective coding establishes a core theme to explain all other main categories established earlier in analysis. Fassinger (2005) described selective coding as the process of creating an encompassing "story", which reintegrates the themes and explains their inter-relationships. Therefore, this final stage involves the creation of an emergent theory that best represents the data.

\section{Trustworthiness of the Data}

Although few statistical calculations exist to determine validity and reliability within qualitative research, the goal remains to accurately portray findings that best represent the original data collected from the participants. Stake (1995) suggested the trustworthiness of the qualitative analysis can be established through a variety of different manners and are dependent on the type of methodology implemented. Trustworthiness in the current project was established through a number of methods including triangulation of data, use of an audit check, reporting the raw data, the use of memo writing, and bracketing. 
Triangulation. Stake wrote that as researchers, we should strive to be "accurate in our measurement and logical in our interpretation of those measurements" (Stake, 1995, p. 109). Through the use of triangulation, researchers can take efforts to ensure the accuracy of the data and its interpretations by including multiple sources of inquiry. This study utilized three triangulation methods (i.e., data source, investigator, and methodological) to improve the trustworthiness of possible outcomes.

Data source triangulation refers to the collection of information at multiple intervals with varying participants to see if the same results occur (Stake, 1995). It was anticipated that it would take multiple months to collect enough data necessary for this study as few trips are scheduled per month. Additionally, OBVP participants were solicited from programs that occurred around the country. It was thought this information would help determine if there were regional differences or anomalies created due to the type of chosen activity (e.g., backpacking, kayaking, and mountaineering) or location.

Investigator triangulation requires the inclusion of at least one other researcher to determine the accuracy of the data interpretations. As two investigators never interpret information entirely the same, triangulation naturally occurs whenever multiple investigators have a corresponding understanding of the data (Stake, 1995). As it specifically relates to grounded theory, investigator triangulation can most easily occur in the discussion of coding. Dr. Jeffrey Daniels, the dissertation chair connected with this study, graciously agreed to be a secondary rater and evaluate my original analysis of the emergent codes, categories, and themes found in the data.

Finally, I used methodological triangulation. Using "multiple approaches in a single study, we are likely to illuminate or nullify some extraneous influences” (Stake, 1995, p. 115). 
Therefore, mixed methods decreases limitations common in a single methodological design (Greene, Caracelli, \& Graham, 1989). Methodological triangulation adds to the richness of the data by exploring varying perspectives of the same phenomena by asking questions such as how, when and why certain behaviors occur (Jick, 1979).

Reporting the raw data. Kvale and Brinkmann (2009) suggested no form of representation, writing, or reporting is absent of bias. Therefore, within qualitative data analysis researchers are encouraged to include raw excerpts from the interview transcriptions. "Quotes give the reader an impression of the interview content, and preferably also the personal interaction of the interview conversation, and they exemplify the material used for the researcher's analysis" (Kvale \& Brinkmann, 2009, p. 279). Providing actual statements from the interview allows the reader to see the interpretation of the data and the original raw material. By presenting both, the reader is able to draw logical conclusions with regards to how the analyst interpreted the data.

Memo writing. Memo writing is a technique commonly used in grounded theory, which aids the researcher as he or she transitions from raw data to more conceptual levels (Miles \& Huberman, 2004). Within qualitative research, memos are thoughts, questions, or concerns that arise during the analysis of the data. They allow for "refining and expanding codes further, developing key categories and showing their relationship, and building toward a more integrated understanding of events, process, and interactions in the case" (Miles \& Huberman, 2004, p. 74). Miles and Huberman (2004) indicated memo writing is especially important in inductive inquiry as it allows the researcher to pull together incidents that appear to have commonalties. When these notes become public, they serve as another form of transparency regarding how the researcher interacted with the data to formulate emerging theory. 


\section{CHAPTER III}

\section{Results}

The goal of the current study was to explore the influence of the Outward Bound Veterans Program on the experience of posttraumatic growth among military personnel. This chapter will share the results of the research project. A mixed methods approach was used to analyze the data and describe an emerging theory. The results will be presented in sequential order with the quantitative data discussed first, followed by a description of the qualitative results.

\section{Quantitative Results}

This section of the dissertation will focus on the quantitative data that were analyzed. These analyses were conducted for three primary reasons. First, prior to the current study, there has been very little data collected on posttraumatic growth among a veteran population. Most research in this area had been conducted looking at resiliency, an inconsistently defined construct. Second, few publications have used the PTGI as a repeated measure; therefore the potential benefits and challenges of using the measure in this manner will be discussed. This is based primarily on the virtually impossible nature of anticipating a trauma and therefore capturing premorbid conditions. Most studies have examined constructs that correlate with the reports of PTG, rather than interventions that promote PTG. Thirdly, the existing literature suggested a relationship between PTSD and PTG. Participants from various military branches with diverse combat experiences had self-selected into the OBVP, therefore endorsed PTSD symptomology was used as a covariate.

Descriptive Statistics. A total of 474 OBVP participants were invited to participate in this study. Advertisements began on June $18^{\text {th }}, 2013$, concluding on December $10^{\text {th }}, 2013$. Over 
the course of six months, a total of 146 individuals agreed to participate in the study and were emailed access to the online survey. Of the 146 participants, 119 completed the pretest portion of this study. A total of 102 participants completed both pre- and posttest surveys. Of the 102 participants that completed both surveys, seven were eliminated from this study based on missing data or response patterns (e.g., answering the same number for each questionnaire and completing in an unexpectedly short time or completing one survey, but not another). Therefore, the following results are based on the data of 95 participants (50 Treatment group, 45 Waitlist control).

The demographic characteristics of the participants are shown in Table 2. Although there were 95 participants in the study, the totals in each category (e.g., Marital Status) may vary because of missing demographic data. Participants were not required to answer every question of the demographic section to proceed with the study. The average age of respondents was 36.3 . Men comprised $73.4 \%$ of the total sample. Among all the participants, a majority $(74.7 \%)$ identified as White. A total of $10.5 \%$ of the participants were Hispanic/Latino, while the remaining $13.8 \%$ were individuals who identified as Asian/Asian-American/Pacific Islander, Black/African-American, Native American, or did not associate with one of the listed racial categories. Nearly half (45.3\%) of the participants reported being married while $38.0 \%$ were single. Most participants (68.4\%) indicated they were no longer active duty and were not registered reservists. A majority of the participants indicated they were enlisted (84.2\%) and had participated in two or more tours $(60.0 \%)$. Approximately half $(44.2 \%)$ of the participants were members of the US Army, with a relatively equal distribution among most of the other military branches. Nearly three-quarters $(74.7 \%)$ of the respondents had experienced enemy fire and well over half (62.1\%) had accrued some physical health concern related to military service. Finally, 
$58.9 \%$ of the participants reported having received some form of counseling since beginning in the military.

Table 2

Demographic Information

\begin{tabular}{|c|c|c|c|c|c|c|}
\hline \multirow[t]{2}{*}{ Variable } & \multicolumn{2}{|c|}{ Waitlist } & \multicolumn{2}{|c|}{ Treatment } & \multicolumn{2}{|c|}{ Total } \\
\hline & $\mathrm{n}=45$ & $\%$ & $\mathrm{n}=50$ & $\%$ & $\mathrm{n}=95$ & $\%$ \\
\hline Age (mean) & \multicolumn{2}{|c|}{36.2} & \multicolumn{2}{|c|}{36.4} & \multicolumn{2}{|c|}{36.3} \\
\hline \multicolumn{7}{|l|}{ Gender } \\
\hline Male & 35 & 77.8 & 34 & 68.0 & 69 & 73.4 \\
\hline Female & 10 & 22.2 & 15 & 30.0 & 25 & 26.6 \\
\hline \multicolumn{7}{|l|}{ Race } \\
\hline White & 33 & 73.3 & 38 & 78.0 & 71 & 74.7 \\
\hline Hispanic/Latino & 5 & 11.1 & 5 & 10.0 & 10 & 10.5 \\
\hline $\begin{array}{l}\text { Asian/Pacific- } \\
\text { Islander }\end{array}$ & 1 & 2.2 & 4 & 8.0 & 5 & 5.3 \\
\hline $\begin{array}{l}\text { Black/African- } \\
\text { American }\end{array}$ & 2 & 4.4 & 1 & 2.0 & 3 & 3.2 \\
\hline $\begin{array}{l}\text { Native } \\
\text { American }\end{array}$ & 1 & 2.2 & 0 & 0 & 1 & 1.1 \\
\hline Other & 3 & 6.7 & 1 & 2.0 & 4 & 4.2 \\
\hline \multicolumn{7}{|l|}{ Marital Status } \\
\hline Single & 13 & 28.9 & 23 & 46.0 & 36 & 38.0 \\
\hline Married & 24 & 53.3 & 19 & 38.0 & 43 & 45.3 \\
\hline Divorced & 5 & 11.1 & 4 & 8.0 & 9 & 9.5 \\
\hline Separated & 3 & 6.7 & 4 & 8.0 & 7 & 7.4 \\
\hline \multicolumn{7}{|l|}{ Active Military } \\
\hline Yes & 13 & 28.9 & 17 & 34.0 & 30 & 31.6 \\
\hline No & 32 & 71.1 & 33 & 66.0 & 65 & 68.4 \\
\hline \multicolumn{7}{|l|}{ Currently a } \\
\hline \multicolumn{7}{|l|}{ Reservist } \\
\hline Yes & 13 & 28.9 & 17 & 34.0 & 31 & 32.6 \\
\hline No & 32 & 71.1 & 33 & 66.0 & 64 & 67.4 \\
\hline \multicolumn{7}{|l|}{ Rank } \\
\hline Enlisted & 38 & 84.4 & 42 & 16.0 & 80 & 84.2 \\
\hline Officer & 7 & 15.6 & 8 & 84.0 & 15 & 15.8 \\
\hline \multicolumn{7}{|l|}{ Tours } \\
\hline 1 & 13 & 28.9 & 16 & 32.0 & 29 & 30.5 \\
\hline 2 & 15 & 33.3 & 17 & 34.0 & 32 & 33.7 \\
\hline 3 & 7 & 15.6 & 3 & 6.0 & 10 & 10.5 \\
\hline 4 & 1 & 2.2 & 5 & 10.0 & 6 & 6.3 \\
\hline 5 & 3 & 6.7 & 1 & 2.0 & 4 & 4.2 \\
\hline $6+$ & 2 & 4.4 & 3 & 6.0 & 5 & 5.3 \\
\hline
\end{tabular}


Table 2, Continued

\begin{tabular}{|c|c|c|c|c|c|c|}
\hline \multirow[t]{2}{*}{ Variable } & \multicolumn{2}{|c|}{ Waitlist } & \multicolumn{2}{|c|}{ Treatment } & \multirow[b]{2}{*}{$\mathrm{n}=95$} & \multirow{2}{*}{$\begin{array}{r}\text { Total } \\
\%\end{array}$} \\
\hline & $n=45$ & $\%$ & $\mathrm{n}=50$ & $\%$ & & \\
\hline \multicolumn{7}{|l|}{ Military Branch } \\
\hline Army & 20 & 44.4 & 22 & 44.0 & 42 & 44.2 \\
\hline Navy & 8 & 17.8 & 3 & 6.0 & 11 & 11.6 \\
\hline Air Force & 6 & 13.3 & 6 & 20.0 & 12 & 12.6 \\
\hline Marines & 4 & 8.9 & 9 & 18.0 & 13 & 13.7 \\
\hline Coast Guard & 1 & 2.2 & 0 & 0 & 1 & 1.1 \\
\hline National Guard & 6 & 13.3 & 5 & 10.0 & 11 & 11.6 \\
\hline \multicolumn{7}{|l|}{ Received Enemy } \\
\hline \multicolumn{7}{|l|}{ Fire } \\
\hline Yes & 34 & 75.6 & 37 & 74.0 & 71 & 74.7 \\
\hline No & 7 & 15.6 & 8 & 16.0 & 15 & 15.8 \\
\hline \multirow{2}{*}{\multicolumn{7}{|c|}{$\begin{array}{l}\text { Physical Health } \\
\text { Issues }\end{array}$}} \\
\hline & & & & & & \\
\hline Yes & 30 & 66.7 & 29 & 58.0 & 59 & 62.1 \\
\hline No & 15 & 33.3 & 21 & 42.0 & 36 & 37.9 \\
\hline \multicolumn{7}{|l|}{ Received } \\
\hline \multicolumn{7}{|l|}{ Counseling } \\
\hline Yes & 25 & 55.6 & 31 & 62.0 & 56 & 58.9 \\
\hline No & 20 & 44.4 & 19 & 38.0 & 39 & 41.1 \\
\hline
\end{tabular}

The Statistical Package for the Social Sciences (SPSS) was used for data analysis. To test the hypothesis that the Outward Bound Veterans Program had a significant impact on PTG, a repeated-measures analysis of covariance (ANCOVA) was utilized. A general linear model was conducted which included the dependent variables PTG_Pre and PTG_Post as the withinsubjects repeated factor. Waitlist control versus Treatment groups served as the betweensubjects variable. To test the relationship between the covariate and the linear combination of the PTG_Pre and PTG_Post scores, PTSD_Pre was used as the covariate.

Hypothesis I. The results from the multivariate tests demonstrated a significant relationship between the linear combination of the repeated-measure (PTG_Pre and PTG_Post) and the covariate $\mathrm{F}(1,92)=6.974,(p=.01)$. This information indicates the covariate explained 
a significant percentage of variance in the PTG scores. This analysis yielded a small effect size of $\eta_{p^{2}}=.07$. According to the convention described by Dattalo (2008), a small effect consists of values between .02 and .12 , a medium or moderate effect size falls between .13 and .25 , and a large effect constitutes values greater than .26. Additionally, there was a significant interaction between the linear combination of the PTG scores (Pre and Post) and the PTG group variable of Waitlist control versus Treatment groups $\mathrm{F}(1,92)=9.949,(p=.002)$. See Table 3 for details. This analysis yielded a small effect size of $\eta_{p^{2}}=.098$.

Table 3

Within Groups Comparison of PTG

\begin{tabular}{llllllll}
\hline & $\begin{array}{l}\text { Mean } \\
\text { Square }\end{array}$ & df & $\begin{array}{l}\text { Wilks’ } \\
\text { Lambda }\end{array}$ & F & Sig. & $\begin{array}{l}\text { Partial Eta } \\
\text { Squared }\end{array}$ & $\begin{array}{l}\text { Observed } \\
\text { Power }\end{array}$ \\
\hline $\begin{array}{l}\text { PTSD_Pre } \\
\text { (covariate) }\end{array}$ & 1518.45 & 1 & .930 & 6.974 & .01 & .070 & .743 \\
$\begin{array}{l}\text { PTG } \\
\text { Group }\end{array}$ & 2166.15 & 1 & .902 & 9.949 & .002 & .098 & .877 \\
\hline
\end{tabular}

Because there was a significant interaction in the repeated measures analysis, a stepdown analysis was utilized. The comparison of the corrected PTG_Post means for the Waitlist control and Treatment group was evaluated. This analysis revealed a significant difference between the post-test means of the Treatment group and Waitlist control $\mathrm{F}(1,92)=7.654,(p$ $=.007$ ), with a Treatment post-test mean of 70.98 and a Waitlist mean of 60.91 . This analysis yielded an effect size of $\eta_{p^{2}}=.076$, which is a small effect. Figure 1 provides a visual representation of the Waitlist control PTG-Post mean of 60.91 and the Treatment PTG_Post mean of 70.98 . 
Figure 1

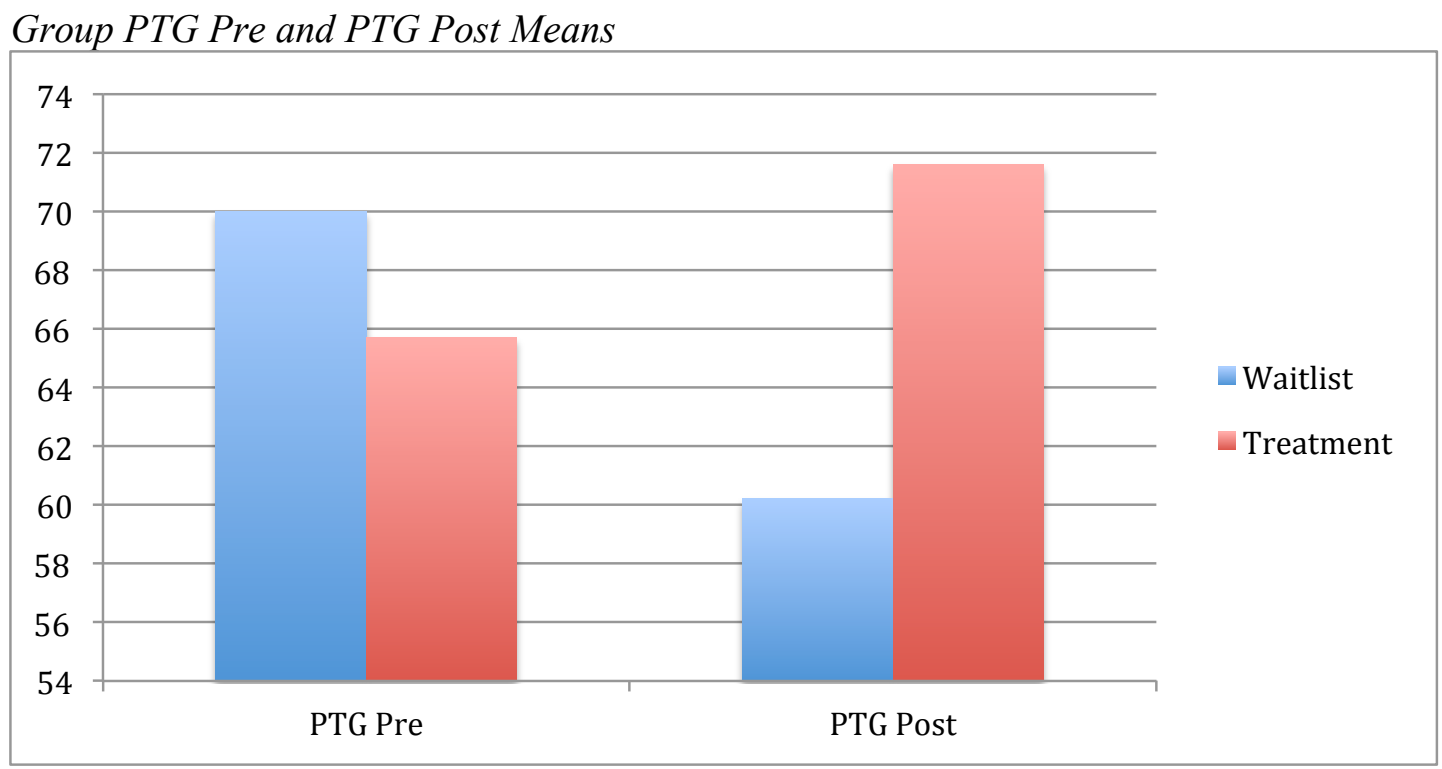

Hypothesis II. As the PTGI has five subscales measuring distinctive theoretical components of psychological growth, a multivariate analysis of covariance (MANCOVA) was conducted to determine if significance would be found among the subscales. A general linear model was again conducted, but using dependent variables Relating to Others, New Possibilities, Personal Strength, Spiritual Growth, and Appreciation of Life. Additionally, Waitlist control versus Treatment groups comprised the between-subjects variable. To test the relationship between the covariate and the linear combination of the five PTG_Post subscales between the Waitlist and Treatment groups, PTSD_Pre was again used as the covariate.

The results from the multivariate tests demonstrated a non-significant $(p>.05)$ relationship comparing the five PTG_Post subscales from the Waitlist and Treatment groups and the covariate $\mathrm{F}(5,88)=.878, p=.499$. See Table 4 for details. In this circumstance, the covariate did not significantly account for much variance in the dependent variables. However, results from the multivariate tests indicated a significant difference between the Waitlist control 
and the Treatment group on the linear combination of the PTG_Post scores with $\mathrm{F}(5,88)=.809, p$ $=.002$. This level of significance allowed for further review of the univariate between-subjects tests.

Table 4

\begin{tabular}{|c|c|c|c|c|c|c|}
\hline Effect & $\begin{array}{l}\text { Wilks' } \\
\text { Lambda }\end{array}$ & $\mathrm{F}$ & $\begin{array}{l}\text { Hypothesis } \\
\text { df }\end{array}$ & $\begin{array}{l}\text { Error } \\
\text { df }\end{array}$ & Sig. & $\begin{array}{l}\text { Observed } \\
\text { Power }\end{array}$ \\
\hline $\begin{array}{l}\text { PTSD_Pre } \\
\text { Covariate }\end{array}$ & .952 & .878 & 5 & 88 & .499 & .301 \\
\hline $\begin{array}{l}\text { PTG } \\
\text { Group }\end{array}$ & .809 & 4.157 & 5 & 88 & .002 & .947 \\
\hline
\end{tabular}

Between-subjects. The results from the tests of between-subjects effects revealed important findings. Comparing the means of the five PTG_Post subscales from each group indicated the Relating to Others scale was the only factor that was statistically significant $(p<$ 001). This analysis yielded an effect size of $\eta_{p^{2}}=.132$, which is a medium effect (Dattalo, 2008). The comparative means from the individual factor, Personal Strengths, yielded a nearly significant value of $p=.058$. It should be noted, however, that the Relating to Others variable was the only one with an observed power greater than .80. A full list of the between-subjects effects can be found in Table 5 .

Table 5

Between Subject Effects for PTG Post

\begin{tabular}{lcccccc}
\hline \multicolumn{1}{c}{ Factor } & df & $\begin{array}{c}\text { Mean } \\
\text { Squares }\end{array}$ & F & Sig. & Parial Eta Squared & Observed Power \\
\hline Relating to Others & 1 & 627.706 & 13.938 & .000 & .132 & .959 \\
New Possibilities & 1 & 29.982 & 1.071 & .303 & .012 & .176 \\
Personal Strength & 1 & 83.855 & 3.697 & .058 & .039 & .477 \\
Spiritual Growth & 1 & 4.562 & .556 & .458 & .006 & .114 \\
Appreciation of Life & 1 & 30.635 & 2.449 & .121 & .026 & .341 \\
\hline
\end{tabular}

\section{Qualitative Results}


Grounded Theory analysis was used to analyze eight interviews from Outward Bound Veterans Program participants after they had completed their program. Through this analysis, an emergent theory was developed. The central category of the emergent theory states that interrelated experiences of the program, environment, and cadre influence perceived posttraumatic growth for OBVP participants.

The participants from this study were chosen sequentially based on their elevated results from the PTGI. The participant scores were organized in descending order based on the difference between their Pre_PTGI and Post_PTGI results. The first 34 participants were contacted before eight participants agreed to participant. A total of four men and four women were interviewed ranging in age from 27 to 53. The time frame between when each participant's trip had completed until the interview ranged from 28 days to 150 days. All participants were White with the exception of one individual who identified as Latina. Half of the individuals were previously members of the US Army while two individuals were from the Navy and the other two were veterans of the Air Force. All eight participants had been enlisted during their active duty. Finally, the participants completed a variety of OBVP expeditions including: backpacking in the Mahoosuc Mountains of Maine, backpacking in the Sierra Nevada Mountain Range, rafting throughout the southwest, and backpacking in the Appalachian Mountains.

Three central constructs emerged: the individual contextual factors pertaining to each trip, the unique group process that was created through the interaction of the contextual factors, and the resulting posttraumatic growth factors. A total of twelve main categories emerged that describe the constructs listed above. There are an additional nine subcategories that compose the main categories. The contextual factors consist of three main categories: program, environment, and cadre. Separately, the group process also consisted of three main categories: overcoming 
adversity, social learning experiences, and the contributing group dynamics. Finally, six posttraumatic growth factors emerged: relating to others, new possibilities, personal strength, spiritual change, appreciation of life, and altruism.

The initial section of this section provides an explanation of the two constructs that compose the emerging theory. In describing these constructs, the underlying main categories and secondary categories will be defined. After completing these descriptions, the qualitative results portion of this chapter will conclude by clarifying how the constructs, main categories, and secondary categories jointly compose the emergent theory.

The data from all the participants were compared and contrasted using a framework developed by Ladany, Thompson and Hill (2012). This procedure allows for the researcher to quantify the frequency with which a developed code appeared across participants. Consistent with Ladany et al. (2012), the term General was utilized when six or more participants reported a core idea. If four or five individuals mentioned a core idea, then the label Typical was applied. The term Variant was used when reported by two or three participants. Daniels et al. (2010) added to this analysis by developing labels for core ideas mentioned by a minor, but believed by the researcher, to be valuable information. Therefore, the authors suggest using the label Unique when only a single participant mentions an important core idea. 
Table 6

Endorsement of Main Categories $(n=8)$

\begin{tabular}{lll}
\hline Main Categories & $\begin{array}{l}\text { Number of participants } \\
\text { endorsing category }\end{array}$ & Frequency
\end{tabular}

\section{Contextual Factors}

Environment

Nature/Outdoors

7

Weather

6

Terrain

6

General

General

Cadre

Participants

8

General

Leaders

7

General

Program

OB Structure

Remembrance Ceremony

Group Talks

2

General

Adventure Pursuits

7

8

Typical

Variant

General

General

\section{Group Process}

Social Learning

Group Cohesion

Overcoming Adversity

7

8

8

\section{Psychological Growth}

Relating to Others

New Possibilities

Personal Strength

Spiritual Change

Appreciation of Life

Altruism
8

8

7

2

7

4
General

General

General

Contextual factors. The interview participants provided a variety of concrete, descriptive information (e.g., weather, activity, etc.) that generalized across expeditions. These Contextual Factors were coded into three main categories: Environment, Cadre, and Program. The Environment main category is composed of three subcategories: Nature/Outdoors, Weather, and Terrain. The Cadre category is composed of two subcategories: Participants and Leaders. The Program main category is composed of four subcategories: Outward Bound Structure, 
Remembrance Ceremony, Group Talks, and Adventure Pursuit. This section will focus on these various main categories, subcategories, and descriptor codes that together compose the Contextual Factors construct.

Environment. The categories that compose the Environment main category all pertain the physical setting experienced by each participant. For many of the participants, the environmental factors represented moments of challenge, experiences of discomfort, opportunities for group bonding, and seemingly paralleled military settings.

Nature/Outdoors. The experience of being in the natural environment was a central theme for many of the interviewed participants. These experiences allowed for unique opportunities, distancing from modern distractions, and focus on basic needs. The subcategory of Nature/Outdoors was the most frequently mentioned category within the Environment construct and was most commonly associated with more existential topics such as mindfulness, spirituality, and beauty.

Many individuals commented on nature and their appreciation of its beauty. The surroundings were described much like a piece of artwork, having no other distinct purpose. For instance, in the case of Participant 3, she commented that the "sunsets were beautiful. Looking at the stars at night with the Milky Way, was just as visible as everything else, with such a dark sky was wonderful." This seemingly took her back to a much younger time as, "it was just...how many years has it been since I've seen stars like that, well, maybe never quite that well...certainly a decade or two." Similarly, Participant 6 stated, "I think the appreciation of nature...I have a couple of acres here and just walking outside and spending time outside and kind of just appreciating what it has to offer..." There were several more statements about the simplistic beauty found in early morning sunrises (Participant 6), standing on a mountain peak 
(Participant 2) or admiring the power of the open water (Participant 8). It was evident that at least some of these experiences were appreciated as an end product serving no other purpose.

Most often when nature was discussed, it was in relationship with another internal process. Since there were less day-to-day distractions, participants were able to focus on the here and now. "Just something about, you know, the outdoors and being out there and everything, especially for that week. I think it really just opens you up" (Participant 2). He later commented on experiences of faith, "I mean, I'm a Christian so I'm just totally in awe of God's creation and just being out there was just amazing." For individuals like Participant 1, her statements seemed to parallel mindfulness practices and outcomes. "It was life changing, it opened up a whole new - it grounded me. I felt grounded where I didn't have that before" (Participant 1). Participant 8 indicated how being in the outdoors seem to allow for an opportunity to process difficulties:

And when I came home we went through all these cancer treatment, radiation programs and when I got back from deployment, she [participant's dog] [insert who, in brackets - his wife?] ended up passing away, so I had time to reflect on that while I was out there, so yeah, things have changed for me in the last year and a half. So I had a lot of time to reflect while I was out on my trip. Which was good. (Participant 8)

For individuals like participant 4, experiencing the natural surroundings meant greater awareness of the luxuries of every day life. He commented:

I think it probably has a lot to do with just society in general and how easy things are here, and just power, electric, flushing toilets, and running water and everything's handed to us in our daily environment in cities and stuff like that, 
and really getting back to nature where you have to do stuff to survive. I don't think we were ever in a situation where I felt like we were in danger for our lives or anything, but going to get water, not like I could go to the fridge and get a bottle or anything, we needed to go find a clean, puddle pretty much and treat the water just to drink. I think part of it [was] the accomplishment. (Participant 4) For this participant, there seemed to be a sense of pride as well as an awareness of how many of the basic life struggles are removed from his life (e.g., finding clean water to drink).

Weather. The weather was seemingly an important uncontrollable factor on each trip. It was occasionally discussed as a component adding to the beauty and enjoyment of the experience. Often, when the weather was temperate, it was described briefly and used as a segue to a more meaningful experience, "and that was, it was beautiful, the weather was mostly good, but...I loved the river rafting, I loved being on the water, I loved seeing nature, I loved seeing the rock" (Participant 3).

A majority of the time weather was mentioned, it was in the context of how it added to the personal challenge of the trip. Participant 1 stated, "There was never a time when we were not wet. It was miserable. So...But, you know, we sucked it up." These experiences could have detracted from the experience, yet for most individuals, it served as an opportunity for group cohesion or personal growth. "So, you were getting challenged everyday, and it'd get cold and windy and you know we were doing it together so it was a bonding experience too" (Participant 2). "It was miserable conditions. So it was like you were bothers and sisters. You don't get that with strangers, that immediate" (Participant 1). "It rained pretty much every day on us, which allowed us to unite as a group" (Participant 7). 
Although most of the participants eventually associated the inclement weather with a growth experience, it was also a catalyst for conflict. "I think definitely with the rain, since it was bad weather, you know we had something to complain about, and there were some personality conflicts, right off the bat on the course..." (Participant 7). It is interesting to ponder how the experience of challenging weather may have contributed to or potentially detracted from experiences of psychological growth. For the participants interviewed in this study, it seemingly led to a positive outcome. However, it easily could have taken away from the experience of other participants. This an area discussed later in the developed theory, but ultimately needs further exploration.

Terrain. The word terrain or landscape is frequently associated with ground or earth and therefore may not be the best word choice for this factor. As participants also embarked on expeditions involving kayaks or rafts, this researcher searched for an appropriate term that encompassed water. However, no better word choice could be found and therefore Terrain is used broadly to allow for descriptions of trails, peaks, rivers, and oceans.

In much a similar fashion as weather, the unexpected terrain led to moments of adversity. Likely, participants did not always traverse steep hills or choppy water, but these were the experiences most readily described. Participant 5 recalled a challenging situation while being in a tandem kayak and paddling through rising waves. "The water, the conditions were sort of pushing us in different directions" (Participant 5). Similarly, Participant 4 shared an experience of being in an unfamiliar environment.

I'm in Florida, so we're nothing but flatness out here. I mean we do hikes and road bikes and stuff like that but it's nothing like what we dealt with there, and the trip wasn't what I expected it to be. When they said canyons I figured, we'll 
get in a canyon and it will be flat, but that just wasn't the case with the rock beds and the different obstacles we had to overcome. (Participant 4)

These situations were described with feelings of angst and pride, not accurately depicted in the emotionless transcripts. For individuals like Participant 4, who was injured during an IED explosion, the terrain was potentially a real physical barrier. Therefore, he later described being overcome with joy when realizing he was capable of navigating a more challenging environment than he previously thought he could.

Several participants commented on the parallel of the OBVP expedition with their military experience. Indeed, the presence of other military personnel in a communal task was comparable to elements of deployment. Depending on the expedition, the terrain was also a factor that seemingly encouraged memories of military events. Participant 2 reported, "The terrain we were on, it reminded me a lot of Afghanistan. Like there were parts of it, I was like, man! It did surface some memories, like remembering the fear of what's around the next corner, but you know what I'm saying?" For this participant, engaging with the landscape resulted in an emotional response of being afraid. He was able to immediately recall images from deployment. Participant 1 had a similar response, "I mean because that was probably the closest environment that you could have to your deployment. You know, like a hellhole deployment, that you could get. We went through some really bad crap."

Reading this section of transcript almost made it difficult to comprehend how the OBVP expedition led to perceived positive outcomes since it also evoked such negative images. Participants reconnected with difficult thoughts and emotions from a time when their life was threatened. However, the participants' lives were never in serious danger and they were able to feel supported by fellow veterans and group leaders. Participant 6 indicated, "And it was, you 
know, as muddy and scary as it was, I came back you know, going these guys really have my back." It is perhaps because of these parallels that participants were able to have a corrective emotional experience and begin healing from traumatic events that occurred while deployed.

Cadre. Whenever possible, this researcher attempted to use the actual words described by the participants to develop the factors listed above. Therefore, when searching for a general umbrella term for the participants and leaders, I recalled Participant 7's use of the word "cadre". He used the noun several times throughout the interview. I needed to look up the precise definition of the word and found that it means "a small group of people specially trained for a particular purpose or profession" (Merriam-Webster online dictionary, n.d.). A second definition of the word indicated cadre could also mean a "key group of officers and enlisted personnel necessary to establish and train a new military unit" (Merriam-Webster online dictionary, n.d.). Collectively, these depictions accurately portrayed the accompaniment of leaders and participants working together to accomplish the joint task of survival, group cohesion, and adventure activity.

Participants. It is noteworthy that all eight individuals commented on the value of being on a trip designated solely for veterans. This was one of the few factors that was endorsed by all those interviewed. The reasons varied why this was so meaningful. For some participants, the similarity in military training led to felt cohesion. Multiple participants mentioned a work ethic readily seen in other veterans and not shared with most civilian coworkers and colleagues. Being with other veterans meant feeling understood, as there was a previous shared experience regardless of military branch. However, other individuals initially struggled to relate to others depending on their enlisted military branch or deployment experiences. Eventually the disparity served as a learning experience allowing participants to strive for a common ground, rather than 
focusing on disparities. Likewise, two female participants voiced an apprehension of being on a trip with other veterans. A possible factor may have been that both women were on expeditions unbalanced with more men. Despite these early concerns, each woman indicated feeling safe and a valued member of the group by the end of the trip.

All individuals that participate in an OBVP are either active military or veterans. Despite this commonality, some veterans had strong oppositional feelings against others that had not deployed. Participant 2 very honestly shared that,

At first I felt like I judged them, like well, these people are like, nobody there except for maybe a Marine a little bit, saw any combat. So I was kinda like, these people, they don't know, you know what I'm saying. They deploy, you know Air Force, they deploy three months, and then they come home, and they deploy in nice places, even in Iraq and Afghanistan. I was kind of like, and you guys are using this money... (Participant 2)

At this point in the interview, there was a sense of resentment. In the eyes of this participant, deployment in other military branches was seen as a relative luxury and therefore they did not equally deserve the cost free OBVP expedition. Participant 2 continued to describe his personal experience, “... especially from my unit, that neverthey just got blown up by an IED, by you know in a Humvee, they might have broke a leg, and they're still struggling today". This passage made it seem as though this initial comparison of experiences made him feel even more isolated. Even among veterans, he had a unique and painful experience.

Participant 2 was likely correct that he was exposed to more life threatening and gruesome images, at least in comparison to those on his OBVP expedition, but this 
focused perspective initially kept him from finding the commonalities and connecting to others on the trip. Later in the interview, he commented,

For the first couple of days, I was like, don't talk to me, but I was just like quiet, still kinda thinking well maybe just soaking it all it... and like man, you know, that snotty mentality that you have to check real quick. And they're all, you know they've all become friends, and uh, I was really impressed by all of them... I guess I was getting myself worked up, but then I opened up in the end and it became fun towards the past 3 days or so, and the one person on the trip said, you know, here comes his personality, wow it's coming out. (Participant 2)

For a majority of those interviewed, being on a trip with other veterans meant an instant sense of connectedness. This was emphasized by Participant 4 who said, "I guess it felt like we were a squad, you know right off the bat." Therefore, "there was a sense of camaraderie, I think that more easily comes with military, mostly former military group, than your average group might have otherwise" (Participant 3).

The reasons for the increased sense of camaraderie were seemingly based primarily in shared values and experience. Participant 7 commented on an instant connection found in company of others that had similar military memories.

It's interesting because we all bond immediately. We have such a commonality that you can tell... we immediately start razzing each other about you know, boot camp or our branches of service and stuff like. I mean at the end of the trip, we were like a little family, like I mean at the airport, we're hugging, we're drinking beer, we're hanging out I mean, it's definitely a camaraderie that you don't have anywhere else. (Participant 7) 
Some participants vocalized being grateful being in the presence of others with a shared work ethic. "It was the fact that that's what people do in the military is you help each other out. You're part of a unit, part of being in an organization to assist others and include others, because you have common links, common goals" (Participant 3). Participant 4 had a similar perspective, I think the trip was very successful with the group we had. I think it was more successful than if I had went with a group of civilians, 'cause we're all ingrained with the military and how we work, just tasks that need to be accomplished, and everyone just stepped up and know these tasks need to be done before we can relax and have a good time. (Participant 4)

Beyond work ethic, Participant 5 commented, "I think the veterans part - the thing we had in common was a sense a duty".

Directly relating to the nature of this study, at some point during the interview process, all participants described experiencing some form of military trauma or civilian transition issues. Therefore, it seemed meaningful that all of the individuals experienced a sense of being understood or accepted by at least one person on the expedition. Participant 1 shared, "I've been in counseling since I came back. So that probably...that group setting with other vets was not something that I've ever had. You know, other veterans, who, some of them, some of their experiences were worse than me." For Participant 6, being on an expedition with not just veterans, but other female military personnel was very influential. "Hearing somebody else's story too, because I am not around, especially other female veterans, and hearing some of - what happened to them was very powerful and helpful" (Participant 6). Collectively, these statements indicate an 
appreciation for a program restricted to military personnel based on the inherent commonalities and struggles uniquely found in military culture.

Leaders. The participants had very interesting reactions to the Outward Bound leaders. The responses varied from admiration to general mistrust. There are likely numerous reasons for this discrepancy. However, the rationale is restricted to those mentioned by the interviewed participants.

Several of the participants commented on being positively taken aback by the emotion and appreciation voiced by the leaders. Participant 1 recalled one of her leaders indicating, "You know, just listening to you guys, I want to thank you, because I had no idea what you guys go through and what you guys have gone through in your military career...You guys have opened up, most civilians never get to realize.” She expressed feeling as though sharing her story provided an opportunity to educate a group of civilians and have their information respectfully received. The mutual respect between the OB civilian leaders and military participants appeared to help foster a greater sense of trust and cohesion. "Oh, it was a two way street, they had so much respect for us, and we had so much respect for them, just knowing they knew what they were doing, and that uh, and they also would say from time to time...they just really had the utmost respect for us" (Participant 6).

Several participants positively commented on experiencing little delineation between the participants and leaders. "They didn't make us feel like they were civilians and we were military or have a separation or anything. It was one group and we acted as such" (Participant 4). The leaders' purposeful intention to discourage subgroups was evidenced later in statements such as, “They didn't single anyone out and like this person more than that person. Everyone was treated as equals and that helped out as well" (Participant 4). 
Overall, most of the participants expressed some form of admiration for the leaders. "I was impressed by how they led the trip, and they did step back and let us do things. It was fun, they made it real, they asked real questions" (Participant 2). By experiencing the leaders as competent seemingly increased a sense of safety regarding participation in the adventure activities. Participant 6 reported, "Our guides were so knowledgeable. You felt safe all the time because you knew they knew exactly what they were doing. So that kind of anxiety was really gone within the first day or so. We were in good hands." This sense of safety seemed to extend to emotional vulnerability.

Not only did they feel comfortable with us and we could confide in them, but they almost felt like they had something to learn from us. So we showed them the respect that they deserved as leaders, but they looked at us like, you guys have actually done things that we could never dream of, and we want to learn as much from you as you guys hopefully can learn from us. (Participant 7)

Although most of the participants experienced the leaders as positively contributing to the OBVP expedition, it seems meaningful to note that this was not universally expressed. Participant 3 had virtually nothing to say about the leaders other than being paired with an instructor that did not say much. Participant 8 had the most adverse response to the leaders. She recalled a situation where a tandem kayak capsized.

Most of them were late 20s. So we basically had to surrender ourselves to the experience of a 20-year-old instructors and allow them to take over as their experience to get these guys back on the boat, get their gear up righted, and we weren't even allowed to help our fellow soldiers. And that was basically something that, as a former military for 22 years, as a leader in the military, you 
know, as a NCO, as a Staff Sergeant, I wasn't allowed to help at all. And that was kind of - it was hard, but it was interesting to watch - you know here we are as soldiers and we're not allowed to help our own partners, you know like wow! I am surrendering myself to somebody else. So it was interesting to filter those emotions too, and just sit back and relax, you had to sit back and relax, and go through those emotions too. So, it actually was kind of cool to allow myself to do it. (Participant 8)

This participant later commented on her own awareness of needing control and difficulty feeling relaxed in any situation. At no point in the interview did she verbalize ever fully trusting the leaders, however it was instances like the one described above that made her more aware of her own process. This allowed her to practice more mindfulness and make purposeful efforts to relax and let go of control.

Program. The activities span beyond the advertised adventure pursuits. Certainly, each OBVP participant has the opportunity to kayak, rock climb, or hike. The promise to engage in these high adventure activities are what draws individuals to Outward Bound and therefore are the main interests listed in the OB brochure and website. However, when speaking to OBVP participants that had completed their expedition, it is evident that the adventure pursuit only captured a piece of the experience. In addition, many of those interviewed described meaningful participation in a remembrance ceremony, an opportunity to honor one's military commitment and the sacrifices or tragedies endured. Structurally, the OB philosophy imposes restrictions and expectations on each of its participants. The requirements, such as no cell phones, had a reported impact on the participants. Finally, many individuals commented on their involvement in formal 
and informal "group talks". These moments supposedly allowed for opportunities for selfdisclosure, social learning, acceptance, and group cohesion.

Outward Bound Structure. The Outward Bound Structure refers to the policies, requests, and restrictions to participate in an OBVP. The most frequently endorsed policy was related to the use of electronics. The benefits were almost verbatim across participants and were perhaps best captured in this passage, "It's a great time to clear the cobwebs that had been going on, and it was - without any of that outside noise like cell phones. There's no radio, no mp3 players, there's nobody holding up their finger to talk to you because they're on the iPad or whatever" (Participant 6). The lack of technology seemingly influenced the ability to be in the present moment. Additionally, there were no concerns about how to socially navigate others that were absorbed by a device and therefore, it was seemingly easier to connect to fellow participants.

Several participants across expeditions noticed other purposeful efforts made by Outward Bound leaders to create an inclusive environment. "They actually told people they weren't supposed to single themselves out or form cliques" (Participant 3). This seemed to be emphasized with varying degree. Some leaders prompted interventions designed to purposely help participants feel noticed and included.

I don't want to say secretly watch, but we had a buddy system, and we were supposed to find out what we could about those people, and at the end of the course, we divulged something we learned about them and...you were supposed to help them out but you didn't say you were their secret partner until the end. And that was really nice to hear everybody's thoughts and feelings about each other and get those moments where you're just free to open up to somebody that you don't know and some of that information is a little different than normal... 
that you would talk about, but it was still enlightening to openly share your feelings and see it come back to you in a positive light. (Participant 7) Seemingly being cognizant of the potential divisions among the participants, a leader on Participant 5's expedition expressed the following.

I think one of the most meaningful moments for me was when we were getting started with each other and the lead instructor said that you really have to understand that even though you want to see the differences between yourself and the other people here, the point of this trip is to focus on the things that you have in common. And you'll realize as you go through this week, if you focus on those things that you have so much more in common with everyone else than the differences with them. (Participant 5)

Remembrance Ceremony. An activity listed in the OBVP staff manual is the facilitation of a remembrance ceremony. This consists of designating a specific time when veterans are encouraged to recall aspects of their service they wish to remember. Based on the descriptions from the interview process, the verbal prompts varied, as well as the associated experiential activity. However, the premise of remembering and honoring past individuals or experiences remained a consistent thread.

Although the remembrance ceremony is a suggested activity, it is unknown if it is intentionally included in each expedition. Of the eight interviewed participants, only two mentioned participating in a remembrance ceremony. The flexibility afforded to Outward Bound instructors may dictate the emphasis placed on this activity or whether it happens at all. The staff manual describes how non-veteran leaders could respectfully facilitate and participate in a remembrance ceremony. The manual also normalizes that such activities could be 
uncomfortable for leaders without a military background. Therefore, there could be a conscious or subconscious effort not to introduce a ceremony. Despite the uncertainty regarding the consistent practice of remembrance ceremonies, the two individuals that mentioned the activity were emotionally affected by the event.

Participant 2 recalled being introduced to his remembrance ceremony during a hike to Madera Peak.

That was really powerful for you know, the group, because one of the things they had us do is grab a rock right before we were about to summit and just say, you know, who's this rock for. It could be a family member, it could be a buddy in combat, somebody you lost, somebody like that, and that's where actually a lot of people broke down in tears. I mean we were Marines, Air Force, whatever, but it was an emotional time. For me, it was people that we lost when I was over there, and for others it was their mother or somebody in their life, their wife. It sounded almost silly at first, then as you got up there, you realized what it was all about. You just, kind of like that rock, was like carrying that burden. You know, and just releasing that burden or something, you know what I'm saying? That was definitely powerful. (Participant 2)

For this individual, he was asked to do a relatively simple task of carrying a rock. Yet, there were also so many intricacies involved with this act. He did so while physically exerting himself up a mountain peak. While summiting he was asked to think about someone and then verbalize the name(s) of those remembered or honored while in the company of fellow veterans. Clearly, for this individual, it was a powerful experience that allowed him to release some emotional "burden". 
The remembrance ceremony for participant 5 was less experiential, but occurred on a symbolically important date, September $11^{\text {th }}$. In recalling the event, she remembered her instructor stating,

I think we all felt like it was right and so he was the one who sort of made it happen, but we felt like it was our sort of duty to talk about it. But once we got through - sort of we went around the group and we said this is when I deployed, this is where I deployed, this is how long I deployed for, and sort of talked about it. In the end, I think everyone went around and sort of talked about their deployment experience and what it meant to them and I think after that, after we had gotten through that sharing, I think we did feel a stronger bond. (Participant 5)

The focus of this event seemed less about honoring a specific individual and more about recalling meaningful memories of deployment. Rather than feeling an emotional release, the end result for this participant was feeling more connected with the other group members.

Group Talks. With the exception of one individual, all other participants indicated they had engaged in a meaningful group discussion at some point during their expedition. In general, most evenings, participants had the opportunity discuss a topic relevant to their OBVP expedition, military experience, issues with transitioning, or other relevant topics. Participant 5 highlights, "we were usually around the campfire and were talking to each other about different stuff before bed." According to the participants, the level of intensity, leader facilitation, and length of time devoted to these group talks varied across trips. Like the remembrance ceremonies, there was not a specific structure nor was this meant to be a therapy group. 
However, these experiences seemingly did occur more frequently and were positively recalled by those interviewed for this project.

Although trained clinicians did not run the "group talks," nor was the objective to be specifically therapeutic, several of the identified outcomes correlate with group therapy (Burlingame, McClendon, \& Alonso, 2011). Participant 1 confirmed the sense of having greater freedom to talk about issues fostered trust, intimacy, and general well being. "The groups helped get me talking by them just providing a safe environment. That was outside the norm for me" (Participant 1). As a result, individuals were able to talk about their experiences in a new way, or at all. "Just opening up, waiting to open up, that was a highlight...It's just I've never talked to people, especially from my unit, that never- they just got blown up by an IED” (Participant 2). There was a perception of cohesion and being understood. "We just were all around the fire and people were telling things that we didn't feel comfortable telling non-veterans" (Participant 6). Finally, Participant 4 described an emotional release with being able to talk about such experiences.

I mean I'm active Army, active National Guard, so I'm around people all the time, but not everyone has deployed and gone through different deployment scenarios and stuff, and talking with other guys about what went on and how our deployments were. It kind of just helps, you know in some ways, to be able to talk about and to other people about it and get it out there and they understand, just one of those things. So I guess it was almost just a relief off my chest, is probably another way to put it. (Participant 4)

Adventure Pursuits. As described above, the adventure pursuits are the activities typically associated with Outward Bound. A purposeful effort was made to select individuals 
from varying types of expeditions completed throughout the United States for the qualitative interviews. As a result, a single pursuit such as "kayaking" would not generalize to all participants and therefore a more broad term was used. It was noteworthy that despite the varying adventure pursuits completed, many of the themes overlapped. At least five individuals endorsed each of the following experiences related to the adventure pursuits: novel experience, excitement, risk-taking, and being physical/active.

Several of the participants described being surprised by the level of physical activity required by the OB program. Individuals, like Participant 1, took the initiative to train for the expedition. As a result of her preparations, she expressed feeling proud that she was able to keep pace with the fittest men. "I started training, so that opened up a whole new world for me, actually, all the time hiking and stuff, because I did some heavy training for it" (Participant1). Conversely, Participant 2 recalled being "challenged, you know, the altitude, and the packs were about 60 pounds." The physical challenge associated with these experiences seemed to reinforce the sense of accomplishment discussed by nearly all participants at the end of the expedition. This was represented in Participant 3's response, "Was physically challenging, absolutely, but I triumphed against all odds." It is possible that participants were also experiencing the positive neurological benefits associated with exercise (Edman, Lynch \& Yates, 2014).

Engaging in activities such as rappelling, kayaking in open water, or even sleeping under the stars was a unique situation for most of the participants. As participants talked about this aspect of their experience, there was a sense of excitement to their voice. When asked about her previous outdoor experience, Participant 1 responded, "Oh no! Are you kidding? No, no, no, give me a bed. Give me a hotel room. But nope, since I've gotten home, I've gone camping about three times. I've been planning a hiking trip for next summer...So, that's really opened up 
outside for me." Participant 4, the young man from Florida stated, "It was a mini slot canyon, only about a mile long, but none of us had ever done anything like that before, we all got into it" (Participant 4). Participant 6 talked with child-like excitement, "doing the rapids, and just jumping off the rocks - I thought I'd never do that!" There were several more short passages depicting how the activities were meaningful and reinvigorating.

At times, it was challenging to discern the theme of excitement from a novel experience, as they frequently appeared in tandem. However, it seemed meaningful to separately describe the positive emotional energy resulting from these experiences. This was evident Participant 6's description of rafting in the southwest.

The river was pretty aggressive at the time because we had all the flooding in Colorado. The river was very high and after going through it, I was like Oh My God, I made it. It was this moment of excitement and exuberance, you know when you see people on TV going "wahoo", whooping and hollering when they finish. All you can see is these walls of water coming at you... (Participant 6) This level excitement was echoed by other participants while describing their adventure pursuits, “I started picking up kayaking before I went on the trip, but I wasn't prepared for how excited I would be to be out on the open water" (Participant 5). However, it was also expressed when describing group dynamics, "Everyone was just really enthusiastic about it and nobody was questioning anything or having second thoughts. Everyone just jumped in head first and really I guess took in the moment and we all had a great time" (Participant 4). Participant 8 had the same positive affect when seeing a shark: "it was just an exhilarating moment, I just wanted my picture taken with it." 
Another interesting secondary benefit to the participation in high adventure activity was the opportunity to engage in perceived risk-taking situations. According to the participants, certain adventure pursuits elicited high levels of adrenaline and focus that had not been experienced since combat scenarios. Participant 3 talked at length about steering his raft through a perceived dangerous set of rapids. Participant 5 described a sense of being "scared and excited all wrapped into one" as she prepared to jump off a low level cliff into a pool of water. Perhaps the most descriptive experience was shared by Participant 1 when talking about her day of rock climbing and rappelling. She recalled a feeling of "pure adrenaline and fear". However, in wanting me to understand the importance of this experience, she continued,

I mean in the military...I tell people when I was deployed, when you're deployed, it's like you live over there in vivid color. Because everything is so critical and everything is so...you have to watch everybody and watch what's going on to make sure no one wants to hurt you. When you get back here, everything's in grey. There's nothing here, your life, you feel dead because that adrenaline is gone. (Participant 1)

For this individual, rappelling off a cliff helped her feel fully alive again.

Group Process. The Group Process describes the important interpersonal experiences that occurred as a result of the Contextual Factors listed above. It is the interaction and not simply the presence of the Contextual Factors that provides an explanation of how PTG occurs as a result of participation in an OBVP expedition. As the military participants came in contact with all the categories described above, three themes emerged. Social Learning, Overcoming Adversity, and Group Cohesion represent the main categories that appear to precede the experiences of psychological growth. These categories are mutually influential and frequently 
overlap in the transcripts, however they are seemingly distinct constructs and important to the growth process.

Social learning. The literature on social learning theory is extensive and will not be fully represented in this chapter. However, given the frequency in which it was noted by participants, and its relevancy to psychological growth, it seemed important to describe overarching themes associated with the topic. Albert Bandura (1977) provided evidence that observational learning can have powerful, reinforcing outcomes. According to the theory, humans can learn by observing one another, but also by the consequences that result from a behavior. As the participants essentially spent every waking hour together for a week, social learning was occurring almost constantly, which reinforced group norms, acceptable behavior, and skill acquisition.

Nearly all eight participants $(n=7)$ endorsed some degree of learning from other participants. On a pragmatic level, Participant 5 described a frustrating situation when she was attempting to get her shelter tied to a tree.

I sat there and I would tie these knots and I would think, oh I got it right this time, and I would try to stake something down, and it wouldn't work. I remember sitting there tying knots for, it felt like a good 15-20 minutes, and we only had to tie 6 knots and then stake them down and I remember thinking this is really stupid, why isn't this working, and I really just wanted to get up and quit. I went and got a guy who had gotten all his things done, and I said 'Hey, look it seems like you know a lot about this, and could you help me figure this out and you basically have to teach me like I'm a first grader, like I have no idea what I'm 
doing and can you walk me through this.' And he came, he walked me through it, and ten minutes later we were done. (Participant 5)

Observational learning extended beyond utilitarian tasks and applied to more emotional and psychological domains. More specifically related to posttraumatic growth, OBVP participants were reinforced to talk about military experiences by watching others share their story, but also by the positive and supportive responses provided by others. Furthermore, Bandura (1977) suggested social learning is enhanced when the observer believes that the person demonstrating the behavior is similar to himself or herself. "Some of the guys that were there were into a lot heavier stuff than I was and hearing their stories helped me, to know that other people have gone through hardships" (Participant 4). Hearing the narrative provided by other veterans seemingly helped observing participants re-examine their perspectives related to their military events.

You see especially in some of the older soldiers that were there, their stories really had a huge impact on me. To see that it wasn't always easy, but I've done this or that and know they are completely different from where they started...But you see their struggles, and you compare them to your struggles, and you kind of really value the systems you have in your life, or my life, that allow me to not necessarily go down those paths. (Participant 7)

Group cohesion. Based on the accounts of each participant, there was undoubtedly a group construct that was influencing factors such as participant enjoyment, openness, and psychological growth. A review of group counseling, group dynamics, and outdoor education literature yielded numerous proposed variable titles (e.g., group atmosphere, climate, alliance, etc.) with inconsistent definitions. However, Burlingame, McClendon, and Alonso (2011) 
condensed the literature on cohesion and developed a comprehensive construct relevant and encompassing of the reported experiences from OBVP participants. It was suggested that group cohesion is comprised of three types of relationships: member-member, member-group, and member-leader (Burlingame et al., 2011). Within each of these relationships cohesion is measured based on relationship quality and relationship structure. According to the authors, structure refers to the function of the relationship. This can occur vertically, as members view the competence, genuineness, and warmth of the leaders. Horizontal structure refers to memberto-member relationships or member-to-group and indicates how members are drawn to others for emotional connection or to accomplish a task. Separately, relationship quality is factored into two dimensions: 1) belonging and acceptance and 2) interpersonal work factors. This definition of cohesion seemed to account for the variability in responses regarding the cadre.

This section will focus primarily on relationship quality, which was noted by nearly all eight participants. Common phrases used to describe relationship quality consisted of acceptance, common ground, belonging, and understanding. All individuals shared at least a brief comment on the group cohesion, providing a general backdrop of their experience, "It was nice to have a common...to know that you're not alone, 'cause most of us go through life around civilians, and they don't have a clue" (Participant 1). "You know, we're all similar, we're all going through the same things" (Participant 7). Participant 4 shared, "I made some good friends, a lot of camaraderie there, and just felt really comfortable from day one... as a whole group, all 10 or 12 of us with the guides."

Most of the time, the depiction of feeling accepted, safe, and understood provided a gateway to revealing personal difficulties related to their military service or transition to civilian life. Towards the end of the interview, Participant 4 talked about revealing personal information 
about his trauma for the first time, "That was really hard for me, and being able to talk about that and stuff, and he kind of went through a similar situation- I never talked about that before, and to have someone who can understand what I went through was really helpful for me." Perhaps the most descriptive and passionate example came from Participant 6:

Well, just like I said, there's people around me, going- shaking their head, and you knew exactly what I was talking about. There were quite a few of us that were there, that we have, that we suffer from PTSD. And people who don't really understand, they wanna say, well I don't know why you can't get over that, it happened so long ago. Because everybody that was there understood that you don't and you were able to talk without somebody saying that again. Just having somebody else say, 'I know what you mean.' I’ve given my friends, my close friends a break, and like I said they don't know that, I'm not gonna tell them, I'm sorry I felt resentful to you when you wouldn't listen to me or kind of gave me the 'Oh here we go again', but I'm able to not have to put that on them cause now I have somebody who really does understand that...But the other thing too is knowing that I'm not the only one out there who feels what I'm going through. For the longest time I did, because, like I said, I don't have other female Veterans where I live and I'm just not in contact with other Veterans besides the VA, but that's usually just for appointments. I didn't have somebody else that I could talk to about it. And just that feeling of being part of something again... (Participant 6)

Through group cohesion, participants were provided a sense of validation and worth.

"To know that you weren’t weird, and there's something wrong with you - accepted" 
(Participant 6). Participant 3, who later endorsed a significant trauma history, reportedly was able to perceive himself more positively due to the group cohesion and affirming comments. "I learned that I could be accepted for who I was. Being accepted by the group - including me, and positive comments, and encouraging comments and respect...[crying]" (Participant 3). This individual is middle aged and reportedly has felt like an outcast among his civilian colleagues and peers. For the first time in decades, he reported feeling accepted and having a sense of worth.

Overcoming adversity. Each of the participants described at least one vivid moment involving overcoming some adverse condition. This was an unexpected theme, yet the data analysis suggested the perseverance through physically strenuous activity, uncomfortable weather, or perceived risky situations (e.g., rock climbing) was highly associated with group cohesion and psychological growth. Several of the passages have aspects that overlap with Burlingame et al.’s (2011) cohesion factor of relationship structure. However, Overcoming Adversity is representative of specific and high intensive situations.

Overcoming adverse conditions was described as individual experiences or as a group task. Whenever the situation was described individually, it was associated with becoming more aware of one's physical or psychological fortitude.

There was never a time when we were not wet. It was miserable. I mean continuing on a grueling hike, it would have been easy to ease up and just for me to realize the strength that I had and what I now possess. I mean all my training and everything- I was not the weakest link. You know? I was carrying other people's stuff. It was good to know just how strong I was, emotionally and physically. (Participant 1) 
Participant 4, who struggled with physical limitations since an IED explosion reported, Just being able to overcome- there were a couple of obstacles that we came up to and I was like, 'Oh my God, there's no way I'm going to be able to do this" and saying it to myself, and other people with me, really gave me the motivation to just try it and see what I could do and it ended up being I could do it just like everybody else. (Participant 4)

Participant 6, a woman that described herself as lacking much confidence and self-esteem reflected on a day of rafting after the group had just completed an intense set of rapids.

They took us to a waterfall, I wanna say a 10 foot drop from the rocks, jumping from the rocks into the pool, and they're doing it! Are you gonna do it K-----? Like I don't know. Then finally I decided I'm gonna do it. I mean, I'll regret it if I don't...like the rapids we had gone through too, even though you're scared, and I didn't try to show I was scared, I was scared and excited all wrapped into one.

(Participant 6)

Even participant 3, who mostly gave short, emotionless responses proudly commented, "Was it challenging, yes it was. Physically challenging, but I triumphed against all odds.”

Adverse conditions were also cited as opportunities for improving social factors within the group. Several explicit messages were mentioned in the interviews such as bonding, belonging, and unity. Participant 7 reflected fondly on the adverse whether conditions and how it helped the group to become closer. "It rained pretty much every day on us, which allowed us to unite as a group that way and have and adversary in the weather. The challenges were some of the most meaningful things that effected us." Participant 2 specifically remembered the connection formed while backpacking with his group during frigid temperatures. 
I'm an Army Paratrooper, and tough marches, up on cliffs, but I mean it was still challenging, you know, the altitude, and the packs were about 60 pounds, and we were still challenged. So, you were getting challenged every day, and it'd get cold and windy and we were doing it together so it was a bonding experience too.

\section{(Participant 2)}

Meanwhile security, optimism, and acting on behalf of the greater good were implied

messages found within the transcripts. Recalling the first night of his trip, Participant 4 shared the turmoil of an unexpected storm,

Coming out as strangers and sleeping under this little tarp that they had, the Outward Bound shelters, and they started collapsing and stuff, and instead of people worrying about themselves and just making sure they stayed dry and comfortable, it was more people looking out for each other and not even knowing each other. No one even asked for help, it was just offered right off the bat.

\section{(Participant 4)}

Towards the end of their expedition, the veterans with Participant 2 had the opportunity to self-navigate their group to a specified location.

We overshot our group coordinates, and what was kind of funny, but didn't feel too funny at the time, the leadership just stepped back and let us figure it out, and it was starting to get late, the sun was starting to go down, and we were already high in elevation so it was starting to get cold, even though it was the end of August. The wind was blowing, it was starting to get chilly, and it was like man, let's find this darn place. And we came together, and I was just amazed at the whole attitude of everybody, there was not one person that was like F- this, or 
whatever, it was just, everybody was like let's just get this done, and I was like yeah, that's good stuff. (Participant 2)

The following participants expressed a sense of safety and trust placed on the group during moments of heightened stress and perceived danger. "It's funny because throughout the trip, you know we're going on these hikes, and your footing gets off and there's always somebody there to catch you with their arms right away - we're gonna help each other through this" (Participant 6). While paddling across open water in windy conditions, Participant 5 described a stressful situation. She attempted to keep herself and partner focused and calm by reminding them both of the presence of the group.

There's something interesting about being in a tandem kayak with somebody. He was - I could - you can sort of feel what they're doing, the other person in the kayak. So, he was behind me and I could feel him tensing up. I said, 'Are you okay?' and he said, 'Yes, I'm fine, I think I'm gonna be fine'. Everything is really tipping and I can see that the wind is just really pushing the water over us and I feel like we're gonna top over and I said - 'This is no big deal.' And he said, 'What happens if we go over?' I said, 'If we go over, then we come back up and everyone is here to help us'. (Participant 6) 
Posttraumatic Growth. A majority of the posttraumatic growth variables that resulted from the Contextual Factors and Group Process were consistent with Calhoun and Tedeschi's (1998) five factors: Relating to Others, New Possibilities, Personal Strength, Spiritual Change, and Appreciation of Life. However, this researcher found a sixth category that was seemingly not accounted for by the original PTG factors. In review of the eight transcripts, a theme of altruism also emerged, which will be described fully below.

Relating to others. One of the most heavily endorsed factors observed in the transcripts was Relating to Others. As described by Calhoun and Tedeschi, Relating to Others refers to "a greater sense of intimacy, closeness, freedom to be oneself, and disclosing even socially undesirable elements of oneself or one's experience" (Calhoun \& Tedeschi, 2006b, p. 5). All eight participants provided numerous statements indicating how close they felt to the other participants, how these relationships helped construct positive memories of the trip, and the psychological benefit of these connections.

As previously described, the Contextual Factors and Group Process allowed for an instant sense of connection. "It was like coming home, we didn't know each other, but we're a family. I don't think you can get that at another kind of group" (Participant 5). These initial interactions seemingly helped the formation of the group and subsequent interactions. "You sleep together, I mean its $24 / 7$, you're together. You're closer to them than you are to your family. They know more stuff about you than your family does. So you just get a bond that nobody will ever understand" (Participant 8). The OBVP expedition touched upon personal needs that had not been fulfilled since their enlistment.

And that just reminded me of how much I missed the camaraderie of other Veterans that you knew in every day life. If you just-you've got your good 
friends, you've got your best friends, but there's something about knowing they've got your back...I haven't felt that way in a long time. (Participant 6) One of the questions of this project was whether such gains would be sustained after the participants returned home. Reflecting back on her expedition that had concluded 81 days prior, Participant 4 reported, "I would say the real difference that I see is, one of the guys I'm in the unit with. Him and I have a closer relationship than we did before." Participant 6 , who was interviewed 50 days after the conclusion of her trip, stated, "The feeling of I'm the only one going through this, I don't have that anymore, not in the military anymore and just the camaraderie of it and the sense of belonging to something bigger than you..." Participant 7 was interviewed 34 days after the conclusion of his trip.

You kind of trash talk between branches sometimes, you know the grass is greener on the other side or they've got it better and we've got it harder, and that was certainly prevalent there between you know, Army, Marine, Air Force people, but it allowed to break down those walls as well. And to realize, you know what? We're all soldiers at heart, we just chose a different branch to go into, you know, like rival colleges. We were really all interconnected. By that meaning, you know we're all over the United States... (Participant 7) Prior to her OBVP expedition, Participant 1 reportedly was experiencing significant PTSD and depression. On the day she received her acceptance letter from Outward Bound, she had considered suicide. Reflecting back on the trip she stated, "I mean I opened up about things I'd never opened up to anyone about. Without that bond or without those people, I may still be in the garage with the car running" (Participant 1). This participant was interviewed 131 days after her expedition. She is now in a romantic relationship and shared the following: 
I mean I'm now open to trusting people, within the scope of my comfort level, you know? So, now I'm letting people in more. Intimacy, I mean relationships, it's helped open that door. Talking about it-they allowed me to be in a safe environment where I was able to talk. So, I've brought that back here, where it was like a roadblock that I couldn't get past. (Participant 1)

New possibilities. Individuals that have survived challenging life events have occasionally been open to exploring new possibilities (Calhoun \& Tedeschi, 2006a). The authors described this factor as "developing new interests, new activities, and perhaps embarking on significant new paths in life" (Calhoun \& Tedeschi, 2006b, p. 5). It is noteworthy that New Possibilities is the only other posttraumatic category that was described by all the participants.

Participant 1 is the individual that has described some of the most overt life changes as a result of her OBVP experience. She was also the one that endorsed significant depressive symptomology conditions, which included a suicidal gesture. Her expedition experience let her to believe, "You can be whatever you want to be. You can do whatever you want to do. You know, and this, this can be a new starting point for you. I have hope now... I see a future and not a pine box."

Since returning to Florida, Participant 4 reported engaging in more physical activity. And um, just being able to overcome you know there were a couple of obstacles that we came up to and I was like oh my God, there's no way I'm going to be able to do this, and you know, saying it to myself, and other people with me, really gave me the motivation to just try it and see what I could do and it ended up being, you know I could do it just like everybody else did... You know like I was saying earlier, I think the mental block I had on my physical strength has been 
broken down and after the trip, now I'm doing a lot more active stuff and pushing myself a lot more here in Florida. I think the trip really helped me get through that. (Participant 4)

Participant 3 seemingly expanded Calhoun and Tedeschi's view of New Possibilities by suggesting the challenges experienced through the OBVP also allow for “new perspectives." This seemed consistent with Participant 7's reflection. He described a change in worldview as opposed to a change in activity or behavior.

I would say that the physical challenges of it as well also made a difference in my life because it's not always going to be easy and things might not always go the way you planned, but we can still work on those things for the good, better and different. It really set in for me that life is a journey, and sometimes you just gotta go with the flow I guess you could say, and where you end up might not be where you thought you were, but you just have to jump in feet first and go for it, and this might just be temporary troubles I'm having now, they might alleviate in the next couple of years and I'll forget about it, you know, it's almost like a give and take. You gotta go through it and take the opportunities as they present themselves, and you know what it might not always get better, but it has a chance to get better. (Participant 7)

The following two participants made an important life decision regarding their careers as a result of their OBVP expedition. "When I got back, some of the things I'd been thinking about were going back to work, and I hadn't worked for about two years, and as soon as I got back, I got my resume ready, and got it out there. I started working about 3 weeks ago" (Participant 6). Similarly, Participant 5 shared the following: 
So I've sort of been on the fence about going to nursing school for almost a decade. And I'm finishing up my pre-req's now and I'm going and whether or not I like it. I don't know if I'll like it, I'm on my way there, and all I can think is if it was a mistake, or if it wasn't, I can't sit here and not do anything about it. I have to try. So I think that there was a good two years after I deployed where I was just sort of stuck and I thought it's not even worth it to try. But in just the trying, even since the program has ended in these short few months, I feel like whether I try something and it's a success or a failure, it's the trying that matters. And it's the trying that is life. So I find that I enjoy things more now and I can't help but think that the experiences will stay with me. (Participant 5)

Personal strength. According to Calhoun and Tedeschi, (1998) traumatic events can lead individuals to becoming aware of personal strengths. As described previously, it is common for individuals to construct fictional fantasies (e.g., bad things happen to bad people) in order to create a sense of safety (Rajandram et al., 2011). However, experiencing a trauma can lead to an increased awareness that the world can also be an unsafe place. Bad things actually can happen to good people. For some individuals, this new fear and vulnerability can be paralyzing. However, the surviving of traumatic events can also lead individuals to develop healthy, realistic worldviews (Calhoun \& Tedeschi, 1998). The survival and re-engagement with life tasks can lead individuals to realize they had greater personal strength than once believed.

At the end of each interview, participants often responded with personal growth experiences that occurred as a result of the OBVP expedition. Some individuals shared briefer remarks regarding personal growth. "Just, for me, realizing the strength that I had and what I now possess...It was good to know just how strong I was, emotionally and physically...I was 
even able to have better conversations with my psychologist" (Participant 1). Participant 6 shared a resurgence of self-confidence, "I gained a lot of self-confidence that I didn't - that I used to have, well, I kinda took it back. And it was from doing the rapids, and just jumping off the rocks - I thought I'd never do that!” Some individuals were lengthier in their description. Participant 4, the individual that had experienced a physical injury during his deployment, expressed the following:

I hurt my knees, and I think I felt like I was really limited, and this trip and stuff, I was able to see that I'm - I can push myself a lot through a lot more than I thought I could. It wasn't just personal strength, I was able to overcome I guess some of the anxiety I had about my knees and stuff. And then, I guess more mental growth with just more confidence, going through it with other people who had gone through what I've gone through...Just as a person with a feeling of accomplishment. I've done a lot of trips and stuff, but this was just something where I really felt like I accomplished a lot. (Participant 4)

Participant 5 shared the most detailed description of her struggles with feeling more vulnerability as a result of her military deployment while also recognizing her personal strength. I spend so much time second-guessing myself and getting stuck thinking all the ways that something could go wrong that I don't do it. I don't think I'm living in the moment, I'm just sort of stuck. I think that happened to me a lot while I was in the military, especially when I was deployed there were so many situations where sometimes I was forced to go somewhere where I didn't want to go and I kind of went out of duty, but inside I was kind of kicking and screaming. Now I still struggle with it, I struggle with taking risks and sort of moving forward and 
thinking - I still sort of worry about all the bad things that are gonna happen, but I try not to let them get in the way... (Participant5)

In a separate response, she indicated,

I think it was a place that I learned about me, and that I am stronger than I thought I was before, and that I am capable of doing more things. Now I'm a happier person, I feel sort of liberated, I feel free, and I feel like I'm really living my life in the moment and not thinking about all the things I should have done could have done. And every once in awhile I'll still get stuck on - well I haven't been trained to do all these things and I think this is the Air Force part of me coming out - I wasn't trained to do this, I don't know if can do it. But I'm more of a risk taker and it makes me happier to be more of a risk taker. So compared to deployment, I would say I'm a much happier person. Compared to being in the military, I'm still a much happier person. (Participant 5)

In an almost ideal manner, she ended with the following:

I think the Outward Bound experience has given me more confidence in myself, confidence that maybe I didn't have before, or I did, but for whatever reason was really shaken, especially by certain things that happened in the military. I think that it really empowered me to sort of take control of things that happened in my life. (Participant 5).

Appreciation of life. Surviving or witnessing a life threatening event can result in a greater appreciation of life (Tedeschi et al., 1998). Frequently, survivors report a changed sense of priorities. "Although the specifics are different for different persons, a common theme is the articulation of greater meaning being found in intrinsically important priorities and less 
importance being attached to extrinsic priorities" (Calhoun \& Tedeschi, 2006b, p. 6). This shift in perspective and values was also consistent in those who had recently completed an OBVP expedition.

After returning home, Participant 4 remembers how his interactions with his friends and family had changed. "I also think, my wife said it also, that I seem like I've been happier since I've been back from that trip. I think that's a personal gain for me” (Participant 4).

Participant 6 frequently spoke of felt anxiety and daily stress. Attempting to create a sense of control, he described working to the point of exhaustion in attempt to anticipate inevitable problems. The passage reflects his effort with letting go of worry.

We learned to be there in the moment, and just appreciating the moment and not thinking what's going on back home, is this getting done, is that getting done.

You know, I finally learned to clear my head and enjoy what I was doing at that moment of time and it was other people reminding us all to do that and that sounds real simple. You need to stop and enjoy what's going on, but you know as an adult and with your responsibilities, your head starts going in 20 different directions, and you are missing out on the experience. And taking in the scenery and really appreciating it. And just the whole situation going on, the river running, there's a huge bird that's been following us, and you know, it was just little things like that. (Participant 6)

Similarly, for Participant 8, there was an overall greater satisfaction with life. She reported previously noticing, "I've been hanging on to all of this stuff I just keep bottled up, all of the stress that goes on in my life with school and home life and all of this stuff." 
Since returning from her OBVP expedition, a civilian colleague apparently noticed a change in her. This was her response:

I care about my time off. That's about all I care about! Vacation and time off. I mean I don't really take things as seriously, it's just life. So the things I care about are my time off, spending time with my dogs, and being outside. So, to me it's just, life is too short so just enjoy every moment that you have. The more time I have away from work and just enjoying work, that's the best. For me, I think for me just learning how to enjoy life a little bit more. (Participant 8)

Spiritual change. The dimension of spiritual change "tends to reflect a greater sense of purpose and meaning in life and perhaps clarity with the answers given to the fundamental existential questions" (Calhoun \& Tedeschi, 2006b, p.6). Although this factor is not limited to aspects of faith, "there can be a greater sense of the presence of God, an increased sense of commitment to one's chosen religious tradition, or a clearer understanding of one's religious beliefs" (Tedeschi et al., 1998, p. 14). Only two of the eight individuals endorsed dimensions of spiritual change. The few reported gains stated by the interviewees is consistent with the lack of statistical significance found among the larger quantitative sample. However, changes in this concept were particularly meaningful for Participant 4 and especially Participant 2.

Participant 4 is the individual that currently lives in Florida. Being on a trip in the western United States was seemingly enlightening for this individual. Throughout the interview, he attributed different personal gains from reconnecting to nature. In this passage, he is describing his reconnection to his faith.

I used to be fairly religious in my younger years and for me, I guess almost like a spiritual connection for me to rekindle that fire I had. Not to preach or anything, 
but just to know that in my eyes, what God has created here, just taking a second and when I walk outside or feel the wind in my face, to just appreciate what we have. It kind of rekindled that for me. (Participant 4)

For Participant 2, it was evident that the OBVP expedition and being in nature was a spiritual experience. "When I'm outside, it's definitely that I can hear from God better and converse with him [about] stuff that is happening in my life and stuff that's coming up." Based on his interview, he had a pre-existing Christian faith and did not describe any specific deepening of spiritual matters. However, this participant had also described feeling anxious about how to proceed with his life after his military experience. He stated, "I don't really know where I want to be.” Therefore, the participation in the OBVP was less about finding faith. Instead,

To be honest with you Joe, it was more just peace. I can't really just point to anything and say God said you are going to be doing this, or this is what I made you for. It was like, just peace. It was like, chill out, you know I got this, you know just keep walking with me and we'll get there, and you just need to chill out. And that's what I did - I got - which was just a really awesome gift to have, just peace, and just what better place than out there in the mountains. (Participant2) Altruism. Altruism is the belief or practice of disinterested and selfless concern for the well-being of someone or something other than oneself (Merriam-Webster online dictionary, n.d.). This definition extends beyond the care for other humans, which is consistent to the acts generated by the participants in this study. Although several participants described engaging in altruistic acts towards other members, there were also instances of an increased desire for the 
care of the environment. This corresponded with increased sustainability efforts as well as an effort to pick up trash found in the environment.

After his OBVP expedition, Participant 7 shared how he had a greater pull to help other military personal heal and address unhealthy coping patterns. He works at a university and has been readily aware of student veterans with psychological issues.

And again with that wealth of knowledge that I've accrued, I can help those people by being understanding and also being open to them. Which again in the military, they are around it all the time and that's the social norm. Drinking, and not drugs per say, but being in that environment. And then the college social norm is kind of similar but a little bit different. But being able to combine the two allows me to - you know, be a better leader that way, and I think that really - you know you don't just look at them and say OK you're failing because you chose drugs or alcohol, to cope with your problems. There's deeper meaning to it than that and you have to dig to find that, be open to find that and not rush to judgment. (Participant 7)

Apart from wanting to specifically help others, Participant 8 reported being more consciousness of discarded human trash found throughout the environment. It is noteworthy that this individual was self-described as, "I'm just a nature freak anyway. I like being out there, I like doing things, I mean I like the outdoors, that's what I do on my days off, in the summer I'm out climbing 14ers, backpacking, camping..." Her desire to care for the environment reportedly grew as a result of the expedition.

It was funny because we were out on that beach and you know there's so much stuff that washes up on the shore, like trash and whatever. I spent a lot of time 
when I was out taking pictures cleaning up the beach. I'd find myself just

cleaning up the trash and putting it in piles, so I'm more conscious aboutespecially if I find myself out walking around and I see trash, I'm picking up a lot more stuff. It's kind of interesting, but I definitely am more conscious about that. (Participant 8)

Participant 4 shared a very similar sentiment.

I think with the whole philosophy of Leave No Trace that Outward Bound you know, presses on, really made me appreciate what this world has to offer, and that it's important to kind of protect what we have and not just go in there and stomp around like a bunch of cavemen or whatever, and just leave whatever we feel like. And just making sure that Mother Nature is taken care of. (Participant 4)

\section{Overview of the Emergent Theory}

The final component of the qualitative section is a discussion of how the constructs and their underlying categories work together to describe a theory of how posttraumatic growth is fostered in former deployed veterans who participate in an OBVP expedition. The emergent theory is represented in Figure 2. The theory postulates that every OBVP participant is naturally exposed to Contextual Factors described above. Within every expedition, each Contextual Factor is likely to vary as elements change due to programmatic considerations (e.g., type of activity) as well as uncontrollable variables (e.g., weather or participant characteristics). It is the interaction of the Contextual Factors that comprise the Group Process. Although any number of group dynamics or processes could have emerged, the participants most readily endorsed Social Learning, Overcoming Adversity, and Group Cohesion as factors influencing Posttraumatic Growth outcomes. As highlighted by the eight interviewed participants, the traditional five 
factors associated with PTG were reported: Relating to Others, New Possibilities, Personal Strength, Appreciation of Life, and Spiritual Growth. However, evidence within the transcripts supported Altruism as a sixth factor.

The notable experiences of the Outward Bound Veterans Program highlighted by the interviewed participants consist of the main categories: Environment, Activities, and Cadre. Outward Bound is most often associated with the experiential activities facilitated in picturesque settings. It is the opportunity to engage in new experiences that offer excitement and risk, which draws individuals to these programs. However, OBVP participants have also described meaningful experiences associated with formal and informal group conversation and ceremonies aimed at honoring the sacrifices involved in military deployment. These pursuits only partially describe the OBVP experience. The activities are detailed by the remote terrain, challenging environment, and sometimes harsh weather. Meanwhile, all of the events are collectively experienced with other military participants and Outward Bound leaders.

Due to the difficult terrain, uncomfortable weather, or physical challenge associated with the activities, all of the participants experienced adverse conditions. The overcoming of these difficult situations resulted in expressed feelings of accomplishment. The qualitative data gathered several weeks to several months after the completion of the expedition demonstrated an association between overcoming adversity in a group setting and prolonged endorsement of the posttraumatic growth factors: personal strength, relating to others, and new possibilities.

Participants also described learning socially from the other veterans. At times, the situations were for practical considerations, such as learning how to erect a shelter. However, participants also observed the benefits of voicing difficult military memories. They described feeling supported, accepted, and understood by the other veterans. Furthermore, these moments 
allowed for a release of emotional "burden". Additionally, these experiences led to greater group cohesion and were associated with PTG factors: appreciation of life, relating to others, and new possibilities. 
Figure 2

Emergent Theory

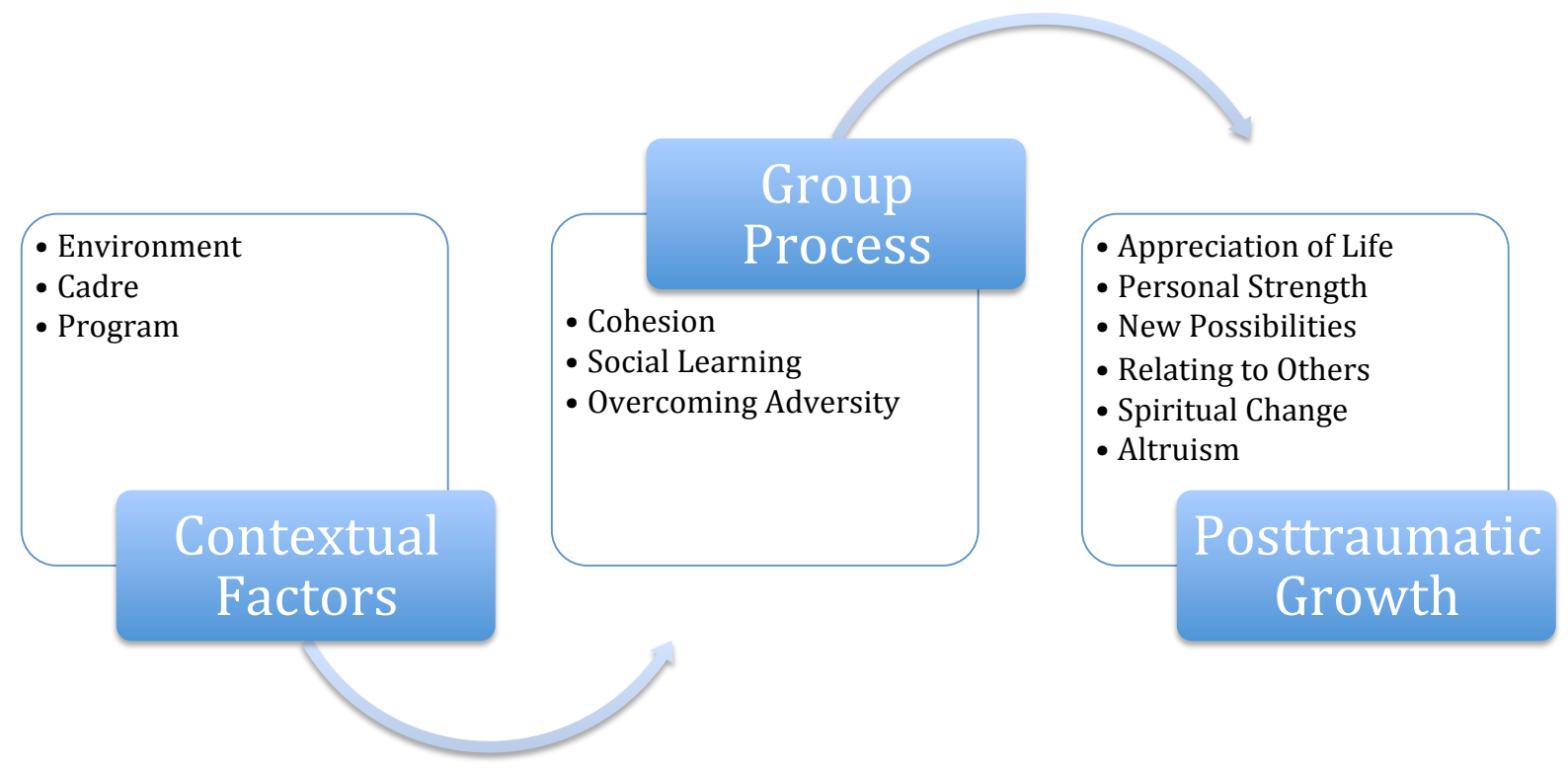


Finally, group cohesion was a consistent theme throughout the interviews. Some participants described an instant sense of connection due to being on an expedition with all military personnel. There was a common experience and shared values that seemingly permeated other trip experiences. Military work ethic was noted during less intensive moments such as collectively setting up camp before relaxing, but also during a heavy storm that resulted in tarps collapsing. The group cohesion instilled a sense of physical and emotional safety and seemingly influenced how efficiently participants completed a task. This main category was most heavily associated with PTG factors: relating to others and new possibilities.

The data support the idea that there is a reciprocal relationship between the factors endorsed in the Group Process. All participants described at least one instance of being physically or emotionally challenged at some point during their expedition. How these situations were perceived, endured, and resolved was related to what was learned from others and the group cohesion. The influence of group cohesion was readily evidenced in one participant who described her group as "the Wolf Pack". This participant indicated that the narrative used to describe how the participants conquered the challenging terrain was socially constructed through nightly story telling. Finally, moments of adversity seemingly deepened group cohesion and fostered further opportunity for social learning. In summary, Group Process factors do not occur in isolation; instead they can potentially work to shape one another and create opportunities for growth.

It is not suggested that the all elements of the Group Process are equally needed for growth to occur. Indeed, each participant stressed the importance of different factors and one individual did not report instances of social learning. Perhaps it is helpful to recall that experiences of posttraumatic growth are gradient rather than dichotomous. Although each factor 
may not be necessary for growth, the presence and strength of each concept may be directly proportional to PTG outcomes.

The results of the Contextual Factors and Group Process suggest Outward Bound Veterans Programs offer opportunities for veterans to increase a sense of posttraumatic growth. Although all five traditional PTG factors were endorsed, Relating to Others and New Possibilities occurred with the greatest frequency, though Appreciation of Life and Personal Strengths were also commonly endorsed. Finally, half of the interviewed participants described engaging in altruist thoughts or behaviors because of their OBVP expedition. These selfless acts were directed toward others as well as to the environment. Therefore, this theory suggests the possible inclusion of a sixth PTG factor, at least as it pertains to the OBVP. 


\section{CHAPTER IV}

\section{Discussion}

The mental health of returning war veterans continues to be a major focus of the media and research publications. Despite the awareness of pathology associated with combat, research has suggested the frequency of posttraumatic growth is a more common experience (Tedeschi et al., 1998; Updegraff \& Taylor, 2000). However, the prevalence of PTG among deployed veterans has been minimally explored. Furthermore, PTG research has primarily focused on the cognitive restructuring that occurs within survivors with limited focus on behavioral interventions that lead to psychological growth.

In 2011, Tedeschi and McNally published an article entitled, Can We Facilitate Posttraumatic Growth in Combat Veterans. The present dissertation aimed to address this question by exploring the influence of the Outward Bound Veterans Program on reported posttraumatic growth outcomes. This was determined by comparing quantitative results from participants that had completed an OBVP expedition with individuals that had yet to complete a trip. Secondly, qualitative data was collected to understand how the participation in an OBVP fosters posttraumatic growth. This research question was evaluated through telephone interviews with participants who had endorsed elevated experiences of PTG on the quantitative measure. The analysis allowed for the development of an emergent theory.

The data from the quantitative portion addressed the first research question: For current and former members of the United States Armed Forces, does Outward Bound Veterans Program promote posttraumatic growth? The results demonstrated that not only can PTG be fostered through creative intervention, but also provides factors that aid the growth process. The results indicated the PTG posttest scores of the Treatment group were significantly higher than the 
Waitlist control group, presenting evidence that the OBVP positively influences psychological growth among veterans. These findings are valuable as it is believed this was the first intervention evaluated that positively influences PTG outcomes among veterans.

The quantitative results also yielded unexpected findings. Although the posttest scores of the Treatment group increased, the results also revealed a decrease in baseline PTG scores for the Waitlist group. It is unknown the exact reasons for this trend, however the results may add to the substantiated concerns regarding the mental health issues that increase after individuals are discharged from the Armed Services. Previous longitudinal research (Hoge et al., 2004; Milliken et al., 2007) has demonstrated returning veterans often experience a delayed onset of psychopathology up to a year after discharge. As there was over a month between the completion of the pre- and posttest measures, it is possible the decrease scores correlate with adjustment issues. Furthermore, according to the literature, the sample in this study is among the most at-risk military personnel for developing psychopathology based on their exposure to combat (Adler et al., 2005), lower rank (Seal et al., 2007), and multiple tours (Surgeon General, 2006). It was evident among the interviewed participants that many were struggling from previous military trauma and complications associated with transitioning to civilian life. These issues could easily have impacted relatedness, spirituality, appreciating life, awareness of new possibilities, and views of personal strength.

A second interesting finding was the PTG factor, Relating to Others, was the only subscale that reached statistical significance. It is noteworthy that other studies with veterans found Personal Strength to have a pronounced effect (Feder et al., 2008; Maguen et al., 2006). Limited statistical power (.477) may have played a role in limiting the significance of the comparison conducted, suggesting a larger sample size that yielded the recommended power of 
.80 (Cohen, 1988) might have produced a significant finding for this subscale. It is recommended that future studies explore this question with more participants.

The interview transcripts provided descriptive information regarding the meaning and importance of relatedness for OBVP participants. Consistent with other individuals that have experienced a trauma, some participants reported heightened vigilance or mistrust of others. They were quick to form negative opinions and judge the conduct of colleagues and therefore would focus on the differences between themselves and other participants. For some individuals, their memories were so traumatic and singular that they described an inability to feel understood even among other veterans. Therefore, in their day-to-day lives, participants had socially isolated and primarily had not discussed their military experiences. This sense of separateness did not allow for any refutable evidence that others had experienced similar difficulties and prevented exposure to new, healthier cognitive patterns. As a result unhealthy beliefs and behaviors perpetuated.

The participation in an Outward Bound Veterans Program deconstructed the emotional barriers between individuals. This was seemingly done through a variety of explicit and subtle experiences. The OBVP is exclusively offered to members of the US Armed Forces. This segregation seemed to be an important effort in reducing concerns of being misunderstood. Participants described having a shared work ethic and values, which contributed to an instant connection. They had a common history, but also collectively experienced the completion of the OBVP. This process allowed participants to find commonalities, which were further encouraged by the OB leaders. Through Outward Bound policies, participants were not permitted to bring technological distractions that would keep them from forming connections. Separately, the participants were provided a forum for discussion resulting in formal and informal opportunities 
to honor the sacrifices associated with military service. Finally, they were able to observe the psychological benefits and support received by those that talked about difficult memories.

Collectively, this influenced a sense of connection that seemingly enhanced the psychological wellbeing of the participants.

There was concern that the gains associated with Relating to Others would not persist. It is likely that this is a partial reality given individuals completed the posttest measure roughly two weeks after returning home. Although no quantitative data were collected demonstrating longitudinal effects, the information shared during the interviews provides some support for lasting experiences of relatedness. A total of eight participants were interviewed between 34 and 131 days after their expedition had ended. Each individual endorsed improved social relationships, a freedom to be oneself, or greater intimacy since returning from their respective OBVP experience. This is an area that requires further investigation, but there is at least some evidence that an experience of relatedness endures after the completion of the program.

A potentially interesting result was the number of individuals reporting altruistic acts. In Tedeschi and Calhoun's (1998) earlier writings, there is a section devoted to compassion, empathy, and giving to others. It is evident that the originators of PTG perceive altruism as an indicator of growth (Tedeschi \& McNally, 2011). However, there is an absence of statements on the existing PTGI specifically related to altruism. In a later text, the authors reported, "It remains an empirical question as to whether or not this increased experience of compassion translates into a greater degree or frequency of altruistic acts" (Calhoun \& Tedeschi, 2006b, p. 5). Perhaps altruism is too behavioral and a representation of the cognitive restructuring process already associated with PTG. Selfless acts could conceivably be subsumed under an existing PTG factor such as Relating to Others and denoted within the single PTGI statement, "I have 
more compassion for others." Although the intention may have been to capture altruism within this item, Volhardt and Staub (2011) found the construct to be a "distinctive factor" not represented in current PTG research that seemingly focuses on cognitive reconstruction and not behavioral change. Furthermore, Brewer and Sparkes' (2011) qualitative results from a study of parentally bereaved children also found altruism to be a unique factor. Although this is likely debatable, there is existing literature to support the inclusion of altruism as a sixth and separate factor.

Grounded in the qualitative data, the developed emergent theory addressed the second research question: How, if at all, does Outward Bound Veterans Program promote posttraumatic growth? The results provided an understanding of how the Outward Bound Veterans Program fosters posttraumatic growth. A number of contextual factors consistently appear within every expedition and are highlighted by the Program, Environment, and Cadre. It is the complex interaction of these factors that create the Group Process, which ultimately provides a medium for growth. Specifically, Social Learning, Overcoming Adversity, and Group Cohesion emerged as the most frequently endorsed constructs influencing PTG.

Social learning was highlighted throughout the interview transcripts as a contributor to the growth process. At times, OBVP participants described learning from others for practical purposes associated with learning how to care for oneself in unfamiliar, outdoor settings. More specifically related to PTG, individuals were reinforced to discuss their military history by observing others. Albert Bandura (1977) postulated the prevalence of learning through watching others is enhanced when the model is believed to be similar to the observer. Although the construct of social learning has not been statistically correlated with posttraumatic growth, researchers have discussed the power of appropriate models. Calhoun and Tedeschi emphasized 
that support from credible sources that have "been there can be crucial in determining the degree of willingness trauma survivors have to incorporate new perspectives or schemas" (Calhoun \& Tedeschi, 2004, p. 8). According to the authors, supportive others that are deemed credible aid in the growth process by offering new perspectives and providing a way to develop a personal narrative about the changes that have occurred (Calhoun \& Tedeschi, 2004). Therefore, being on an OBVP expedition for a week, open only to veterans, provides ample opportunity for observational learning from individuals that have 'been there'.

The survivor's primary reference group further influences the growth process. These are the individuals that have immediate sway over the survivor and frequently share similar attitudes and assumptions (Calhoun \& Tedeschi, 2006b). The authors suggest, "Individuals usually do not experience the aftermath of crisis as socially isolated and disconnected persons, but their experience unfolds within the diverse influence of their primary reference groups" (Calhoun \& Tedeschi, 2006b, p. 12). The response of others during moments of disclosure either promotes or socially inhibits the growth process.

The reason why social learning was described as opposed to another construct, such social sharing that readily appears in the literature, is because few individuals actually talked about their personal disclosing that occurred on the expedition. Rather, greater emphasis was placed on their reactions to others. They were surprised and relieved to hear the similarities in stories. It is likely that social sharing eventually did occur for those interviewed and could therefore provide further explanation for the reports of psychological growth.

Since research on social learning associated with PTG was not found in the literature, it is unknown the reasons this construct came to the forefront. The studies reviewed for this dissertation primarily explored PTG that occurred naturally within participants without 
intervention. Frequently, researchers measured constructs such as support seeking (Kent et al., 2013) or religious practices (Currier, Mallot, Martinez, Sandy, \& Neimeyer, 2013) that correlated with growth factors. They also evaluated personal factors such as optimism (Prati \& Pietrantoni, 2009) that provide explanatory evidence why certain individuals are inherently more likely to experience PTG. These studies did not focus on specific methods to foster psychological growth in veterans. For individuals that have been insular or untrusting, and for whom growth did not come naturally, there was a question of how to initiate the process of growth. Tedeschi and McNally (2011) hypothesized that a necessary component to the change process is to help survivors form a coherent trauma narrative. A suggested method included "introducing the stories of others who referred to posttraumatic growth to illustrate the possibility of change" (Tedeschi \& McNally, 2011, p. 22). Perhaps for certain individuals observing others processing their own story may precede social sharing and may help participants begin to internalize a personal narrative.

A second process variable that emerged was Group Cohesion, which highlighted the lack of felt connection, understanding, and social support within the participants' daily lives. Authors that have examined components of social support have found results similar to the current study. For instance, clinical reports indicate support groups for bereaved parents have elicited a strong emotional bond (Calhoun \& Tedeschi, 2004). Over time, the parents felt as though friends and family grew tired of the repetitive stories and difficult emotions. Parents felt misunderstood and lacked further opportunity to cognitively process and create a new narrative. Calhoun and Tedeschi noted the sharing and hearing other tragic stories created further cohesion and a surprising sense of intimacy. A new "sense of family" was established as a result of having "revealed more and been accepted more than in any other personal relationship" (Calhoun \& 
Tedeschi, 2004, p. 9). Likewise, participants in the current study were able to feel understood and attach to the group.

The research on collective trauma experiences provides another lens with which to view the influence of group cohesion. In the wake of national tragedies, such as the United States disaster that occurred on September $11^{\text {th }}, 2001$, a communal response commonly emerges within the greater population (Rime, Paez, Basabe, \& Martinez, 2010). Besides increases in reported anxiety and depression, a collective mood surfaces along with manifestations of solidarity (Pennebaker \& Harber, 1993). This likely occurred on OBVP trips given the shared military history and participation in the OBVP expedition. Furthermore, the authors found that within these populations, "collective ceremonies with symbolic meaning strengthened well-being, and positive affect, and increased interpersonal attraction, empathy, and pro-social behavior as well as positive emotional climate" (Rime et al., 2010, p. 1031). The authors' description seemed consistent with the OBVP remembrance ceremonies as well as the reported outcomes. Within these environments, the increase of sharing emotional experiences will often lead to the fulfillment of personal needs such as relatedness (Rime, 2009). This insight provides further explanation why Relating to Others was so highly endorsed by OBVP participants.

A single study explored combat exposure and unit cohesion as predictors of PTG (Mitchell, Gallaway, Millikan \& Bell, 2013). Ultimately, the authors found significant findings that unit cohesion was associated with higher levels of PTG. However, the strength of the association was relatively weak and likely only significant given the large sample size. The authors hypothesized that the "soldiers in our sample may have had supportive unit members, but may not have fully utilized these resources to accomplish the cognitive processing that is necessary to produce growth" (Mitchell et al., 2013, p. 391). Though no statistical data were 
gathered, the emergent theory from the current study suggests group cohesion was an important variable influencing participant psychological growth. The difference in results may point to the influence of an extraneous variable, such as group culture or norms, not fully explored in either study.

A surprising category that emerged within the qualitative data was the frequency with which individuals discussed the importance of overcoming adverse conditions while completing their OBVP expedition. These situations occurred in the context of challenging weather, difficult terrain, or emotionally challenging situations. As a result of these experiences, individuals described enhanced group cohesion, relatedness, increased confidence, awareness of personal fortitude, and openness to new possibilities.

Understanding the importance of this category was initially perplexing, as no other PTG studies have described similar constructs. However, there are multiple texts citing PTSD as a threat to self-esteem (Resick et al., 2010) and self-efficacy (Hirschel \& Schulenber, 2009). The passages that describe the category of Overcoming Adversity seemingly represent a sense of accomplishment. Hirschel and Schulenberg (2009) provided evidence of how trauma experiences have a negative impact on beliefs about a person's own abilities as to whether they can take action and accomplish goals. Consistent with other literature, the authors found a strong association between self-efficacy and prevalence and severity of PTSD symptomatology. It was therefore recommended that raising self-efficacy could be useful in the treatment of PTSD. Perhaps overcoming adversity was associated with an increase in perceived self-efficacy. These findings would be consistent with Hirschel and Schulenber's findings, though this hypothesis requires further study. 
Separately, several statements associated with this category also depicted parallels between the OBVP and military deployment. While facing an adverse condition, participants described interacting with other military personnel, engaging in physically taxing responsibilities, and navigating terrain similar to combat settings. For many veterans, this experience surfaced memories of deployment. In other words, the participants were engaging in what could be described as exposure. Exposure work, either imaginal or in vivo, is a pivotal component of several trauma-based protocols such as Prolonged Exposure Therapy. These treatments emerged from the foundational work associated with classical and operant conditioning for acquisition of fear, and the concept of extinction for fear reduction (Foa \& Meadows, 1997). Exposure is viewed to be integral, within these protocols, for creating behavior change, emotional processing, and cognitive restructuring for individuals with PTSD. Furthermore, exposure work experientially addresses issues of avoidance that often serve as the greatest barriers to growth (Resick et al., 2008). Therefore, it can be conceptualized that on some level, the veteran participants engaged is exposure work without realizing that it was occurring. If this is true, it is therefore not surprising that individuals interviewed for this study favorably described these moments of adversity. Conversely, this may also suggest a certain percentage of participants may experience heightened anxiety or even increased symptoms of PTSD (Foa, Zoellner, Feeny, Hembree, \& Alvarez-Conrad, 2002).

Broadly, the prevalence of the three group processes identified in this study are consistent with some of the therapeutic factors identified by Irvin Yalom (2005). He specifically devotes an entire chapter to group cohesiveness suggesting, "the need for belonging is innate in us all" (Yalom, 2005, p. 56). According to Yalom, within the group setting, any past experiences can be accepted, translating to a greater sense of trust, self-disclosure and empathy. Yalom has 
suggested that imitative behavior or social learning was the least helpful of his 12 identified factors. However, he noted that imitative behavior has led to increases in acceptance, selfconcept, and self-esteem. Furthermore, Yalom suggested this factor was not fully explored within his study, as the "items in this category seem to have tapped only a limited sector of this therapeutic mode" (Yalom, 2005, p. 95). Finally, overcoming adversity does not directly parallel any of Yalom's therapeutic factors. However, he does describe "interpersonal output" derived in group settings. The group atmosphere may provide an avenue for a corrective emotional experience and the opportunity to learn about one's personal strengths. It is possible that Yalom was describing the output seen in this study caused by the veteran participants conquering some environmental challenge. The parallels between the emergent theory and Yalom's therapeutic factors serve to highlight the therapeutic benefits of Outward Bound Veterans Program.

The emergent theory suggests OBVP offers no single pathway for veterans to develop PTG, rather it is the interconnection of variables that allows this process to occur. It is evident based on the factors that emerged in the Group Process, that exposure and social factors were influential. Although group cohesion and social learning appear to be key elements in the social process for this setting, these variables may not generalize to other interventions. Calhoun and Tedeschi have acknowledged the complexity assessing the influence of social variables, "suggesting that certain types of responses to certain kinds of behaviors on the part of the person in crisis will have a relationship with the degree of growth reported" (Calhoun \& Tedeschi, 2006b, p. 14). Therefore, further exploration is required to understand the importance of social learning, cohesion, and accomplishment as factors that promote PTG.

\section{Limitations}


Although this study contributes meaningfully to the existing research, there are a number of limitations that are important to address. As with many research projects conducted in a practical setting, there was an inability to control for a number of extraneous factors. This study followed a quasi-experimental design given the impracticality of randomly distributing individuals into Waitlist and Treatment groups. Although there were early considerations of how randomization could be accomplished, this notion was quickly abandoned due to the number of programmatic and participant factors that could not be controlled. Despite the lack of randomization in the study, the aim was still to demonstrate causality regarding the impact of the OBVP on posttraumatic growth. However, the lack of randomization can be viewed as a major weakness and a threat to the internal validity of this study (Harris et al., 2006).

The sample associated with this study additionally limits the generalizability to other military personnel. Of the total OBVP participants solicited, only $25 \%$ completed the entire study. Additionally, there likely was a selection bias given veterans self-enroll into an OBVP, as well as into this study. Therefore, the results of this study apply to a select group of individuals that are motivated to participate in an adventure-based program, such as Outward Bound. Furthermore, this population is narrowed based on those willing and able to participate in the research component.

Another limitation involved data collection. Research has demonstrated that mental health concerns increase at varying times post deployment. Knowing the dates of discharge for the research participants could have been helpful in explaining the quantitative results. This information was asked of each participant, however upon further review of data collection procedures there are any number of reasons why $51 \%$ of the participants did not complete this question: 1) Each question was optional and could be skipped while allowing participants to 
complete the rest of the study, 2) The question format was text entry and therefore more labor intensive, 3) To participate in this study, individuals could still be active personnel, which would explain a certain percentage of the blank responses, 4) After completing service in one military branch, some individuals re-enlist in another branch. Therefore, how to respond to this question could be confusing, 5) Other participants are no longer enlisted, but are part of the Reserves or National Guard. For these individuals, the question may have appeared ambiguous. Depending on the research question, this information is potentially vital to explaining the data. It is suggested that future researchers give more thought regarding how to collect this information given the considerations listed above.

Limitations can also be observed within the qualitative data collection procedure. The original study design involved the researcher interviewing participants face-to-face either during or immediately after the trip. This option was eventually replaced with the decision to conduct phone interviews due to relative ease and reduction of cost associated with using a phone. However, Hoyt and Bhati (2007) have described the drawbacks of not observing individuals in their natural environment. There was further concern about discussing sensitive topics, such as military trauma, without greater establishment of rapport. Additionally, it was seen as a deficit to not observe nonverbal responses. Although the decision to conduct phone interviews was made based on the limitations described above, there seemed to be a general loss in understanding of the full trip experience that could have been gained by conducting interviews in person.

\section{Implications}

The current project was predicated on the belief that if provided an exciting and lengthy forum through which previously deployed veterans could socially engage with other members of 
the Armed Services, posttraumatic growth would occur. The purpose of this study was twofold: 1) to determine if PTG occurred for individuals that participated in an OBVP, and 2) to develop a theory of how this process occurs. The data has several theoretical and practical implications that may be useful for Outward Bound, therapeutic settings, and further theory development of PTG among returning veterans.

Outward bound. The results of the current study are directly beneficial to the Outward Bound Veterans Program. However, as the agency does not have specific clinical goals, the following recommendations may need to be adapted to fit the mission and policies for Outward Bound.

There are a number of uncontrollable variables that exist within every Outward Bound expedition, however there are also certain factors that are in the control of the agency or leaders. The program policies additionally add to this process by not allowing distractive technology, fostering group activity, and providing opportunities for numerous social interactions.

Additionally, the qualitative data suggested that having a program closed to veterans was viewed as an asset and pathway for cohesion and discussion of military experiences. Efforts that Outward Bound leaders made to encourage group cohesion were favorably seen by this study's sample. Specific examples include having participants provide positive feedback to a partner at the conclusion of the expedition, encouraging participants to seek assistance from other veterans rather than the leaders, and promoting the similarities between participants over the temptation to look for differences.

The Outward Bound leaders have an important and influential role in the group process. In general, leaders that took a more egalitarian approach with the veterans were seen more favorably. Those that were empathetic and welcomed being taught about the veteran's military 
history were generally well received. Conversely, leaders that assumed a friendly position without establishing rapport or those that imposed a more authoritarian role seemingly created a divide between staff and participants.

Outward Bound requires that all participants must be in good physical health to participate in an expedition, however it is unknown what screening occurs for mental health issues. This question is raised not for the sole purpose of screening out individuals with extreme psychopathology, although this certainly may be the case at times. Rather, knowing certain issues may help Outward Bound administrators guide potential participants with making course selections. Additionally, it may be beneficial to have recommendations from a psychological or psychiatric provider how to best support a participant on a given trip. Certainly there are ethical issues involved with this suggestion that would need to be navigated. However, given the known prevalence of psychological issues within this population, there are also genuine safety concerns with individuals that experience significant symptoms of PTSD while several miles from support. Furthermore, most Outward Bound instructors are not trained mental health providers and may not have the experience to handle unexpected psychiatric situations as they arise.

Although Outward Bound is not a mental health agency, there are certainly wellness outcomes associated with the expeditions. Based on qualitative reports, it appears as though the rate of occurrence and depth of remembrance ceremonies and group talks vary. It is unknown how the Outward Bound agency reinforces the facilitation of these activities, however the data suggested that these events served as meaningful opportunities for growth. Therefore, in addition to facilitating quality outdoor programming, veteran wellness is seemingly also served by allowing the participants the opportunity to engage in discussion that honors past military sacrifices and collectively process past military events. 
Finally, the qualitative results suggest greater consideration for gender issues. Several of the female participants interviewed in this study indicated being one of the few women on their trip. According to the participants, this gender discrepancy included the Outward Bound leaders. This information seems valuable as three of the female interviewees described feeling anxious or even fearful regarding being a gender minority. At least one of the participants alluded to experiencing a military sexual trauma. As a result, participants may benefit from gender segregated expeditions. This may not only increase a sense of safety, but for some individuals increase a sense of relatedness when surrounded by individuals with a similar military experience.

Outside agencies. It would seem as though the results from this study would have limited applicability outside Outward Bound, yet there are a growing number of programs being developed to assist veterans with the adjustment to civilian life. As a result, there are increasing amounts of veterans taking advantage of these free or reduced fee opportunities. Programs such as Project Healing Waters (Project Healing Waters, n.d.), Semper Fi Odyssey (Outdoor Odyssey, n.d.), Hope for the Warriors (Hope for the Warriors, n.d.), and Wounded Warriors (Wounded Warriors, n.d.) have similar missions to the Outward Bound Veterans Program and attract hundreds of veterans annually. There are a number of implied health benefits associated with each of these programs, though limited research exists to support such claims.

The current study demonstrates that aspects of these programs are physically or mentally challenging for veterans. Understanding the potential hazards and benefits could be valuable in establishing credibility of an intervention and supporting veterans with health issues attracted to these programs. The aim is not to shape these programs to become more clinical, as they seemingly already provide wellness outcomes in their existing form. Furthermore, specific 
therapeutic goals would suggest the inclusion of mental health professionals. Rather, research outcomes could provide greater understanding of how such programming could be used as an adjunct to enhance psychological growth for certain veterans. Therefore, research on the psychological benefits and the types of specific individuals likely to grow from adventure-based programming is strongly recommended.

The data also provides broad considerations for the treatment of veterans that have experienced a trauma. The inclusion of experiential activity may provide an opportunity for a stimulating learning environment that allows for multi-dimensional processing of a traumatic event. Additionally, within a group context, social learning from other veterans offers a model for the growth process. Separately, it is recommended that facilitators take an active role to help confront unhealthy social barriers to enhance greater cohesion and relatedness. Being from a different military branch or the subjective rating of severity related to a trauma experience only segregates individuals and solidifies avoidance. Finally, it is recommended that the development of pro-social behaviors, such as altruism, be encouraged.

Theory. The data from this study blends with the existing PTG theory. Where Calhoun and Tedeschi's (2006b) model found in Appendix A is primarily devoted to the cognitive processes that promote PTG, the emergent theory associated with this study has focused on the behavioral and environmental factors that promote growth. The emergent theory is specific to a single intervention for a particular population and therefore does not neatly attach to the current model. However, the data draws attention to the behavioral factors that both promote and indicate growth.

In recent years, more studies have researched the increase of altruism (Volhardt \& Staub, 2011) as well as other pro-social behaviors (Frazier et al., 2009) in the aftermath of traumatic 
events. These researchers have questioned the importance of behavioral change in association with PTG. Some researchers have gone so far as to suggest that a person's behaviors are the genuine measure of PTG (Frazier et al., 2009). Although this researcher perceives psychological change can occur without action, altruism as a seemingly distinct factor of growth emerged within this study. More research on the behavioral representations of growth could expand the PTG model and perhaps more accurately depict the growth endorsed by certain individuals not characterized by a change in cognitive processes.

As described by the participants, engaging in exciting and challenging activity provided an opportunity for cognitive processing and posttraumatic growth. Events such as the remembrance ceremony, enduring challenging weather, and socially engaging with other veterans were directly associated with PTG factors. At least for this project, the program experiences and cognitive restructuring seemed to be mutually influential. It is likely that behaviors or activity in other contexts would also be meaningful contributors to the growth process, however this is an area relatively devoid of research. Knowing this information seems particularly valuable for individuals with whom PTG does not occur naturally. Further exploration into behaviors that promote growth could help shape the development of future interventions. 


\section{References}

Adler, A. B., Huffman, A. H., Bliese, P. D., \& Castro, C. A. (2005). The impact of deployment length and experience on the well-being of male and female soldiers. Journal of Occupational Health Psychology, 10(2), 121-137.

Aderka, I. M., Foa, E. B., Applebaum, E., Shafran, N., \& Gilboa-Schechtman, E. (2011).

Direction of influence between posttraumatic and depressive symptoms during prolonged exposure therapy among children and adolescents. Journal of Consulting and Clinical Psychology, 79(3), 421-425.

Altruism. (2011). In Merriam-Webster.com.

Retrieved April 8, 2014, from http:/www.merriam-webster.com/dictionary/hacker.

American Psychiatric Association. (1952). Diagnostic and statistical manual of mental disorders ( $1^{\text {st }}$ ed.). Washington, DC: Author.

American Psychiatric Association. (1980). Diagnostic and statistical manual of mental disorders ( $3^{\text {rd }}$ ed.). Washington, DC: Author.

American Psychiatric Association. (2000). Diagnostic and statistical manual of mental disorders ( $4^{\text {th }}$ ed. text revision). Washington, DC: Author.

American Psychiatric Association. (2013). Diagnostic and statistical manual of mental disorders ( $5^{\text {th }}$ ed.). Washington, DC: Author.

Bandura, A. (1977). Social learning theory. New York: General Learning Press.

Benish, S. G., Imel, Z. E., \& Wampold, B. E. (2007). The relative efficacy of bona fide psychotherapies for treating post-traumatic stress disorder: A meta-analysis of direct comparisons. Clinical Psychology Review 28, 746 - 758. 
Berrera, M. (1986). Distinctions between social support concepts, measures, and models. American Journal of Psychology, 14, 413-445.

Bourke, J. (2011). Shell shock during World War One. Retrieved from: http://www.bbc.co.uk/history/worldwars/wwone/shellshock_01_shtml

Bradley, R., Greene, J., Russ, E., Dutra, L., \& Westen, D. (2005). A multidimensional metaanalysis of psychotherapy for PTSD. American Journal of Psychiatry, 162(2), 214-227.

Breslau, N. (2001). The epidemiology of posttraumatic stress disorder: What is the extent of the problem? Journal of Clinical Psychiatry, 62(17) 16-22.

Brewer, J., \& Sparkes, A. C. (2011). Parentally bereaved children and posttraumatic growth: Insights from an ethnographic study of a UK childhood bereavement service. Mortality, $16(3), 204-222$.

Brown, M. C., Creel, A. H., Engel, C. C., Herrell, R. K., Hoge, C. W. (2011). Factors associated with interest in receiving help for mental health problems in combat veterans returning from deployment to Iraq. The Journal of Nervous and Mental Disease, 199(10), 797- 801.

Burnam, A., Meredith, L.S., Tanielian, T., \& Jaycox, L.H. (2009). Mental health care for Iraq and Afghanistan war veterans. Health Affairs, 28(3), 771-782.

Burlingame, G. M., McClendon, D. T., \& Alonso, J. (2011). Cohesion in group therapy. Psychotherapy, 48(1), 34-42.

Cadell, S., Regehr, C., Hemsworth, D. (2003). Factors contributing to posttraumatic growth: A proposed structural equation model. American Journal of Orthopsychiatry 73, 279-287. Cadre. (2011). In Merriam-Webster.com.

Retrieved April 8, 2014, from http://www.merriam-webster.com/dictionary/hacker. 
Calhoun, L. G., Cann, A., \& Tedeschi, R. G. (2010). The Posttraumatic Growth Model: Sociocultural considerations. In Weiss, T., \& Berger, R. (Eds.). Posttraumatic growth: A cross-cultural perspective (pp. 1-14). Hoboken, NJ: John Wiley \& Sons, Inc.

Callhoun, L. G. \& Tedeschi. R. G. (1998). Posttraumatic growth. Future directions. In R. G. Tedeschi. C. L. Park, \& L. G. Calhoun (Eds.). Posttraumatic growth: Positive changes in the aftermath of crisis (pp. 215-238). Mahwah, NJ: Lawrence Erlbaum Associates, Inc.

Calhoun, L. G. \& Tedeschi, R. G. (Eds.). (2006a). Handbook of posttraumatic growth: Research and practice. Mahwah, New Jersey: Lawrence Erlbaum Associates.

Calhoun, L. G. \& Tedeschi, R. G. (2006b). The foundations of posttraumatic growth: An expanded framework. In L. Calhoun \& R. Tedeschi (Eds.). Handbook of posttraumatic growth: Research and practice (pp. 1-23). Mahwah, New Jersey: Lawrence Erlbaum Associates.

Calhoun, L. G. \& Tedeschi, R. G. (2006c). Expert companions: Posttraumatic growth in clinical practice. In L. Calhoun \& R. Tedeschi (Eds.). Handbook of posttraumatic growth: Research and practice (pp. 291-310). Mahwah, New Jersey: Lawrence Erlbaum Associates.

Cohen, J. (1988). Statistical power analysis for behavioral sciences $\left(2^{\text {nd }}\right.$ ed.). New York: Routledge Academic.

Cohen, J. (1992). A power primer. Psychological Bulletin, 112(1), 155-159.

Cohen, M. \& Numa, M. (2011). Posttraumatic growth in breast cancer survivors: a comparison of volunteers and non-volunteers. Psycho-Oncology 20(1), 69-76.

Congressional Record (July, 2003). Proceedings and debates of the $108^{\text {th }}$ Congress: First Session volume 148 part14. Washington DC: United States Government Printing Office. 
Corbett, Sara. “The Women's War.” The New York Times 18 March 2007: Print.

Cornum, R., Watthews, M. D., Seligman, M. E. P. (2011). Building resilience in a challenging institutional context. American Psychologist, 66(1), 4-9.

Creswell, J. W. \& Miller, D. (2000). Determining validity in qualitative inquiry. Theory into Practice, 39(3): 124-130.

Crisp, S. (1998). International models of best practice in wilderness and adventure therapy. In C. Itin (Ed.), Exploring the boundaries of adventure therapy: International perspectives. Proceedings of the 1st International Adventure Therapy Conference. Boulder, CO: Association for Experiential Education.

Csikszentimihalyi, M. (1991). Flow: The psychology of optimal experience. New York: Harper Perennial Modern Classics.

Currie, S. L., Day, A. \& Kelloway, K. (2011). Bringing the troops back home: Modeling the post deployment reintegration experience. Journal of Occupational Health Psychology, $16(1) 38-47$.

Currier, J. M., Mallot, J., Martinez, T.E., Sandy, C., \& Neimeyer, R. A. (2013). Bereavement, religion, and posttraumatic growth: A matched control group investigation. Psychology of Religion and Spirituality, 5(2), 69-77.

Dattalo, P. (2008). Determining sample size: Balancing power, precision, and practicality. New York: Oxford University Press.

Daniels, J, Volungis, A., Pshenishny, E., Gandhi, P., Winkler, A., Cramer, D., Bradley, M. (2010). "A Qualitative Investigation of Averted School Shooting Rampages." Counseling Psychologist, 38(1), 69-95. 
Davis, C. G., \& Macdonald, S. L. (2004). Threat appraisals, distress and the development of positive life changes after September 11th in a Canadian sample. Cognitive Behaviour Therapy, 33, 68-78.

Department of Defense. (2013). U.S. casualty status as of January 2, 2013. [Data File]. Retrieved from: www.defense.gov/news/casuality.pdf

DePrince, A. P., Chu, A. T. \& Pineda, A. S. (2011). Links between specific posttrauma appraisals and three forms of trauma-related distress. Psychological Trauma: Theory Research, Practice and Policy, 1-12.

De Rivera, J. \& Paez, D. (2007). Emotional climate, human security and culture of peace. Journal of Social Issues, 63, 233-253.

Donovan, B., Padin-Rivera, E., \& Kowaliw, S. (2001). “Transcend”: Initial outcomes from a posttraumatic stress disorder/ substance abuse treatment program. Journal of Traumatic Stress, 14(4), 757-772.

Edman, J. L., Lynch, W. C., \& Yates, A. (2014). The impact of exercise performance dissatisfaction and physical exercise on symptoms of depression among college Students: A gender comparison. Journal of Psychology, 148(1), 23-35.

Erdfelder, E., Faul, F. \& Buchner, A. (1996). GPOWER: A general power analysis program. Behavior Research Methods, Instruments, \& Computers, 28, 1-11.

Ewert, A., Puymbroeck, M., Frankel, J. \& Overholt, J. (2011). Adventure education and returning military veteran: What do we know? The Journal of Experiential Education, $33(4), 365-369$.

Fassinger, R. E. (2005). Paradigms, Praxis, Problems, and Promise: Grounded Theory in Counseling Psychology Research. Journal of Counseling Psychology, 52(2), 156-166. 
Feder, A., Southwick, S. M., Goetz. R. R., Wang, Y. Alonso, A...Vythilingam, M. (2008). Posttraumatic growth in former Vietnam prisoners of war. Psychiatry, 71(4), 359-370.

Foa, E. B., \& Meadows, E. A. (1997). Psychosocial treatments for posttraumatic stress disorder: A critical review. Annual Review of Psychology, 48(1), 449.

Foa, E. B., Zoellner, L. A., Feeny, N. C., Hembree, E. A., \& Alvarez-Conrad, J. (2002). Does imaginal exposure exacerbate PTSD symptoms?. Journal of Consulting and Clinical Psychology, 70(4), 1022-1028.

Frankl, V. (1984). Man's search for meaning. Boston, MA: Beacon Press.

Frazier, P., Tennen, H., Gavian, M., Park, C., Tomich, P., \& Tashiro, T. (2009). Does SelfReported Posttraumatic Growth Reflect Genuine Positive Change?. Psychological Science, 20(7), 912-919.

Fredrickson, B. L. (2001). The role of positive emotions in positive psychology: The broadenand-build theory of positive emotions. American Psychologist, 56, 218-226.

Gass, M. A. (1993). Adventure therapy: Therapeutic applications of adventure programming. Dubuque, IA: Kendall/Hunt Publishing.

Gass, M. A., Gillis, H. L., \& Russell, K. C. (2012). Adventure therapy: Theory, research and practice. New York: Routledge.

Gass, M. A. \& Priest, S. (2006). The effectiveness of metaphoric facilitation styles in corporate adventure training (CAT) programs. 29(1), 78-94.

Gelso, C. \& Fretz, B. (2001). Counseling Psychology ( $2^{\text {nd }}$ ed.). Belmont, CA: Thomson \& Wadsworth.

Gerrish, N., Dyck, M.J., \& Marsh, A. (2009). Post-traumatic growth and bereavement. Mortality, 14, 226-244. 
Greene, J. C., Caracelli, V. J. \& Graham, W. F. (1989). Toward a conceptual framework for mixed-method evaluation designs. Educational Evaluation and Policy Analysis 11(3), $255-274$.

Harris, A., McGregor, J., Perencevich, E., Furuno, J., Zhu, J., Peterson, D., \& Finkelstein, J. (2006). The use and interpretation of quasi-experimental studies in medical informatics. Journal of the American Medical Informatics Association, 13(1), 16-23.

Harris, A. H. S., Thoresen, C. E., \& Lopez, S. J. (2007). Integrating positive psychology into counseling: why and (when appropriate). Journal of Counseling \& Development, 85, 3 13.

Hartig, T., Böö, A., Garvill, J., Olson, T. and Garling, T. (1996). Environmental influences on psychological restoration. Scandinavian Journal of Psychology, 37, 378-393.

Heppner, R. P., Kivlighan, D. M. \& Wampold, B. E. (2008). Research design in counseling (Research, statistics, and program evaluation). ( $3^{\text {rd }}$ ed.). Independence, KY: Brooks Cole.

Herrall, M. C. \& Berglass, N. (2011). Losing the battle: The challenge of military suicide. The Center for a New American Security. Retrieved from http://www.cnas.org/files/documents/publications/CNAS_LosingTheBattle_HarrellBergl ass.pdf

Hirschel, M. J., \& Schulenberg, S. E. (2009). Hurricane Katrina's impact on the Mississippi Gulf Coast: General self-efficacy's relationship to PTSD prevalence and severity. Psychological Services, 6(4), 293-303. 
Hoge, C. W., Castro, C. A., Messer, S. C., McGurk, D., Cotting, D. I., \& Koffman, R. L. (2004). Combat duty in Iraq and Afghanistan, mental health problems, and barriers to care. New England Journal of Medicine, 351, 13-22.

Hoge, C. W., Clake, J. C., \& Castro, C. A. (2007). Commentary: Women in combat and the risk of post-traumatic stress disorder and depression. International Journal of Epidemiology, $36,327-329$.

Hope for the Warriors. (n.d.). Hope for the Warriors. Retrieved April 29, 2014 from www.hopeforthewarriors.org.

House, A. S. (2006). Increasing the usability of cognitive processing therapy for survivors of child sexual abuse. Journal of Child Sexual Abuse, 15, 87-103.

Hoyt, W. T. \& Bhati, K. S. (2007). Principles and practices: An empirical examination of qualitative research. Journal of Counseling Psychology, 54(2), 201-210.

Hyer, L., Boyd, S., Scurfield, R., Smith, D., \& Burke, J. (1996). Effects of Outward Bound experience as an adjunct to inpatient PTSD treatment of war veterans. Journal of Clinical Psychology, 52(3), 263-278.

Janolf-Bulman, R. (1992). Shattered assumptions. New York: Free Press.

Janoff-Bulman, R. (2006). Schema-change perspectives on posttraumatic growth. In L. Calhoun \& R. Tedeschi (Eds.). Handbook of posttraumatic growth: Research and practice (pp. 80-99). Mahwah, New Jersey: Lawrence Erlbaum Associates.

Jick, T. D. (1979). Mixing qualitative and quantitative methods: Triangulation in action. Administrative Science Quarterly, 24, 602-611. 
Keane, T.M., Caddell, J. M., \& Taylor, K. L. (1988). Mississippi scale for combat-related posttraumatic stress disorder: Three studies in reliability and validity. Journal of Consulting and Clinical Psychology, 56, 85-90.

Kent, E. E., Alfano, C. M., Smith, A., Bernstein, L. McTiernan, A., Baumgartern, K. B., \& Ballard-Barbash, R. (2013). The roles of support seeking and race/ethnicity in posttraumatic growth among breast cancer survivors. Journal of Psychosocial Oncology, 31(4), 393-412.

Kilmer, B., Eibner, C., Ringel, J. S., \& Pacula, R. L. (2011). Invisible wounds, visible savings? Using microsimulation to estimate the costs and savings associated with providing evidence-based treatment for PTSD and depression to veterans of Operation Enduring Freedom and Operation Iraqi Freedom. Psychological Trauma: Theory, Research, Practice, and Policy, 3(2), 201-211.

Kvale, S. \& Brinkmann, S. (2009). Interviews. Thousand Oaks, CA: Sage.

Ladany, N., Thompson, B. J., \& Hill, C. E. (2012). Cross-analysis. In C. E. Hill (Ed.), Consensual qualitative research: A practical resource for investigating social science phenomena (pp. 117-134). Washington, DC US: American Psychological Association.

Larner, B. \& Blow, A. (2011). A model of meaning-making coping and growth in combat veterans. Review of General Psychology, 15(3), 187-197.

Lee, J., Luxton, D., Reger, G., \& Gahm, G. (2010). Confirmatory factor analysis of the Posttraumatic Growth Inventory with a sample of soldiers previously deployed in support of the Iraq and Afghanistan wars. Journal of Clinical Psychology, 66(7), 813-819. 
Lepore, S. J. (1997). Social constraints, intrusive thoughts, and negative affect in women with cancer. Paper presented at the annual meeting of the Society of Behavioral Medicine, San Francisco, CA.

Lepore, S. \& Revenson, T. (2006). Relationships between posttraumatic growth and resilience: Recovery, resistance, and reconfiguration. In L. Calhoun \& R. Tedeschi (Eds.). Handbook of posttraumatic growth: Research and practice (pp. 24-46). Mahwah, New Jersey: Lawrence Erlbaum Associates.

Linley, P.A., \& Joseph, S. (2004). Positive change following trauma and adversity: A review. Journal of Traumatic Stress, 17, 11-21.

Maguen, S., Vogt, D. S., King, L., A., King, D. W., \& Litz, B. T. (2006). Journal of Loss and Trauma, 11, 373-388.

Manne, S., Ostroff, J., Winkel, G., Goldstein, L., Fox, K., \& Grana, G. (2004). Posttraumatic growth after breast cancer: Patient, partner and couple perspectives. Psychosomatic Medicine 66, 442-454.

Marlow, B., Carmill, T., \& Cieplucha, H. (2003). An interactive process model of psychosocial support needs for women living with breast cancer. Psycho-Oncology, 12, 329-330.

Martin, C. G., Cromer, L. D., DePrince, A. P., \& Freyd, J. J. (2011). The role of cumulative trauma, betrayal, and appraisals in understanding trauma symptomatology. Psychological Trauma: Theory, Research Practice, and Policy, 942-968.

Meichenbaum, D. (1996). Stress inoculation training for coping with stressors. The Clinical Psychologist, 49, 4-7. 
Meichenbaum, D. (2006). Resilience and posttraumatic growth. In L. Calhoun \& R. Tedeschi (Eds.). Handbook of posttraumatic growth: Research and practice (pp. 355-368). Mahwah, New Jersey: Lawrence Erlbaum Associates.

Meichenbaum, D. (2011). Roadmap to resilience: A toolkit for returning service members and their family members (PDF document). Retrieved from Lecture Notes Online Website: http://www.copingaftercombat.com/

Miles, M. B. \& Huberman, A. M. (1994). Qualitative data analysis: An expanded analysis (2 $2^{\text {nd }}$ ed.). Thousand Oaks, CA: Sage.

Milliken, C. S., Auchterloine, J. L., \& Hoge, C. W. (2007). Longitudinal assessment of mental health problems among active and reserve component soldiers returning from the Iraq War. Journal of the American Medical Association, 298(18), 2141-2148.

Military One Source. (n.d.) Counseling Options. Retrieved February $23^{\text {rd }}, 2013$ from http://www.militaryonesource.mil/.

Miner, J., \& Boldt, J. (2002). Outward Bound USA: Crew Not Passengers (2nd edition). Seattle, WA: Mountaineers Books.

Mitchell, M. M., Gallaway, M., Millikan, A. M., \& Bell, M. R. (2013). Combat exposure, unit cohesion, and demographic characteristics of soldiers reporting posttraumatic growth. Journal of Loss and Trauma, 18(5), 383-395.

Morgan, D. L. (2007). Paradigms lost and pragmatism regained: Methodological implications of combining qualitative and quantitative methods. Journal of Mixed Methods Research, $1(1), 48-76$.

Morse, J. M. (1991). Approaches to qualitative-quantitative methodological triangulation. Nursing Research, 40, 120-123. 
Neimeyer, R. A. (2001). Meaning reconstruction and the experience of loss. Washington, DC: American Psychological Association.

Neimeyer, R. A. (2006). Restoring loss: Fostering growth in the posttraumatic narrative. In L. Calhoun \& R. Tedeschi (Eds.). Handbook of posttraumatic growth: Research and practice (pp. 68-80). Mahwah, New Jersey: Lawrence Erlbaum Associates.

Nolen-Hoeksema, S., \& Davis, C. G. (2004). Theoretical and methodological issues in the assessment and interpretation of posttraumatic growth. Psychological Inquiry, 15, 60-64.

Office of the Surgeon General. Multinational Force - Iraq \& Office of the Surgeon General (2006). Mental Health Advisory Team - IV (Web format). Retrieved from Online Website: http://www.scribd.com/doc/134591/mhat-iv-report.

Orme, D. R. \& Boswell, D. (1991). The pre-intake drop-out at a community mental health center. Community Mental Health Journal 27, 375-379.

Ouimette, P., Vogt, D., Wade, M., Tirone, V., Greenbaum, M. A., Kimerling, R., . . Rosen, C. S. (2011). Perceived barriers to care among veterans health administration patients with posttraumatic stress disorder. Psychological Services, 8(3), 212-223.

Outward Bound USA. (2012). Retrieved from: www.outwardbound.org.

Outward Bound Veteran Program. (2010). Denver, CO: Outward Bound, Inc.

Páez, N., Ubillos, S. \& González-Castro, J. (2007). Social sharing, participation in demonstrations, emotional climate, and coping with collective violence after the March 11th Madrid bombings. Journal of Social Issues, 63(2), 323-337.

Park, N. (2011). Strengths and challenges during peace and war. American Psychologist, 66(1) $65-72$. 
Passarelli, A., Hall, E., \& Anderson, M. (2010). A strengths-based approach to outdoor and adventure education: possibilities for personal growth. Journal of Experiential Education, 33(2), 120-135.

Pennebaker, J. W., \& Harber, K. D. (1993). A social stage model of collective coping: The Loma Prieta earthquake and the Persian Gulf War. Journal of Social Issues, 49(4), 125 145.

Pietraz, R. H., Goldstein, M. B., Malley, J. C., Rivers, A. J., Johnson, D. C., \& Morgan, C. A. (2010). Journal of Affective Disorders, 126, 230-235.

Prati G., \& Pietrantoni L. (2009). Optimism, social support, and coping strategies as factors contributing to posttraumatic growth: A meta-analysis. Journal of Loss \& Trauma, 14(5), 364-388.

Project Healing Waters. (n.d.) Retrieved April 29, 2014 from www.projecthealingwaters.org.

Rajandram, R.K., Ho, S.M., Samman N., Chan, N., McGrath C., Zwahlen, R.A. (2011). Interaction of hope and optimism with anxiety and depression in a specific group of cancer survivors: A preliminary study. BMC Research Notes, 4, 519.

RAND. (2008). Invisible wounds of war. Center for Military Health Policy Research. Retrieved from: www.rand.org

Resick, P. A., Monson, C. M., \& Chard, K. M. (2008). Cognitive processing therapy: Veteran/military version. Washington, DC: Department of Veterans' Affairs.

Rime, B. (2009). Emotion elicits the social sharing of emotion: Theory and Empirical Review, $1,60-85$.

Rime, B., Finkenauer, C., Luminet, O., Zech, E. \& Philippot, P. (1998). Social sharing of emotion: New evidence and new questions. In Stroebey, W. \& Hewstone, M. (Eds.), 
European review of social psychology (Vol. 9, pp. 145-189). Chichester, UK: John Wiley \& Sons Ltd.

Rimé, B., Páez, D., Basabe, N., \& Martínez, F. (2010). Social sharing of emotion, post-traumatic growth, and emotional climate: Follow-up of Spanish citizen's response to the collective trauma of March 11th terrorist attacks in Madrid. European Journal of Social Psychology, 40(6), 1029-1045.

Ritter, L. A., \& Sue, V. M. (2007). Introduction to using online surveys. New Directions For Evaluation, (115), 5-14.

Schubert, S. \& Lee, C. W. (2009). Adult PTSD and its treatment with EMDR: A review of controversies, evidence, and theoretical knowledge. Journal of EMDR Practice and Research, 3(3), 117-132.

Seal, K. H., Bertenthal, D., Miner, C. R., Sen, S., \& Marmar, C. (2007). Bringing the war back home. Archives of Internal Medicine 167, 476 - 482.

Seligman, M. E. P. \& Csikszentimihalyi, M. (2000). Positive psychology: An introduction. American Psychologist, 55, 5-14.

Seligman, M. E. P. \& Fowler, R. D. (2011). Comprehensive soldier fitness and the future of psychology. American Psychologist, 66(1), $82-86$.

Semper Fi Odyssey (n.d.). Outdoor Odyssey Leadership Academy. Retrieved April 29, 2014 from www.outdoorodyssey.org.

Shapiro, F., \& Laliotis, D. (2011). EMDR and the adaptive information processing model: Integrative treatment and case conceptualization. Clinical Social Work Journal, 39(2), 191-200. 
Sharpless, B. A., \& Barber, J. P. (2011). A clinician's guide to PTSD treatments for returning veterans. Professional Psychology: Research and Practice, 42(1), 8-15.

Shay, J. (2002). Odysseus in America: Combat trauma and the trials of homecoming. New York: Scribner.

Smith, R. \& Ranch, S. A. M. (2010). Posttraumatic stress disorder. In Daniel L. Segal \& Michel Hersen (Eds.). Diagnostic Interviewing (4 ${ }^{\text {th }}$ ed.). (pp. 371-396). New York: Springer.

Spellman, E. \& Gillis, H. (2008). Are Challenge (Ropes) Courses an Effective Tool? A MetaAnalysis. Journal of Experiential Education, 31(2), 111-135.

Stake, R. (1995). The art of case study research. Triangulation - chapter 7. (pp. 107-120). Newbury Park, CA: Sage Publication.

Stiles, A. (2011). Go rest, young man. Monitor on Psychology, 43(1), 32-34.

Strom, T. Q., Gavian, M. E. Possis, E., Loughlin, J., Bui, T... \& Seigel, W. (2012). Cultural and ethical considerations when working with military personnel and veterans: A primer for VA training programs. Training and Education in Professional Psychology, 6(2), 67-75.

Tabachnick, B. G., \& Fidell, L. S. (2007). Using multivariate statistics (5th ed.). Boston, MA: Allyn \& Bacon/Pearson Education.

Tashakkori, A., \& Teddlie, C. (1998). Introduction to mixed method and mixed model studies in the social and behavioral sciences. In Mixed methodology: Combining qualitative and quantitative approaches (pp. 3-19). Thousand Oaks, CA: Sage.

Tayor, S. E. Kemeny, M. E., Reed, G. M., \& Aspinwall, L. G. (1991). Assault on the self: Positive illusions and adjustment to threatening events. In J. Stauss and G. R. Goethas1 (Eds.), The self: Interdisciplinary approaches (pp. 239-254). New York: SpringerVerlag. 
Tedeschi, R. G. (2011). Posttraumatic growth in combat veterans. Journal of Clinical Psychology Medical Settings, 18, 137-144.

Tedeschi, R. \& Calhoun, L. (1996). Posttraumatic growth inventory: Measuring the positive legacy of trauma. Journal of Traumatic Stress, 9(3), 455-471.

Tedeschi, R. G. \& Calhoun, L. G. (2004). Posttraumatic growth: Conceptual foundations and empirical evidence. Psychological Inquiry, 15, 1-18.

Tedeschi, R. G., \& McNally, R. J. (2011). Can we facilitate posttraumatic growth in combat veterans?. American Psychologist, 66(1), 19-24.

Tedeschi, R. G., Park, C. L. \& Calhoun, L. G. (1998). Posttraumatic growth: Positive changes in the aftermath of crisis. Mahwah, New Jersey: Lawrence Erlbaum Associates.

Tufford, L. \& Newman, P. (2010). Bracketing in qualitative research. Qualitative Social Work 11(1): 80-96.

United States Department of Veterans Affairs. (June, 2012). Public and intergovernmental affairs. Aggressive National Recruitment effort. Retrieved from:

http://www.va.gov/opa/pressrel/pressrelease.cfm?id=2325

Updegraff, J. A., \& Taylor, S. E. (2000). From vulnerability to growth: The positive and negative effects of stressful life events. In J. Harvey \& E. Miller (Eds.). Loss and Trauma. Philadelphia, PA: Taylor \& Francis.

Vollhardt, J. R., \& Staub, E. (2011). Inclusive altruism born of suffering: The relationship between adversity and prosocial attitudes and behavior toward disadvantaged outgroups. American Journal of Orthopsychiatry, 81(3), 307-315. 
Wallenchinsky, D. \& Brinkerhoff, N. (2012, April 12). 139 Soldiers have died in Iraq or Afghanistan. Retrieved from: http://www.forbes.com/sites/katiedrummond/2012/06/18/female-soldiers-health/

Walsh, V., \& Golins, G. (1976). The exploration of the Outward Bound process model. Denver, Colorado: Colorado Outward Bound.

Wang, Y. (2008). Qualitative research. In P. Heppner, B. Wampold, and D. Kivlighan, Research Design in Counseling ( $3^{\text {rd }}$ ed.). (pp.256-297). Belmont, CA: Thompson.

Wang, P. S., Lane, M., Olfson, M., Pincus, H. A., Wells, K. B, \& Kessler, R. C. (2005). Twelve-month use of mental health services in the United States: Results from the National Comorbidity Survey Replication. Archives of General Psychiatry, 62(6), 629640.

Wortham, S. (2001). Narratives in action: A strategy for research and analysis. New York: Teachers College Press.

Wounded Warrior Project. (n.d.). Wounded Warriors Project. Retrieved April 29, 2014 from www.woundedwarriorproject.org.

Yalom, I. (2005). The theory and practice of group psychotherapy (5th ed.). New York: Basic Books.

Zoellner, T. \& Maercker, A. (2006). Posttraumatic growth and psychotherapy. In L. Calhoun \& R. Tedeschi (Eds.). Handbook of posttraumatic growth: Research and practice (pp. 334354). Mahwah, New Jersey: Lawrence Erlbaum Associates. 


\section{Appendix A}

\section{Model of Posttraumatic Growth}

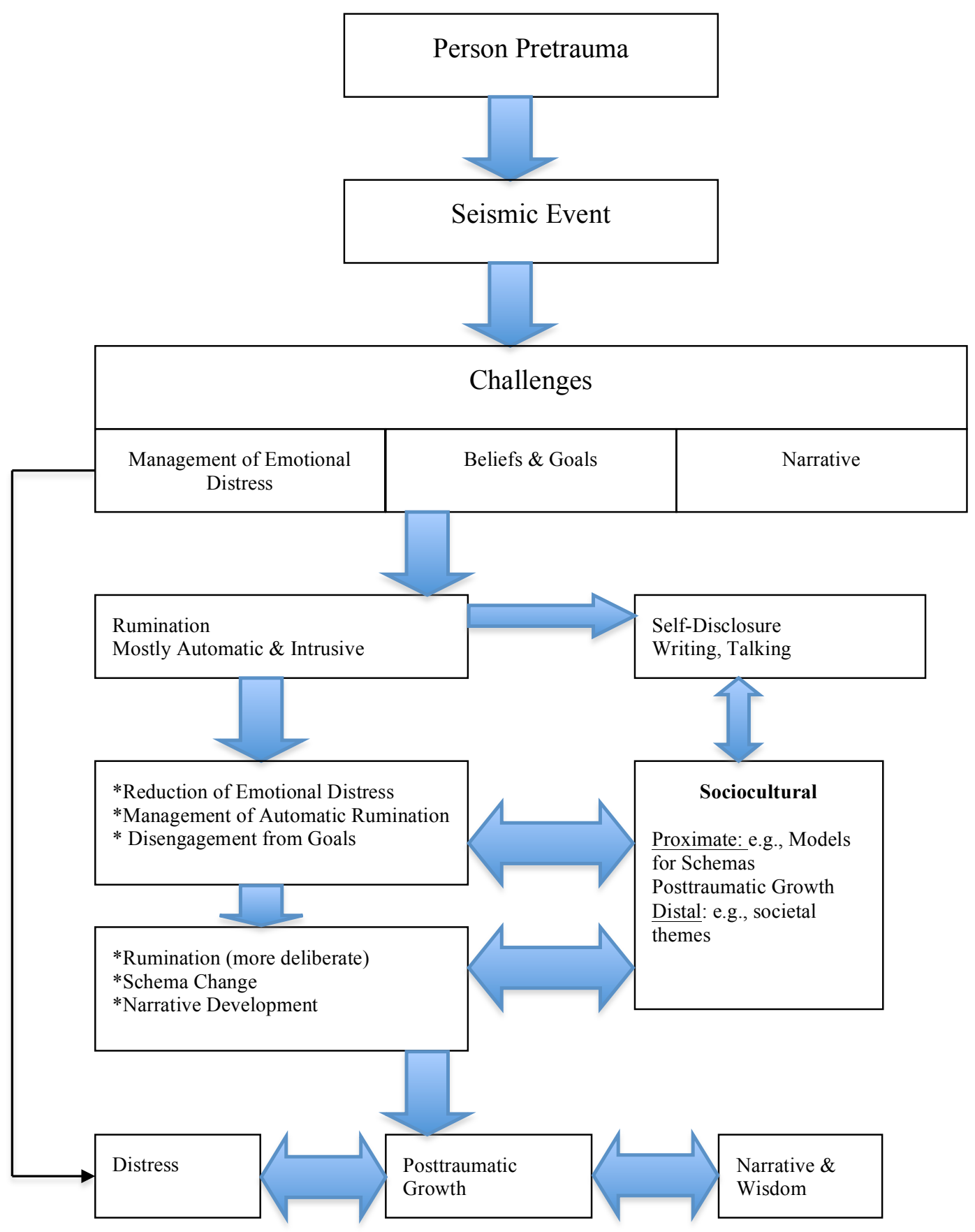

(Adapted from Calhoun \& Tedeschi, 2006b) 


\section{Appendix B}

Letter of Support from Outward Bound

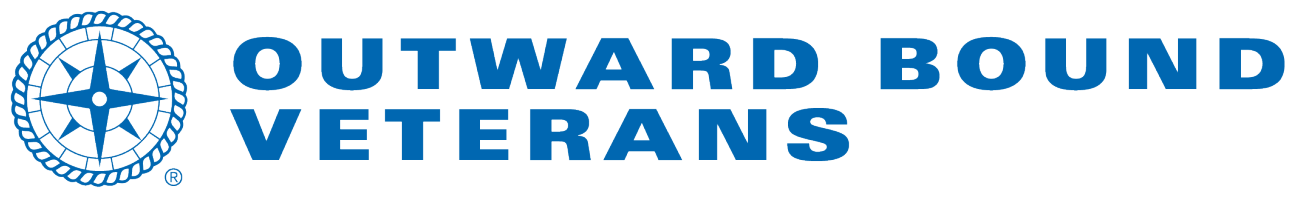

To: Joseph Wassif

From: Chad Spangler, Outward Bound for Veterans

RE: Posttraumatic Growth Research

Date: $1 / 15 / 2013$

I am writing to confirm the support of Outward Bound for Veterans' and our participation in the research project outlined by in your dissertation. We are thrilled to be presented the opportunity to measure the outcomes of our courses, specifically as it relates to resiliency and posttraumatic growth.

We look forward to working with you in the months ahead to conduct your research and will eagerly anticipate your results.

Warm Regards,

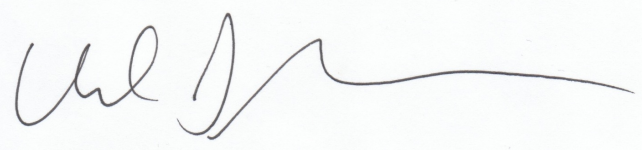

Chad Spangler

National Director

Outward Bound for Veterans

303-800-1957

cspangler@outwardbound.org 


\section{Appendix C}

\section{Letter from David Scheinfeld Regarding Response Rate}

From: David Scheinfeld

To: Joe Wassif

Date: Saturday - July $28^{\text {th }}, 2012$

Hi Joe,

Good to hear from you. All is progressing as well as we can ask for in human subjects research:). We are getting between $50-60 \%$ response rate, so that is pretty good. Happy to talk again this week if you have any specific questions.

I am not sure if you are still wanting to sample from OB vets or not, but I wanted to touch base with you about where we are at in terms of numbers.

Below are all the courses that I have found on the books (I probably last looked two weeks ago, so there may be more). Right now we have had 40 veterans take part in Time 1, it dropped to 36 for Time 2, and we have yet to see what the one-month follow up data will bring. But, I would imagine it may drop again to 30 or so. So we have around $10-15 \%$ decline once vets initiate in the study. Our power analysis says we need 160 participants. I would say there is roughly enough programming below for 200 veterans. So that would mean by Spring of 2013 we may be getting close to our 160 . Now, it is possible they may boost course and then that will happen more quickly.

How long are your measures? How many items? Happy to talk more about this if you have questions or concerns.

Hope all is well, Dave 


\section{Appendix D}

\section{OBVB Recruitment Letter}

Dear Outward Bound Veteran Enrollee,

We are seeking veterans who have enrolled in Outward Bound and would like to take part in a research study that aims to better understand your experiences while participating in the Outward Bound course. We are specifically looking for members of the Armed Services that have been deployed and are participating in their first Outward Bound Veterans Program. This study is being facilitated by Jeff Daniels and Joe Wassif from the West Virginia University. The information collected from this study will greatly benefit Outward Bound's ability to better serve veterans into the future.

Participation in the study involves filling out three online electronic questionnaires on your own computer at two different time points. It will take approximately 15 minutes to complete the online questionnaires at each time point.

You will be compensated for your time. You will be emailed a $\$ 10.00$ Amazon online gift card after the completion of the second set of questionnaires. A few individuals will also be asked to if they would be willing to discuss details about their Outward Bound experience for roughly 30 minutes. This discussion is optional and would not prevent you from taking part in any other part of the study. Those who are willing and complete a discussion with the primary investigator will again be compensated with an additional $\$ 10.00$ gift card, for a total of $\$ 20.00$

Participation in this study is voluntary, and all of your responses will be kept confidential.

If you interested in participating in this study, please email Joe Wassif within a week at jwassif@gmail.com, and he can send you the electronic link to begin the study. 


\section{Appendix E}

\section{Second Recruitment Letter}

Dear Outward Bound Veteran Enrollee,

We wanted to send a reminder email about a research project that is taking place. In an effort to continue offering helpful programming for our military personnel, we are seeking veterans who have enrolled in Outward Bound and would like to take part in a research study that aims to better understand your experiences while participating in the Outward Bound course. We are specifically looking for members of the Armed Services that have been deployed and are participating in their first Outward Bound Veterans Program. This study is being facilitated by Jeff Daniels and Joe Wassif from the West Virginia University. The information collected from this study will greatly benefit Outward Bound's ability to better serve veterans into the future.

Participation in the study involves filling out three online electronic questionnaires on your own computer at two different time points. It will take approximately 15 minutes to complete the online questionnaires at each time point. The information collected from this study will greatly benefit Outward Bound's ability to better serve veterans into the future.

You will be compensated for your time. You will be emailed a \$10.00 Amazon online gift card after the completion of the second set of questionnaires. A few individuals will also be asked to if they would be willing to discuss details about their Outward Bound experience for roughly 30 minutes. This discussion is optional and would not prevent you from taking part in any other part of the study. Those who are willing and complete a discussion with the primary investigator will again be compensated with an additional $\$ 10.00$ gift card, for a total of $\$ 20.00$

Participation in this study is voluntary, and all of your responses will be kept confidential.

If you interested in participating in this study, please email Joe Wassif within a week at jwassif@gmail.com, and he can send you the electronic link to begin the study. 


\section{Appendix F}

\section{Initial Email to Treatment Group}

Dear Outward Bound Veteran Enrollee,

Thank you for your email and interest in this study. Below is a link to begin the study survey. It should take approximately 15 minutes to complete and must be completed within a week. You will again be asked to complete a second survey two weeks after completing your Outward Bound course that will also take 15 minutes. After completing the second set of surveys, you will be emailed a $\$ 10.00$ Amazon gift card within five business days. These surveys must be completed within one week of receiving the email in order to be eligible for the Amazon gift card. All the information you provide on these surveys will be kept confidential.

If you have any questions please feel free to contact Joe Wassif at joseph.wassif@mail.wvu.edu or (304) 216-5106.

Thank you again for taking the time to complete this survey. The information you provide will help future part pants interested outdoor programming.

Pleas click on this link to review the consent form, and if you wish, begin filling out the questionnaire.

LINK 


\section{Appendix G}

\section{Post Course Email}

Welcome back from your Outward Bound course. Please click on the below link to complete your Time 2 questionnaire. It should take approximately 5-10 minutes of your time and needs to be completed within one week of finishing your course. After you complete the questionnaires you will be emailed a \$10.00 Amazon gift certificate within five business days. Please remember that all the information you provide will be kept confidential.

If you have any questions please feel free to contact Joe Wassif at joseph.wassif@mail.wvu.edu or(304)216-5106.

Thank you again for taking the time to complete this questionnaire. The information you provide will help future participants interested in outdoor programming.

Please click on this link to review the consent form, and if you wish, begin filling out the questionnaire.

LINK 


\section{Appendix H}

\section{Initial Email to the Waitlist Control Group}

Dear Outward Bound Veteran Enrollee,

Thank you for your email and interest in this study. Below is a link to begin the study. It should take approximately 8-15 minutes of your time and must be completed within one week. In approximately three to four weeks, you will again be asked to complete a second survey that will again last 5-10 minutes. After completing the second survey, you will be emailed a $\$ 10.00$ Amazon gift card within five business days. All the information you provide on these surveys will be kept confidential.

If you have any questions please feel free to contact Joe Wassif at joseph.wassif@mail.wvu.edu or (304) 216-5106.

Thank you again for taking the time to complete this questionnaire. The information you provide will help future part pants interested outdoor programming.

Pleas click on this link to review the consent form, and if you wish, begin filling out the questionnaire.

LINK 


\section{Appendix I}

\section{Waitlist Control - Post}

Thank you again for your willingness to participate in this study. Please click on the below link to complete your Time 2 questionnaire. It should take approximately 5-10 minutes of your time and must be completed within one week of receiving this email. After you complete the questionnaire you will be emailed a $\$ 10.00$ Amazon gift certificate within five business days. Please remember that all the information you provide will be kept confidential.

If you have any questions please feel free to contact Joe Wassif at joseph.wassif@mail.wvu.edu or(304)216-5106.

Thank you again for taking the time to complete this questionnaire. The information you provide will help future participants interested in outdoor programming.

Please click on this link to review the consent form, and if you wish, begin filling out the questionnaire.

\section{LINK}




\section{Appendix J}

\section{OBVB Interview Recruitment Letter}

Dear Outward Bound Veteran Participant,

You have been selected to participate in an optional phone conversation regarding your Outward Bound program. We value your opinion and hope you are willing to further discuss this experience with a researcher from West Virginia University. The information you provide will help improve the programming offered by Outward Bound and the veteran participants served in the future.

The phone conversation is expected to last approximately 30 minutes and includes four areas of inquiry. The phone call will happen at your convenience. For your time, you will be emailed an additional \$10.00 Amazon online gift card after the completion of the interview. Participation in this study is voluntary, and all of your responses will be kept confidential.

If interested, please email Joe Wassif at joseph.wassif@mail.wvu.edu. Within the subject of your email, please write “OBVP Interview”. He will respond to begin making arrangements for an appropriate date and time for the phone call. 


\section{Appendix K}

\section{Consent Form}

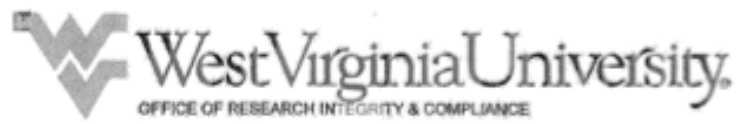

Human Research Protocol
Only Minimal Risk Consent

\section{Only Minimal Risk Informed Consent Form}

Principal Investigator

Department

Protocol Number

Study Title

Co-Investigator(s)

Sponsor (if any)

\section{Contact Persons}

In the event you experience any side effects or injury related to thls research, you should contact Joe Wassif at (304) 216-5106. If you have any questions, concems, or complaints about this research, you can contact leff Daniels at (304) 293-2235 or Chad Spangler at (303) 800-1957. For information regarding your rights as a research subject, to discuss problems, concems, or suggestions related to the research, to obtain Information or offer input about the research, contact the Office of Research Compliance (304) 293-7073.

In addition if you would like to discuss problems, concerns, have suggestions related to research, or would like to offer input about the research, contact the Office of Research Integrity and Compliance at 304-293-7073.

\section{Introduction}

You have been asked to participate in this research study, which has been explained to you by Joe Wassif in the Department of Counseling, Rehabilitation Counseling, and Counseling Psychology at West Virginia University.

\section{Purpose(s) of the Study}

The purpose of this study is to learn more about the experience of psychological growth among veterans that participate in an Outward Bound Program. WVU expects to enroll approximately $100-150$ subjects.

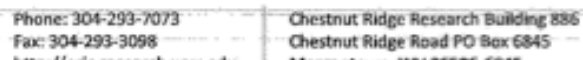

ittp $/ /$ oric.research.wnu.edu 


\section{Description of Procedures}

This study involves the completion of two sets of surveys regarding demographic information, stress related reactions as a result of your time in the military, and experiences of psychological growth. The surveys are to be completed at two different times, approximately four weeks apart. Participants will be selected to participate in either the program group or waitlist group. Those selected to participate in the program group will complete the surveys before and after participating in their chosen Outward Bound Veterans Program. Those in the waitlist group consist of individuals registered for an Outward Bound Veterans Program, but will complete both sets of surveys before participating in their chosen Outward Bound program. Individuals in either group will be asked to complete the same surveys. It is estimated that it will take between 8 and 15 minutes to complete the survey.

Of the approximated 100-150 subjects that complete these surveys, a percentage will be asked to participate in an interview with the coinvestigator, Joe Wassif. This interview will last approximately 30 minutes and will be conducted at a time that is most convenient for you. The interview will be conducted over the telephone and audio recorded. This information will be kept confidential and no identifying information will be utilized. The purpose of this interview is to gain a greater understanding of particularly meaningful experiences related to your participation in the Outward Bound course. By agreeing to participate in the survey portion of this study does NOT require you to complete an interview. Therefore, if asked to be interviewed, you may consent or decline to participate.

\section{Risks and Discomforts}

There are no expected risks from participating in this study, however some of the questions posed in the questionnaires or during the interview may cause a degree of distress. For instance, some questions may remind you of a difficult, challenging, or uncomfortable experience(s) in your life. However, you can always choose not to answer a question or discontinue participation in the study at any time. If you wish to discuss the information above or have any concerns, you may call or email the co-investigator at any time. Additionally, if you need to access supportive services during or after completion of this study, please contact your local Veterans Affairs office for assistance. Or, you can contact the national veterans support hotline at 1-800-273-TALK (8225) for immediate assistance. You can also access services through Military One Source (800) 342-9647 or http//www.militaryonesource.mil. This is a national organization that provides opportunities for telephone or face-to-face counseling. Generally, counselors are located within a 30 mile radius of the caller.

\section{Benefits}

Participants will have the opportunity to further process their Outward Bound experience.

\section{Financial Considerations}

As thanks for your participation, a $\$ 10.00$ Amazon gift card will be emailed to the participants within flve business days of completing Time 2 survey. The participant will not be compensated if they withdraw from the study and will only receive the gift card if each survey is completed within the requested time frame.

Participants involved in the optional interview will be offered an additional $\$ 10.00$ Amazon gift card. Therefore individuals that complete this portion of the study will be compensated with a total of $\$ 20.00$ in Amazon gift cards.

\section{Confidentiality}

The data from this study will be stored securely and kept confidential. Authorized persons from West Virginia University and members of the Institutional Review Board have the legal right to review your research records and will protect the confidentiality of those records to the extent permitted by law. All publications will exclude any information that will make it possible to identify you as a subject. Audiotapes will be kept locked up and will be destroyed as soon as possible after the research is finished. In any publications that result \begin{tabular}{l|l} 
Phone: $304-293-7073$ & Chestnut Ridge Research Building S85 \\
Fax 304-293-3098 & Chestnut Ridge Raad PO Bax 6845
\end{tabular}

http://oric.research.wvu.edo
Morgantown, WV 26506-6845
Page 2 of $5=$

\author{
Subject's Initials/Date
}


from the research, neither your name nor any information from which you might be identifies will be published without your consent.

In addition, there are certain instances where the researcher is legally required to give information to the appropriate authorities. These would include mandatory reporting of infectious diseases, mandatory reporting of information about behavior that is imminently dangerous to your child or to others, such as suicide, child abuse, etc.

\section{HIPAA}

We know that information about you and your health is private. We are dedicated to protecting the privacy of that information. Because of this promise, we must get your written authorization (permission) before we may use or disclose your protected health information or share it with others for research purposes.

You can decide to sign or not to sign this authorization section. However, if you choose not to sign this authorization, you will not be able to take part in the research study. Whatever choice you make about this research study will not have an effect on your access to medical care.

\section{Persons/Organizations Providing the Information}

Outward Bound Veterans Program participant

\section{Persons/Organizations Receiving the Information}

The only individuals directly receiving the information are the researchers within the Department of Counseling, Rehabilitation Counseling, and Counseling Psychology at West Virginia University. As described above, members of the Institutional Review Board at West Virginia University will also have access to the information. Additionally, after your information has been de-identified, it will be shared with Outward Bound.

\section{The Following Information Will Be Used}

The researchers will have access to participants email addresses to send initial questionnaires. Additionally, subject that agree to participate in the qualitative portion will need to share an approprlate telephone number in order to complete the interview. After the data has been collected, all identifying information will be destroyed or deleted.

\section{The Information Is Being Disclosed for the Following Reasons}

Review of your data for quality assurance purposes

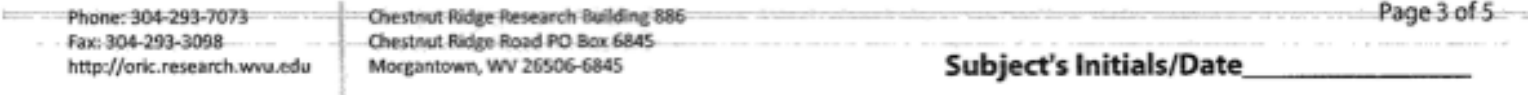


- Publication of study results (without identifying you)

\section{You May Cancel this Authorization at Any Time by Writing to the Principal Investigator}

Dr. Jeff Daniels (304) 293-2235

If you cancel this authorization, any information that was collected already for this study cannot be withdrawn. Once information is disclosed, according to this authorization, the recipient may redisclose it and then the information may no longer be protected by federal regulations.

You have a right to see and make copies of your medical records. You will not be able to see or copy your records related to the study until the sponsor has completed all work related to the study. At that time you may ask to see the study doctor's files related to your participation in the study and have the study doctor correct any information about you that is wrong.

This authorization will not expire unless you cancel it (or has a specific expiration date).

\section{Voluntary Participation}

Participation in this study is voluntary. You are free to withdraw your consent to participate in this study at any time.

Refusal to participate or withdrawal will not affect your ability to participate in your Outward Bound Course. Furthermore, Outward Bound staff have no knowledge of who is a participant of this study.

In the event new information becomes available that may affect your willingness to participate in this study, this information will be given to you so that you can make an informed decision about whether or not to continue your participation.

You have been given the opportunity to ask questions about the research, and you have received answers concerning areas you did not understand.

Upon signing this form, you will receive a copy.

I willingly consent to participate in this research.

\section{Signatures}

Signature of Subject

Printed Name

Date

Time

The participant has had the opportunity to have questions addressed. The participant willingly agrees to be in the study.

Signature of Investigator or Co-Investigator

Printed Name

\begin{tabular}{|l|l|}
\hline Date & Time
\end{tabular}

Pone: $304-293-7073$

Fac: 304-293-3098

htp: $/$ /oric.research.wvu.edu
Chestnut plidge Research Bulding 896

Chestnot Ridee Road PO Bax 6845

Morgantown, WV 26505-6s45
Subject's Initials/Date 


\section{Appendix L}

\section{Demographic Questionnaire}

1) Gender: Male or Female

2) Age:

3) Race:

a. White/European American

b. Hispanic/Latino

c. Asian/Asian-American/pacific Islander

d. Black /African-American

e. Native American

f. Other (please specify)

4) Marital Status:
a. Single
b. Married
c. Widowed
d. Divorced
e. Separated

5) Employment Status:
a. Fulltime
b. Part time
c. Retired
d. Unemployed
e. Student (undergraduate)
f. Student (Graduate)

6) Type of Employment:

7) Are you active in the military: Yes or No

a. If no, Between which dates were you active in the military? Start: (year) to (year)

b. If yes, If you are still active in the military, when did you enroll in the military? (year)

c. If no, are you in the reserves?

8) In which of the following branches did you or are you serving?
a. Army
b. Marines
c. Navy 
d. Air Force

e. U.S. Coast Guard

f. National Guard

9) What is or was your highest rank?

10) What is or was your Military Occupational Specialty?

11) Were you deployed?

a. If so, how many tours did you serve?

b. How long did each tour last?

c. When did you return from your last deployment?

d. Were you involved in combat (experienced enemy fire or engaged with the enemy in any way)? Yes or No

12) Have you experienced physical health issues as a result of your military experiences?

a. If yes, please list below:

13) Since joining the military, have you been diagnosed with any of the following (check all that apply)?
a. None
b. Post Traumatic Stress
c. Depression
d. Alcohol-Abuse
e. Narcotic (drug) Abuse
f. General Anxiety
g. Other

14) During or after active duty, did you seek out any counseling services or medications from a psychiatrist, therapist, social worker, religious leader or any other professional?

a. Yes

b. No

i. If Yes, what type of professional did you see?

1. Psychiatrist

2. Psychologist

3. Social worker

4. Professional counselor

5. Religious leader

ii. How many times did you see this individual?

iii. If No, were you mandated to attend counseling services?

1. Yes

2. No 
15) Please rank the top three reasons you enrolled in your Outward Bound course, by typing a 1 (1st reason), 2 (2nd reason), and 3 (3rd reason).

a. To experience a sense of camaraderie, work as a team with fellow veterans and servicemen

b. To learn a new outdoor sport/skill set

c. To learn more about myself

d. To help work through issues related to my time in the military

e. To provide myself with greater emotional and interpersonal support during my reintegration process

f. To be physically challenged

g. To get in shape

h. To be in nature

i. To increase my motivation in life

j. To find a sense of purpose, hope 


\section{Appendix M}

\section{Permission to Use the Posttraumatic Growth Inventory}

From: Tedeschi, Rich rtedesch@uncc.edu

To: Joseph Wassif joseph.wassif@mail.wvu.edu

Subject: Re: PTGI

Sent: Friday - January 11, 2012 8:08am

Dear Joseph--

You have my permission to use the PTGI. Make sure have an accurate copy. Do you need one from me?

Rich Tedeschi 


\section{Appendix N \\ Posttraumatic Growth Inventory}

As you requested, a copy of the Posttraumatic Growth Inventory (PTGI) follows.

There is no charge for use of the PTGI in not-for-profit research. However, the inventory is not to be reproduced for any kind of general distribution, and it may not be used in for-profit enterprises.

In reciprocation for its use in your work, please send us a gratis copy of any manuscripts, theses, dissertations, research reports, preprints, and publications you prepare in which our materials, or any version of them, is used.

Both L. G. Calhoun and R. G. Tedeschi can be contacted at:

Department of Psychology - UNC Charlotte - Charlotte, NC 28223 USA or by email at Icalhnjr@uncc.edu and rtedesch@uncc.edu 


\section{Posttraumatic Growth Inventory}

Indicate for each of the statements below the degree to which this change occurred in your life as a result of your crisis using the following scale.

Note to investigators - you will need to format the items so that participants have a way of responding to each one. The procedure we recommend is to place the numerical values of the scale after each item. In addition, the Roman numeral codes for the factors should also be removed.

$0=I$ did not experience this change as a result of my crisis.

$1=I$ experienced this change to a very small degree as a result of my crisis.

$2=I$ experienced this change to a small degree as a result of my crisis.

$3=I$ experienced this change to a moderate degree as a result of my crisis.

$4=1$ experienced this change to a great degree as a result of my crisis.

$5=1$ experienced this change to a very great degree as a result of my crisis.

1. I changed my priorities about what is important in life. (V)

2. I have a greater appreciation for the value of my own life. (V)

3. I developed new interests. (II)

4. I have a greater feeling of self-reliance. (III)

5. I have a better understanding of spiritual matters. (IV)

6 . I more clearly see that I can count on people in times of trouble. (I)

7. I established a new path for my life. (II)

8. I have a greater sense of closeness with others. (I)

9. I am more willing to express my emotions. (I)

10. I know better that I can handle difficulties. (III)

11. I am able to do better things with my life. (II)

12. I am better able to accept the way things work out. (III)

13. I can better appreciate each day. (V)

14. New opportunities are available which wouldn't have been otherwise. (II)

15. I have more compassion for others. (I)

16. I put more effort into my relationships. (I)

17. I am more likely to try to change things which need changing. (II)

18. I have a stronger religious faith. (IV)

19. I discovered that I'm stronger than I thought I was. (III)

20. I learned a great deal about how wonderful people are. (I)

21 . I better accept needing others. (I)

Note: Scale is scored by adding all responses. Factors are scored by adding responses to items on each factor. Items to which factors belong are not listed on form administered to participants.

\section{PTGI Factors}

Factor I: Relating to Others

Factor II: New Possibilities

Factor III: Personal Strength

Factor IV: Spiritual Change

Factor V: Appreciation of Life 


\section{Appendix O}

\section{The Mississippi Scale}

Please circle the number that best describes how you feel about each statement.

1. Before I entered the military, I had more close friends than I have now.

$\begin{array}{ccccc}1 & 2 & 3 & 4 & 5 \\ \text { Not at all True } & \text { Slightly True } & \text { Somewhat True } & \text { Very True } & \text { Extremely True }\end{array}$

2. I do not feel guilt over things that I did in the military.

$\begin{array}{ccccc}1 & 2 & 3 & 4 & 5 \\ \text { Never True } & \text { Rarely True } & \text { Sometimes True } & \text { Usually True } & \text { Always True }\end{array}$

3. If someone pushes me too far, I am likely to become violent.

$\begin{array}{ccccc}1 & 2 & 3 & 4 & 5 \\ \text { Very Unlikely } & \text { Unlikely } & \text { Somewhat Unlikely } & \text { Very Likely } & \text { Extremely Likely }\end{array}$

4. If something happens that reminds me of the military, I become very distressed and upset.

$\begin{array}{ccccc}1 & 2 & 3 & 4 & 5 \\ \text { Never } & \text { Rarely } & \text { Sometimes } & \text { Frequently } & \text { Very Frequently }\end{array}$

5. The people who know me best are afraid of me.

$\begin{array}{ccccc}1 & 2 & 3 & 4 & 5 \\ \text { Never True } & \text { Rarely True } & \text { Sometimes True } & \text { Frequently True } & \text { Very Frequently True }\end{array}$

6. I am able to get emotionally close to others.

$\begin{array}{ccccc}1 & 2 & 3 & 4 & 5 \\ \text { Never } & \text { Rarely } & \text { Sometimes } & \text { Frequently } & \text { Very Frequently }\end{array}$

7. I have nightmares of experiences in the military that really happened.

$\begin{array}{ccccc}1 & 2 & 3 & 4 & 5 \\ \text { Never } & \text { Rarely } & \text { Sometimes } & \text { Frequently } & \text { Very Frequently }\end{array}$




\begin{tabular}{|ccccc|}
\hline 8. When I think of some of the things that I did in the military, I wish I were dead. \\
$\begin{array}{ccccc}1 & 2 & 3 & 4 & 5 \\
\text { Never True } & \text { Rarely True } & \text { Sometimes True } & \text { Frequently True } & \text { Very Frequently True }\end{array}$
\end{tabular}

\begin{tabular}{|lcccc|}
\hline 9. It seems as if I have no feelings. \\
\begin{tabular}{ccccc}
\hline 1 & 2 & 3 & 4 & 5 \\
Not at all True & Rarely True & Sometimes True & Frequently True & Very Frequently True
\end{tabular}
\end{tabular}

\section{Lately, I have felt like killing myself.}

$\begin{array}{ccccc}1 & 2 & 3 & 4 & 5 \\ \text { Not at all True } & \text { Slightly True } & \text { Somewhat True } & \text { Very True } & \text { Extremely True }\end{array}$

\begin{tabular}{|l} 
11. I fall asleep, stay asleep and awaken only when the alarm goes off. \\
$\begin{array}{ccccc}1 & 2 & 3 & 4 & 5 \\
\text { Never } & \text { Rarely } & \text { Sometimes } & \text { Frequently } & \text { Very Frequently }\end{array}$
\end{tabular}

12. I wonder why I am still alive when others died in the military.

$\begin{array}{ccccc}1 & 2 & 3 & 4 & 5 \\ \text { Never } & \text { Rarely } & \text { Sometimes } & \text { Frequently } & \text { Very Frequently }\end{array}$

13. Being in certain situations makes me feel as though I am back in the military.

$\begin{array}{ccccc}1 & 2 & 3 & 4 & 5 \\ \text { Never } & \text { Rarely } & \text { Sometimes } & \text { Frequently } & \text { Very Frequently }\end{array}$

\begin{tabular}{|c|c|c|c|c|}
\hline \multicolumn{5}{|c|}{$\begin{array}{l}\text { 14. My dreams at night are so real that I waken in a cold sweat and force myself to stay } \\
\text { awake. }\end{array}$} \\
\hline 1 & 2 & 3 & 4 & 5 \\
\hline Never & Rarely & Sometimes & Frequently & Very Frequently \\
\hline
\end{tabular}

\section{I feel like I cannot go on.}

1

Not at all True

2

Rarely True
3

Sometimes True
4

Very True
5

Almost Always True 
16. I do not laugh or cry at the same things other people do.

$\begin{array}{ccccc}1 & 2 & 3 & 4 & 5 \\ \text { Not at all True } & \text { Rarely True } & \text { Somewhat True } & \text { Very True } & \text { Extremely True }\end{array}$

17. I still enjoy doing many things that I used to enjoy.

$\begin{array}{lllll}1 & 2 & 3 & 4 & 5\end{array}$

$\begin{array}{llll}\text { Never True } & \text { Rarely True } & \text { Sometimes True } & \text { Very True }\end{array}$

18. Daydreams are very real and frightening.

$\begin{array}{lllll}1 & 2 & 3 & 4\end{array}$

Never True $\quad$ Rarely True Sometimes True Frequently True Very Frequently True

19. I have found it easy to keep a job since my separation from the military.

$\begin{array}{ccccc}1 & 2 & 3 & 4 & 5 \\ \text { Not at all True } & \text { Slightly True } & \text { Somewhat True } & \text { Very True } & \text { Extremely True }\end{array}$

20. I have trouble concentrating on tasks.

$\begin{array}{ccccc}1 & 2 & 3 & 4 & 5 \\ \text { Never True } & \text { Rarely True } & \text { Sometimes True } & \text { Frequently True } & \text { Very Frequently True }\end{array}$

\begin{tabular}{|ccccc|}
\hline 21. I have cried for no good reason. \\
$\begin{array}{ccccc} \\
1 & 2 & 3 & 4 & 5 \\
\text { Never } & \text { Rarely } & \text { Sometimes } & \text { Frequently } & \text { Very Frequently }\end{array}$
\end{tabular}

\begin{tabular}{|lcccc|}
\hline 22. I enjoy the company of others. \\
$\begin{array}{ccccc}1 & 2 & 3 & 4 & 5 \\
\text { Never } & \text { Rarely } & \text { Sometimes } & \text { Frequently } & \text { Very Frequently }\end{array}$
\end{tabular}

23. I am frightened by my urges.

$\begin{array}{ccccc}1 & 2 & 3 & 4 & 5 \\ \text { Never } & \text { Rarely } & \text { Sometimes } & \text { Frequently } & \text { Very Frequently }\end{array}$


24. I fall asleep easily at night.

$\begin{array}{ccccc}1 & 2 & 3 & 4 & 5 \\ \text { Never } & \text { Rarely } & \text { Sometimes } & \text { Frequently } & \text { Very Frequently }\end{array}$

25. Unexpected noises make me jump.

$\begin{array}{ccccc}1 & 2 & 3 & 4 & 5 \\ \text { Never } & \text { Rarely } & \text { Sometimes } & \text { Frequently } & \text { Very Frequently }\end{array}$

26. No one understands how I feel, not even my family.

$\begin{array}{ccccc}1 & 2 & 3 & 4 & 5 \\ \text { Not at all True } & \text { Rarely True } & \text { Somewhat True } & \text { Very True } & \text { Extremely True }\end{array}$

27. I am an easy-going, even-tempered person.

$\begin{array}{ccccc}1 & 2 & 3 & 4 & 5 \\ \text { Never } & \text { Rarely } & \text { Sometimes } & \text { Usually } & \text { Very Much So }\end{array}$

28. I feel there are certain things that I did in the military that I can never tell anyone, because no one would ever understand.

$\begin{array}{ccccc}1 & 2 & 3 & 4 & 5 \\ \text { Not at all True } & \text { Slightly True } & \text { Somewhat True } & \text { True } & \text { Very True }\end{array}$

29. There have been times when I used alcohol (or other drugs) to help me sleep or to make me forget about things that happened while I was in the service.

$\begin{array}{ccccc}1 & 2 & 3 & 4 & 5 \\ \text { Never } & \text { Infrequently } & \text { Sometimes } & \text { Frequently } & \text { Very Frequently }\end{array}$

30. I feel comfortable when I am in a crowd.

$\begin{array}{ccccc}1 & 2 & 3 & 4 & 5 \\ \text { Never } & \text { Rarely } & \text { Sometimes } & \text { Usually } & \text { Always }\end{array}$

31. I lose my cool and explode over minor everyday things.

$\begin{array}{ccccc}1 & 2 & 3 & 4 & 5 \\ \text { Never } & \text { Rarely } & \text { Sometimes } & \text { Frequently } & \text { Very Frequently }\end{array}$


32. I am afraid to go to sleep at night.

$\begin{array}{ccccc}1 & 2 & 3 & 4 & 5 \\ \text { Never } & \text { Rarely } & \text { Sometimes } & \text { Frequently } & \text { Almost Always }\end{array}$

33. I try to stay away from anything that will remind me of things which happened while I was in the military.

$\begin{array}{ccccc}1 & 2 & 3 & 4 & 5 \\ \text { Never } & \text { Rarely } & \text { Sometimes } & \text { Frequently } & \text { Almost Always }\end{array}$

34. My memory is as good as it ever was.

$\begin{array}{ccccc}1 & 2 & 3 & 4 & 5 \\ \text { Not at all True } & \text { Rarely True } & \text { Somewhat True } & \text { Usually True } & \text { Almost Always True }\end{array}$

35. I have a hard time expressing my feelings, even to the people I care about.

1

Not at all True

2

Rarely True

3

Sometimes True
4

Frequently True
5

Almost Always True 


\section{Appendix P}

\section{Interview Protocol}

1. Tell me about your experience with OBVP."

2. "Can you tell me about three particularly meaningful moment?

a. What made those moments meaningful?"

i. If the participant gave mostly introspective responses (e.g., learned a lot about self, ask:

1. What about the OBVP promoted these realizations?

ii. If the participant gave mostly activity/ content responses, ask:

1. What was meaningful about those activities?

2. Can you recall any moments of personal growth?

3. Did you notice any differences between the deployed v. nondeployed vets?

iii. What was it like to do the trip with a group of military personnel?

iv. Describe the participant interaction with leaders.

3. What did you learn about yourself as a result of the OBVP?

a. What do you think prompted these insights?

b. What was going on during expedition when you learned them?

4. Do you think the experience of OBVP will have an impact on you in the future?

a. How?

b. What makes you say that?

5. Do you view life/ people any differently now that you've completed your OBVP?

a. Did your OBVP experience influence your worldview? 
6. Is life different now, in comparison to deployment?

a. Have there been any challenges?

b. Do you see the world differently?

c. Did your experiences on the OBVP address any of the challenges you described earlier? 